\title{
Experimental Investigation of Drag Reduction on Automobiles with an Inflatable Boat-Tail
}

\author{
By \\ KATHLEEN MICHELE MCNAMARA \\ Bachelor of Science in Mechanical Engineering \\ Oklahoma State University \\ Stillwater, OK \\ December 2015
}

Submitted to the Faculty of the

Graduate College of the

Oklahoma State University

in partial fulfillment of

the requirements for

the Degree of

MASTER OF SCIENCE

May 2018 
EXPERIMENTAL INVESTIGATION OF DRAG REDUCTION ON AUTOMOBILES WITH AN INFLATABLE BOAT-TAIL

Thesis Approved:

DR. JAMEY JACOB

Thesis Adviser

DR. KAAN KALKAN

DR. KEITH GOOD 


\section{ACKNOWLEDGEMENTS}

I would like to thank my outstanding adviser, Dr. Jamey Jacob, who welcomed me into the most professional and interesting research group in the MAE department. Through his humility, constant support, encouragement, and wisdom, combined with a love for science and problem solving, he has constantly fueled our team to go above and beyond. I am so thankful to be a part of his team. I would also like to thank my \#1 mentor, Ben Loh, for his one-of-a-kind creativity, quick problem-solving skills, and positive attitude. His friendship and support have inspired me throughout the last year and a half of my Master's program. I would like to thank Toyota Research Institute North America (TRINA) and Toyota Motor Corporation (TMC) Japan for their research support. I have learned so much through working with them and I am thankful for all the past, current, and future opportunities they have given me. I want to thank Dr. Kurt Rouser and his research team including Tyler Zimbelman, Matt Durkee, Nick Lucido, and other team members. Throughout the many early mornings to late nights I spent running tests in the wind tunnel they have been so patient and helpful. I want to thank my family and friends, especially my parents who have always supported me and believed in me, and my siblings for encouraging me and inspiring me. I would like to thank my great friends, Geoffrey Donnell and Andrew Garrett, without them I would not have come to OSU in the first place. Most of all, I would like to thank my very best friend and soon-to-be husband, Ehsan Moallem. Without his constant and persistent love, support, and encouragement over the last four and a half years I would be no where near as successful as I am today. He has provided an endless amount of strength and patience to me when I needed it most. Overall, I feel so proud of the experience and knowledge I have gained while working with my wonderful team at OSU. I have learned from my graduate experience

more than any other, that when someone says you are not capable of doing something, do it anyways and make it ten times greater than anyone ever thought possible.

Acknowledgements reflect the views of the author and are not endorsed by committee members or Oklahoma State University. 
Name: Kathleen Michele McNamara

Date of Degree: May 2018

Title of Study: EXPERIMENTAL INVESTIGATION OF DRAG REDUCTION ON AUTOMOBILES WITH AN INFLATABLE BOAT-TAIL

Major Field: MECHANICAL AND AEROSPACE ENGINEERING

ABSTRACT: There is a growing demand for higher efficiency and more environmentally friendly vehicles, including better fuel economy, reduction in wind noise level, and greater vehicle performance and dynamic stability. These factors vary with aerodynamic performance. Overall, aerodynamic drag contributes to as much as $60 \%$ of a vehicles fuel consumption, motivating vehicle manufacturers to investigate new drag reduction applications. When streamlining a vehicle for aerodynamic performance, one method is by boattailing, or rear end tapering. This study includes an investigation of the overall potential of a lightweight yet rigid, inflatable drag reduction device, applied to a motor vehicle. Based on original concepts proposed by Toyota Research Institute North American (TRINA), combined with past research of inflatable technology, an inflatable drag reduction device is designed, manufactured, and tested. Peel strength of adhesive bonds testing provides detailed results of proper heat-sealable fabric utilization, and preferred materials are selected for inflatable models. Through multiple concept considerations and varying design stages ergonomic boattail designs evolve, as does construction, and manufacturing details are included. The inflatable boat-tail as a drag reduction device is examined through wind tunnel testing at Reynolds numbers $\mathrm{O}\left(10^{5}\right)$ by $2 \mathrm{D}$ wake survey and conservation of momentum theory, and multiple system designs are compared. Results show $10-80 \%$ decreased drag coefficients as a function of varying boat-tail construction compared to a baseline model. Wake survey is also performed at multiple heights along boat-tail sections, and 3D effects are investigated. Further investigations include wake survey velocity profiles as a function of angle of attack. Standard deviation and velocity fluctuations are compared for individual systems, and results are discussed. 


\section{Contents}

1 Introduction 1

1.1 Motivation ................................. 1

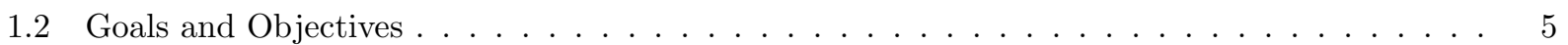

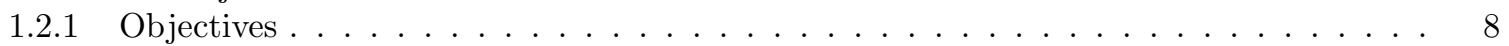

2 Background, Literature Review, Theory 10

2.1 History of Drag Reduction Concepts and Boat-Tails . . . . . . . . . . . . . . . . . . . . 10

2.2 Inflatable History . . . . . . . . . . . . . . . . . . . . . . . . . . . . 16

2.3 Peel Strength Theory . . . . . . . . . . . . . . . . . . . . . . . . . . 17

2.4 Burst Tests Theory . . . . . . . . . . . . . . . . . . . . . . . . . . . 19

2.5 Failure Consideraions . . . . . . . . . . . . . . . . . . . . . . . . . . 19

2.6 Drag Measurements - 2D Wake Survey Theory . . . . . . . . . . . . . . . . . . . 21

3 Experimental Arrangement 25

3.1 Peel Strength Test Set-up . . . . . . . . . . . . . . . . . . . . . . . 26

3.2 Burst Test . . . . . . . . . . . . . . . . . . . . . . . . . . . . 29

3.3 Design of Inflatable Boat-Tail . . . . . . . . . . . . . . . . . . . . . . . . 30

3.3.1 Three Piece Design . . . . . . . . . . . . . . . . . . . . . . . . . 30

3.3.2 Baffled Boat-Tails . . . . . . . . . . . . . . . . . . . . . . . . 31

3.4 Construction Basics . . . . . . . . . . . . . . . . . . . . . . . . . . . . . 36

3.5 Wind Tunnel Wake Survey Experimental Set-up . . . . . . . . . . . . . . . . . . . . . 43

3.5.1 Varying profile height for 2D Wake Surveys . . . . . . . . . . . . . . . . . . . . 52

3.5.2 Variation of attack angles of boat-tail systems . . . . . . . . . . . . . . . . . . 52

3.5.3 Boat-tail Systems Under Dynamic Pressure . . . . . . . . . . . . . . . . . . 53

4 Results and Discussion $\quad \mathbf{5 4}$

4.1 Materials Testing, Selection, and Design . . . . . . . . . . . . . . . . . . . . . 54

4.1 Peel Strength of Adhesive Bonds . . . . . . . . . . . . . . . . . . . . . . . . . 54

4.2 Results of Heat Sealable Packcloth (Sample A) . . . . . . . . . . . . . . . . . . . . . . . . . . 54

4.3 Results of Heat Sealable Oxford (Sample B) . . . . . . . . . . . . . . . . . . . . . . 55

4.4 Results of Heat Sealable Taffeta (Sample C) . . . . . . . . . . . . . . . . . . . . . . 58

4.5 Results of Heat Sealable Ripstop (Sample D) . . . . . . . . . . . . . . . . . . . . . 58

4.6 Final Fabric Results . . . . . . . . . . . . . . . . . . . . . . . . . . . 58

4.7 Burst Testing . . . . . . . . . . . . . . . . . . . . . . . . . 59

4.8 Wind Tunnel Tests Results . . . . . . . . . . . . . . . . . . . . . . . . . 62

4.8.1 Varying Height for 3D Profiles . . . . . . . . . . . . . . . . . . . . 67

4.8.2 Variation of Attack Angles . . . . . . . . . . . . . . . . . . . . 71

4.8.3 Deflection Under Dynamic Pressure . . . . . . . . . . . . . . . . . . . . . 75

4.8.4 Standard Deviation . . . . . . . . . . . . . . . . . . . . . . 76

4.8.5 Measurement Variation . . . . . . . . . . . . . . . . . . . . . . 81

5 Conclusions $\mathbf{8 6}$

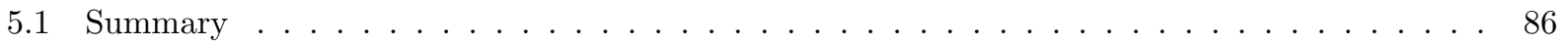

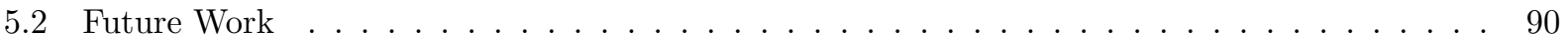




\section{List of Tables}

$1 \quad C_{D}$ for Three Systems at Re=1.59E+5, 10mph . . . . . . . . . . . . . . 63

$2 \quad C_{D}$ for Three Systems at $\mathrm{Re}=2.34 \mathrm{E}+5,15 \mathrm{mph}$. . . . . . . . . . . . . . . . . . . . 63

$3 C_{D}$ for Three Systems at Re=3.15E+5, 20mph . . . . . . . . . . . . . . . . . 63

$4 \quad C_{D}$ for Three Systems at $\mathrm{Re}=3.96 \mathrm{E}+5,30 \mathrm{mph} \ldots \ldots . \ldots$

$5 \quad$ Overall average $C_{D}$ for each system . . . . . . . . . . . . . . . . . . . . . . . 65 


\section{List of Figures}

1 Comparison of low and high aerodynamic drag forces with rolling resistance $[2] \ldots \ldots 2$

2 Influence of surface roughness on boundary layer velocity profile $[2] \ldots \ldots \ldots$

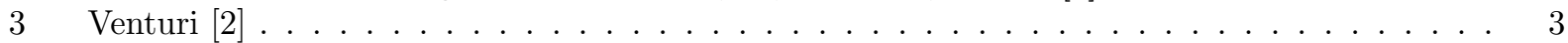

4 Pressure distribution above and below the vehicle body structure $[2] \ldots \ldots \ldots \ldots$

$5 \quad$ After flow wake $[2] \ldots \ldots \ldots \ldots \ldots \ldots \ldots \ldots$

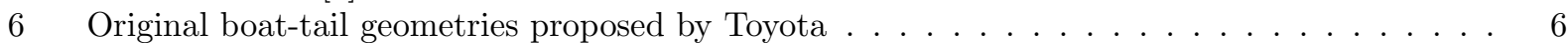

7 Original boat-tail dimensions proposed by Toyota, in inches . . . . . . . . . . . . . . . 7

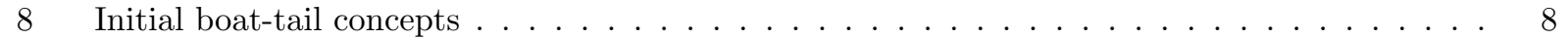

9 General representation of pressure differences on vehicle $[1] \ldots \ldots \ldots \ldots \ldots$

10 The Coanda effect demonstrated on a trailing edge $[1] \ldots \ldots \ldots \ldots \ldots$

11 Trailer configuration simulated at Georgia Tech Research Institute [1] . . . . . . . . . . . 11

12 Different configurations simulated at $\mathrm{KTH}[1] \ldots \ldots \ldots \ldots \ldots \ldots$

13 Results for CFD calculations at KTH when blowing boundary layers [1] $\ldots \ldots \ldots \ldots$

14 Rigid and Aerodynamic boat-tails $[1] \ldots \ldots \ldots \ldots \ldots \ldots$

15 Rear end configuation for Nasa Ames Research Center wind tunnel tests [1] . . . . . . . . . 14

16 Effect of rear end extension on drag coefficient $[2] \ldots \ldots \ldots \ldots \ldots$

17 Internal burst test schematic for flexible pouch $\ldots \ldots \ldots \ldots \ldots \ldots$

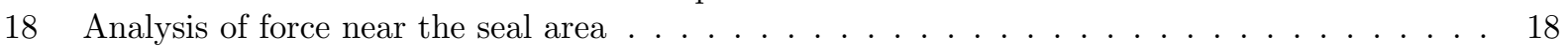

19 Inflatable structure modeled as a thin wall pressure vessel . . . . . . . . . . . . . . . . 19

20 Load versus deflection for generic inflatable structure. . . . . . . . . . . . . . . . . . 21

21 Control volume for drag estimation by momentum balance . . . . . . . . . . . . . . . 22

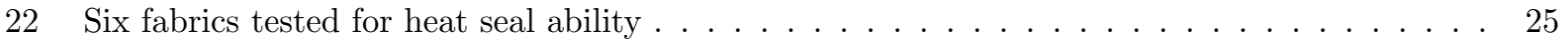

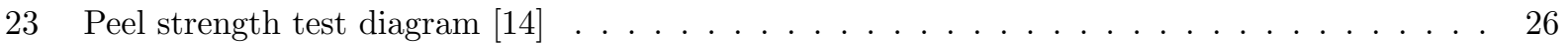

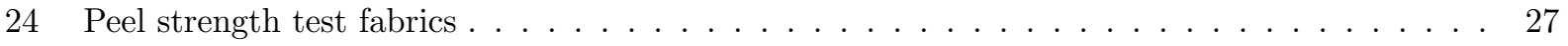

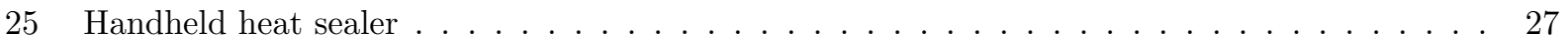

26 Instron Universal Testing Machine . . . . . . . . . . . . . . . . . . . . 28

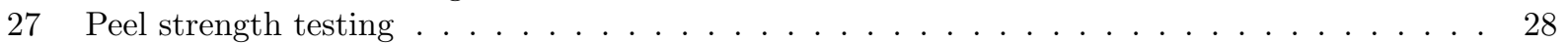

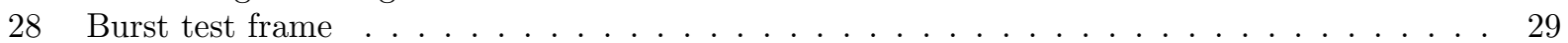

29 Solidworks drawing for inflatable cover design . . . . . . . . . . . . . . . . . . 30

30 Zero-baffle design . . . . . . . . . . . . . . . . . . . . . . . . . 32

31 Inflated zero-baffle boat-tail, HS Oxford and HS plastic sheeting . . . . . . . . . . . 32

32 Two-baffle design . . . . . . . . . . . . . . . . . . . . . . . 33

33 Inflated two-baffle boat-tail, HS Oxford and HS plastic sheeting . . . . . . . . . . . . 33

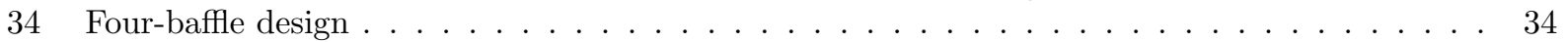

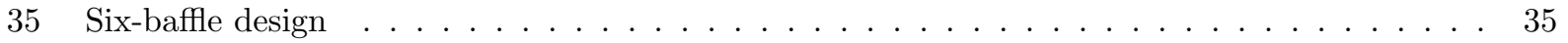

36 Inflated six-baffle boat-tail, HS Oxford and HS plastic sheeting $\ldots \ldots \ldots \ldots \ldots$

37 Linear heat sealer . . . . . . . . . . . . . . . . . . . . . . . 36

38 Initial measurements and markings for a baffled boat-tail . . . . . . . . . . . . . . . 37

39 Complete measurement and markings for a six-baffle bloat-tail . . . . . . . . . . . . 37

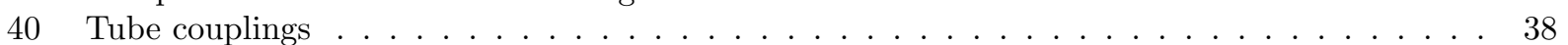

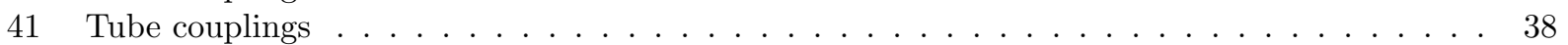

42 Initial heat sealed baffles . . . . . . . . . . . . . . . . . . . . . . . . 39

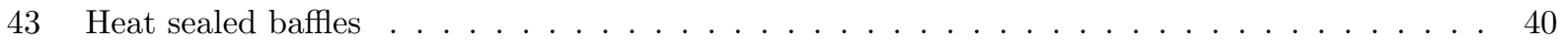

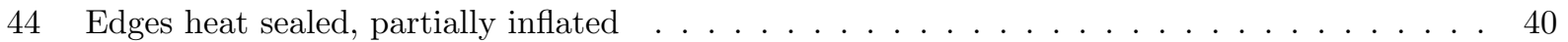

45 Heat sealing corners for proper shape . . . . . . . . . . . . . . . . . . . 41

46 Isometric view of fully constructed and inflated six-baffle boat-tail $\ldots \ldots \ldots \ldots$ 
47 Fully constructed and inflated six-baffle boat-tail . . . . . . . . . . . . . . . . . . . . . 42

48 Comparison of shape for zero, two, four, and six-baffled boat-tails . . . . . . . . . . . . . . . 42

49 A basic schematic of the wind tunnel . . . . . . . . . . . . . . . . . . . . . . 44

50 Flex-tube manometer . . . . . . . . . . . . . . . . . . . . . . 45

51 Omega 10inch pressure transducer . . . . . . . . . . . . . . . . . . . . . 46

52 Three wind tunnel test cases, top view: Baseline, Zero-Baffle, and Six-Baffle . . . . . . . . 46

53 Wind tunnel setup with boat-tail and pitot tube . . . . . . . . . . . . . . . . . 47

54 Baseline system for comparison . . . . . . . . . . . . . . . . . . . . . . . 49

55 Baseline plate attachment frame . . . . . . . . . . . . . . . . . . . . . . 49

56 Six baffle system side view . . . . . . . . . . . . . . . . . . . . . . . 50

57 Six baffle system top view . . . . . . . . . . . . . . . . . . . . . . . . . . 51

58 Wind tunnel cross section with boat-tail . . . . . . . . . . . . . . . . . . . . 51

59 Variation of height for $2 \mathrm{D}$ wake surveys . . . . . . . . . . . . . . . . . . . . . 52

60 Study of deflection under dynamic pressure . . . . . . . . . . . . . . . . . . 53

61 Peel strength test results for HS Packcloth (Sample A) . . . . . . . . . . . . . . . . . . . 55

62 Peel strength test results for HS Packcloth (Sample A) *A2 noted as outlier, not included in average calculations . . . . . . . . . . . . . . . . . . . . . 56

63 Peel strength test results for HS Oxford (Sample B) . . . . . . . . . . . . . . . 56

64 Peel strength test results for HS Oxford (Sample B) . . . . . . . . . . . . . . . . . . 57

65 Peel strength test results of HS Taffeta (Sample C) . . . . . . . . . . . . . . . . . . . 58

66 Peel strength test results of HS Ripstop (Sample D) . . . . . . . . . . . . . . . . . . . 58

67 Final results of peel strength tests for Samples A, B, C, and D . . . . . . . . . . . . 59

68 Predicted burst pressure versus pouch radius . . . . . . . . . . . . . . . . 60

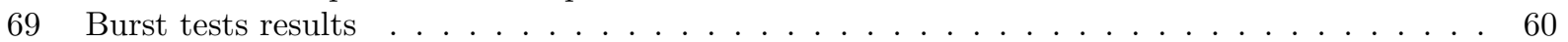

70 Burst test failure . . . . . . . . . . . . . . . . . . . . . . . . . . 61

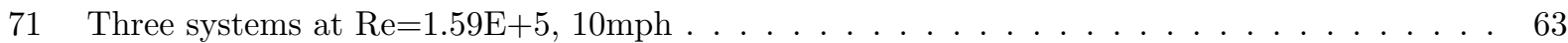

72 Three systems at $\mathrm{Re}=2.34 \mathrm{E}+5$. . . . . . . . . . . . . . . . . . . . . . . 64

73 Three systems at $\mathrm{Re}=3.15 \mathrm{E}+5$. . . . . . . . . . . . . . . . . . . . . . 64

74 Three systems at $\operatorname{Re}=3.96 \mathrm{E}+5$. . . . . . . . . . . . . . . . . . . . . . 65

75 Coefficient of drag vs Reynolds number for three systems . . . . . . . . . . . . . 66

76 Zero-baffle boat-tail at $0 \%, 25 \%$ and mid . . . . . . . . . . . . . . . . . . . . 67

77 Zero-baffle boat-tail at $0 \%, 25 \%$ and mid . . . . . . . . . . . . . . . . . . . . 68

78 Six-baffle boat-tail at $0 \%, 25 \%$ and mid . . . . . . . . . . . . . . . . . . . . . . 68

79 Six-baffle boat-tail at $0 \%, 25 \%$ and mid . . . . . . . . . . . . . . . . . . . . . . . 69

80 Six-baffle boat-tail at $0 \%, 25 \%$ and mid . . . . . . . . . . . . . . . . . . . . . 69

81 Six-baffle boat-tail at $0 \%, 25 \%$ and mid . . . . . . . . . . . . . . . . . . . . . 70

82 Six-baffle and zero-baffle systems at $5^{\circ}$ angle of attack, $\mathrm{Re}=1.62 \mathrm{E}+5$. . . . . . . . . . . . . . 71

83 Six-baffle and zero-baffle systems at $5^{\circ}$ angle of attack, $\mathrm{Re}=3.11 \mathrm{E}+5$. . . . . . . . . . . . . . 72

84 Six-baffle and zero-baffle systems at $10^{\circ}$ angle of attack, $\mathrm{Re}=1.63 \mathrm{E}+5$. . . . . . . . . . . . . 72

85 Six-baffle and zero-baffle systems at $10^{\circ}$ angle of attack, $R e=2.90 \mathrm{E}+5$. . . . . . . . . . . . . 73

86 Six-baffle and zero-baffle systems at $15^{\circ}$ angle of attack, $R=1.62 \mathrm{E}+5$. . . . . . . . . . . . . 73

87 Six-baffle and zero-baffle systems at $15^{\circ}$ angle of attack, $\mathrm{Re}=3.01 \mathrm{E}+5$. . . . . . . . . . . . . 74

88 Study of deflection under dynamic pressure . . . . . . . . . . . . . . . . . . . . 75

89 Results of deflection under dynamic pressure . . . . . . . . . . . . . . . . . . . . 75

90 Standard deviation for baseline system at $15 \mathrm{mph}$. . . . . . . . . . . . . . . . . . . 77

91 Standard deviation for zero-baffle system at $15 \mathrm{mph}$. . . . . . . . . . . . . . . . . . . . . . . 77

92 Standard deviation for six-baffle system at $15 \mathrm{mph}$. . . . . . . . . . . . . . . . . . . . 78

93 Standard deviation for baseline system at $30 \mathrm{mph}$. . . . . . . . . . . . . . . . . . . . 79 
94 Standard deviation for zero-baffle system at $30 \mathrm{mph}$. . . . . . . . . . . . . . . . . . . . 79

95 Standard deviation for six-baffle system at $30 \mathrm{mph}$. . . . . . . . . . . . . . . . . . . 80

96 Velocity fluctuation for baseline system at $15 \mathrm{mph}$. . . . . . . . . . . . . . . . . . . . 82

97 Velocity fluctuation for zero-baffle system at $15 \mathrm{mph}$. . . . . . . . . . . . . . . . . . . 82

98 Velocity fluctuation for six-baffle system at $15 \mathrm{mph}$. . . . . . . . . . . . . . . . . 83

99 Velocity fluctuation for baseline system at $30 \mathrm{mph}$. . . . . . . . . . . . . . . . . . . . 84

100 Velocity fluctuation for zero-baffle system at $30 \mathrm{mph}$. . . . . . . . . . . . . . . . . . . . . 84

101 Velocity fluctuation for six-baffle system at $30 \mathrm{mph}$. . . . . . . . . . . . . . . . . . . . 85

102 Three systems at $\mathrm{Re}=3.96 \mathrm{E}+5 \ldots \ldots$. . . . . . . . . . . . . . . . . . . . 88

103 Coefficient of drag vs Reynolds number for three systems . . . . . . . . . . . . . . . . 89

104 PIV boat-tail models . . . . . . . . . . . . . . . . . . . . . . . . . . . . 92

105 PIV boat-tail models . . . . . . . . . . . . . . . . . . . . . . . . . . . . . . 92

106 PIV six-baffle replica boat-tail model . . . . . . . . . . . . . . . . . . . . . . 93

107 LabView VI . . . . . . . . . . . . . . . . . . . . . . . . . . . . . . . 94

108 LabView Control . . . . . . . . . . . . . . . . . . . . . . . . . . . . 95 


\section{Introduction}

\subsection{Motivation}

There is a growing demand for higher efficiency and more environmentally friendly vehicles. This includes better fuel economy, reduction in wind noise level, and greater vehicle performance and dynamic stability. Fig. 1 shows resistance due to air friction is greater than that of rolling friction for a poorly streamlined and very highly streamlined car against its constant rolling resistance for a typical speed range. Aerodynamic drag can contribute to as much as $60 \%$ of a vehicles fuel consumption giving great reason for drag reduction applications[1]. This has motivated vehicle manufacturers to investigate the nature of air resistance and drag for different vehicle shapes and types in order to achieve more aerodynamic vehicle designs.

Aerodynamics is the study of the interaction between body surfaces and the surrounding air as a solid body moves through the atmosphere with varying relative speeds and wind direction. Whenever there is relative air movement, due to the viscosity of air and the internal friction between adjacent air layers, there is sliding between those adjacent air layers where energy is dissipated. A boundary layer is formed between the surface and airstream and shearing of adjacent air layers takes place. As relative velocity of air particles near the surface become nearly zero, adjacent layers near the surface are affected. It is this viscous interaction generated within the boundary layer that causes skin friction, and varies depending on surface roughness as seen in Fig. 2 [2]. While streamlining a vehicle for aerodynamic performance, practicalities such as feet room, head room, storage, luggage space, and extra passenger space can become limited. One method of making automobiles more aerodynamic without giving up practical vehicle components is by boat-tailing or rear end tapering[1]. Boat-tailing refers to adding an additional aerodynamically shaped section on to the rear end of a vehicle.

To understand the pressure distribution with air flow over a car surface, it is first relevant to understand how air flows through a diverging and converging section of a venturi, as seen in Fig. 3. At entry, the air will be at atmospheric conditions, molecules are close together, pressure is high and speed is low. As the air moves into the converging section, the velocity of the air molecules increases to maintain volume flow. At the narrowest region, pressure drops and flow speed increases 


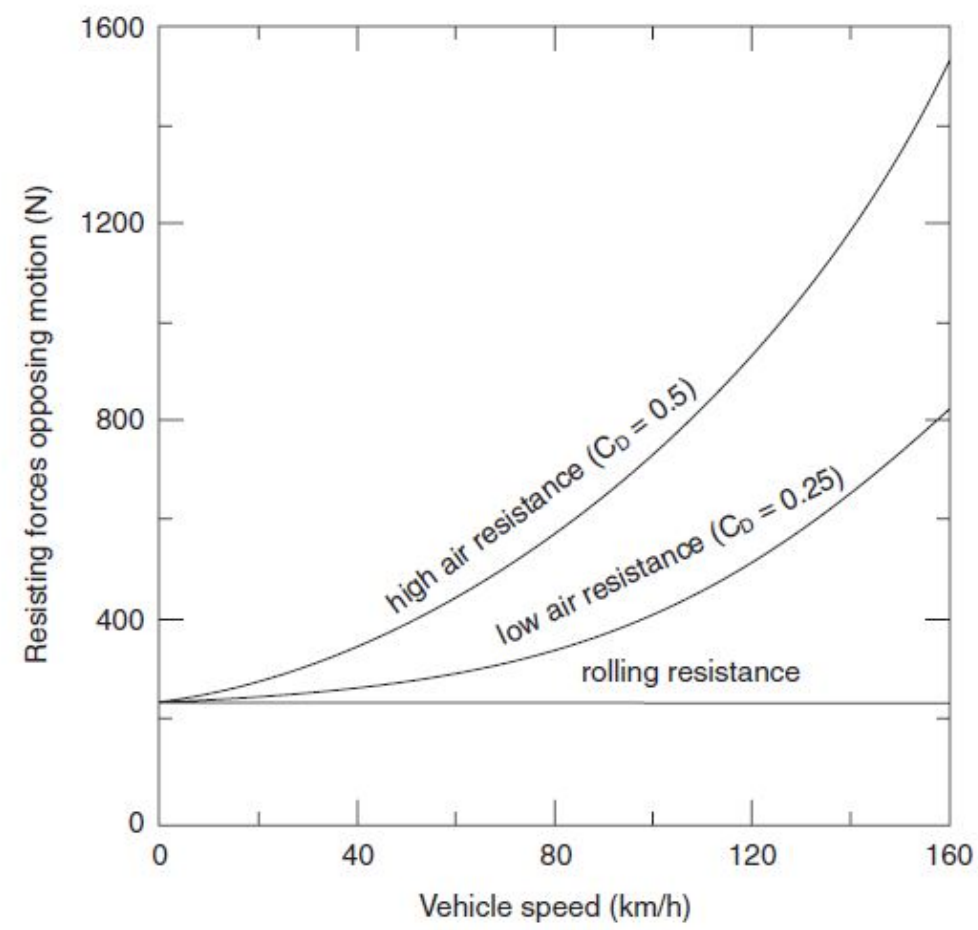

Figure 1: Comparison of low and high aerodynamic drag forces with rolling resistance [2]

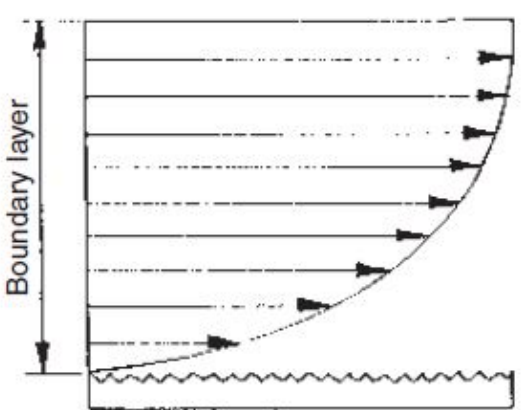

(a) Rough surface

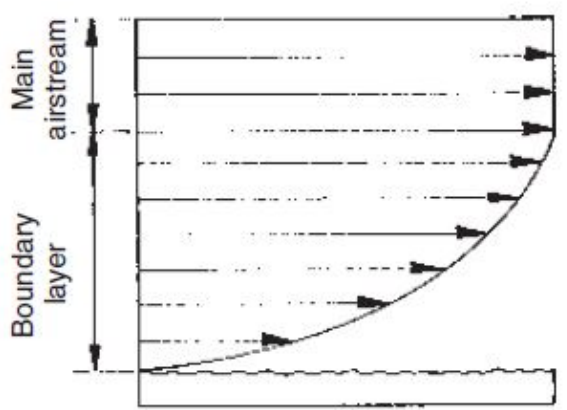

(b) Smooth surface

Figure 2: Influence of surface roughness on boundary layer velocity profile [2] 


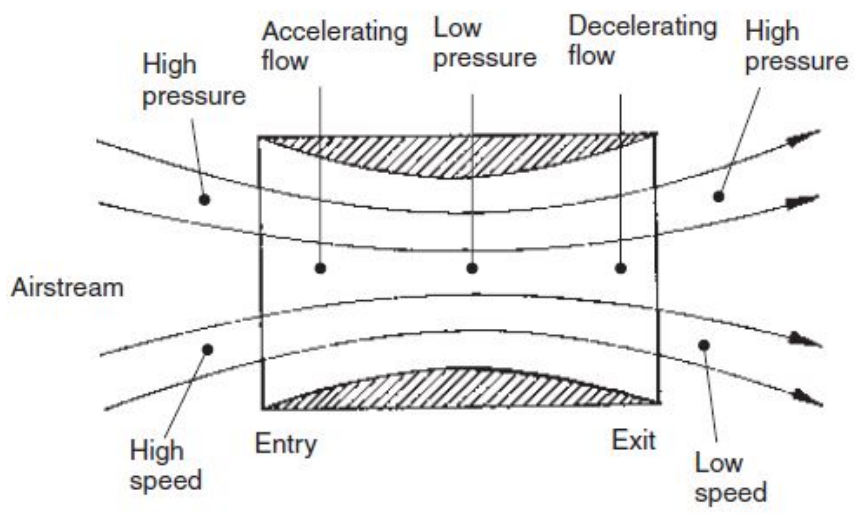

Figure 3: Venturi [2]

as molecules are drawn apart. As the air moves into the diverging sections, flow decelerates and pressure rises.

A similar condition is present for moving vehicles due to the relative air speed and pressure conditions over the upper vehicle profile. As the vehicle is in motion it can be considered to constitute a venturi effect. This condition is show in Fig. 4. In wind tunnel testing, air is scooped into the front hood area, similar to a diverging wedge, and is considered to be initially at atmospheric pressure. As air moves over the vehicle top, it has to accelerate to maintain the rate of volumetric displacement. It is here the air movement is highest, and pressure is reduced as air molecules are stretched apart. Then as air moves over the rear of the vehicle it decelerates to cope with the enlarged flow region. Overall, the pressure distribution is greatly affected by the car's design and speed, as well as the intensity and direction of the wind. If the streamline contour of the vehicle body is such that there are sudden large changes in geometry or shape, as commonly seen in the rear of a vehicle, it is expected to have high pressure drop, leading to turbulent regions and aerodynamic drag, see Fig. 5 . Yet if the streamline contour of the vehicle body is that of a converging rear end, boundary layers stay attached longer and rear end suction and resistance to motion are reduced. Thus the idea of a boat-tail was imagined.

Despite making automobiles more aerodynamic, many boat-tail systems can become counterintuitive due to extra material weight. The investigation of a lightweight aerodynamic system such 


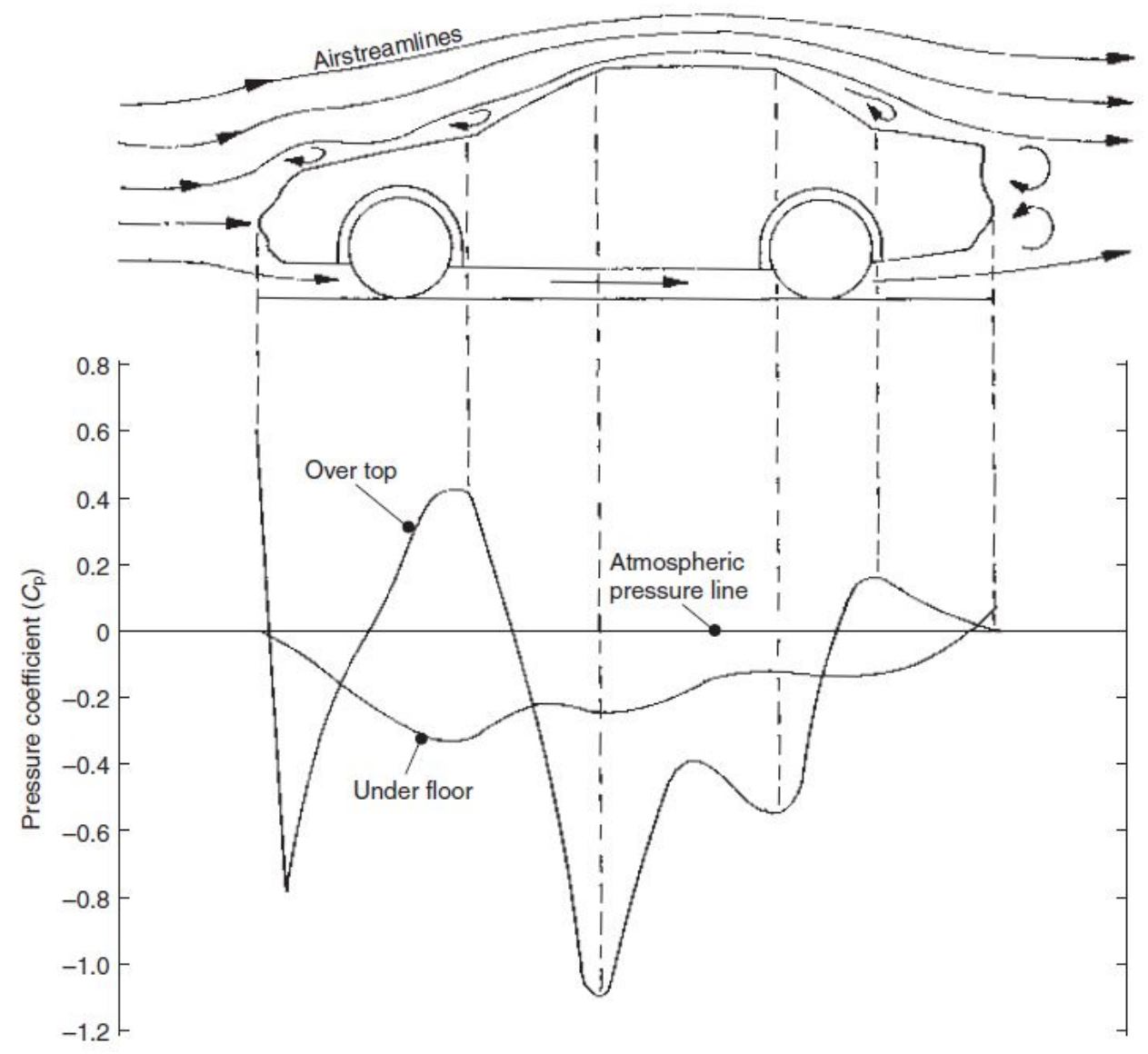

Figure 4: Pressure distribution above and below the vehicle body structure[2]

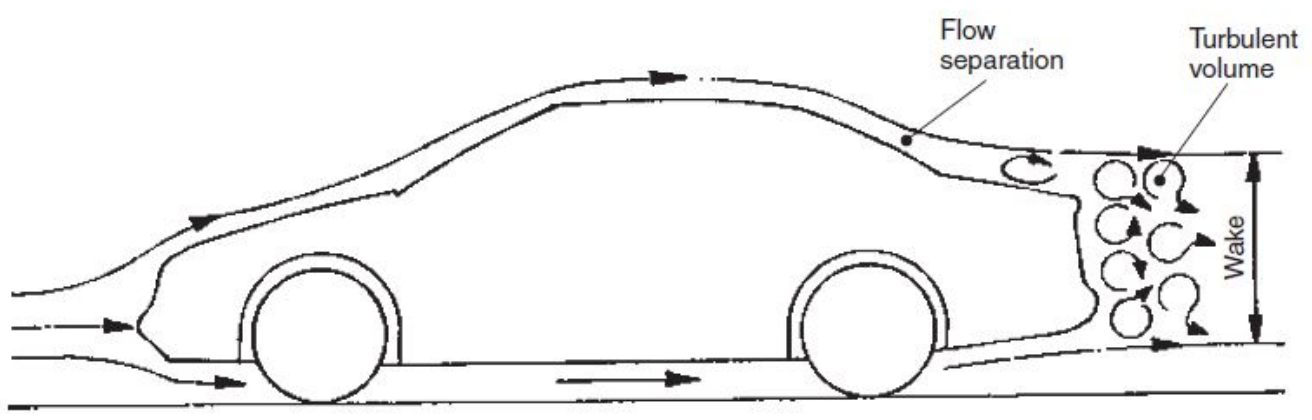

Figure 5: After flow wake[2] 
as an inflatable boat-tail is critical to the successful application of future boat-tailing systems for aerodynamic efficiency. This design can be incorporated into ground or aerial vehicles. This research directly impacts the future of mechanical and automobile design by proving futuristic, lightweight, environmentally friendly, and economic ways to achieve higher efficiency vehicles. A fully inflatable boat-tail was realized, designed, manufactured, and tested. This paper introduces the concepts of aerodynamic drag reduction using inflatable boat-tails.

\subsection{Goals and Objectives}

Design concepts are based on key challenges such as shape design, weight, material selections, stow ability and packing efficiency, deployment reliability, manufacturing ease, mounting and attachment ease, type of inflation system, ability to hold pressure, and common inflatable failures such as wrinkling, deformation, and puncture.

First, and foremost it was necessary to determine if an inflatable boat-tail was possible. Previous research provides analytical and experimental support for such an investigation, by proving use of inflatable geometries as rigid structures for various applications. Initial design stages for the inflatable boat-tail depended on past research investigations along with realistic manufacturing capabilities of the proposed aerodynamic boat-tail dimensions from Toyota. These original designs in Fig. 6 and 7 consisted of sharp fine-point corners, small angles, and geometries which are difficult to achieve with inflatable technology. Inflatable fabric studies and past inflatable structure research were combined with three-dimensional (3D) designs to propose a realistic inflatable boat-tail system based on original proposed dimensions.

Boat-tail systems were to be built as inflatable technology using heat-sealable fabrics. From 3D designs, two-dimensional (2D) fabric layouts were constructed for manufacturing. In order to check which fabrics were best suited for the inflatable boat-tail, experimental peel strength tests were performed. Peel strength theory directly relates to maximum burst pressure of inflatables, and more details will be discussed below. After heat seal peel strength comparison studies were performed between fabrics, dominate fabrics were chosen for final products. Multiple designs of inflatable boat-tails were built. These designs compared ease of manufacture with aerodynamics to 

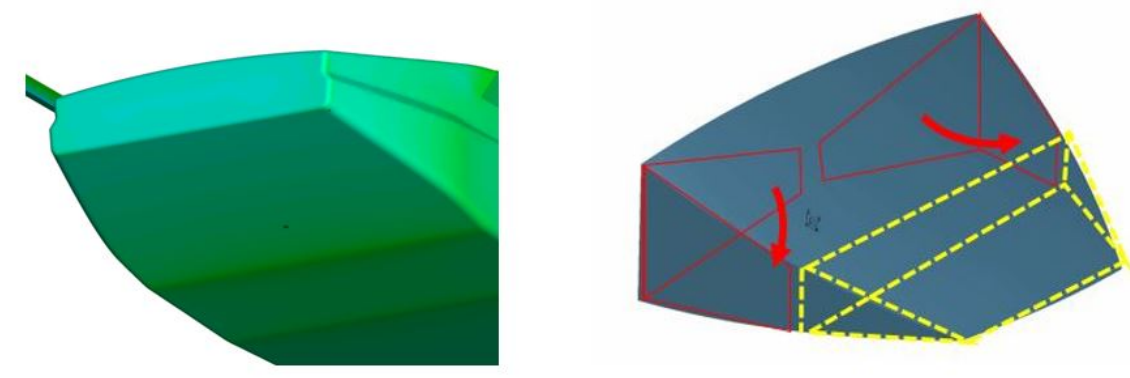

Figure 6: Original boat-tail geometries proposed by Toyota

investigate the most optimum case for final boat-tail design. Two boat-tail systems, plus a baseline system (containing no boat-tail) were imposed to various wind tunnel tests conditions. 


\section{Inflatable Boat Tailing 1:5 scale}

\section{Dimensions given by Toyota}

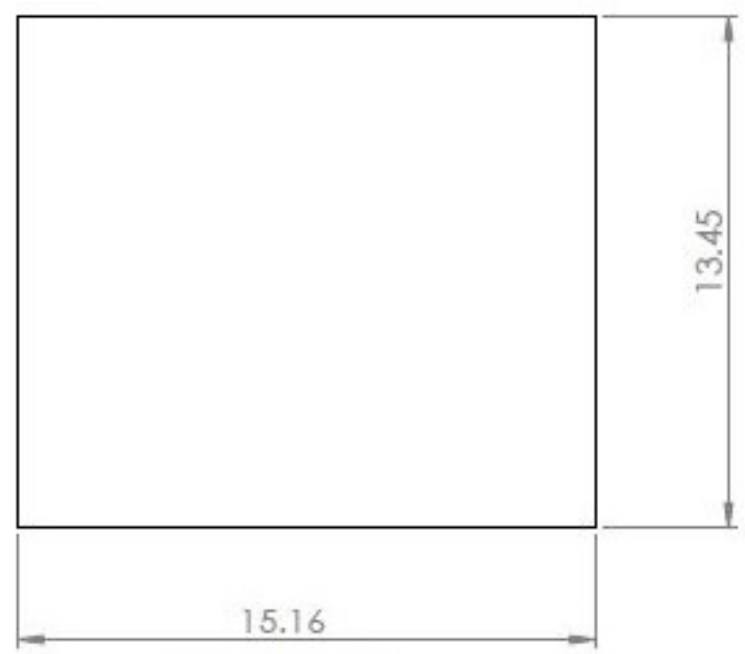

\section{Top View}

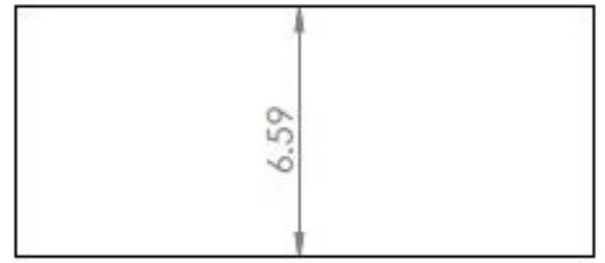

Cross-Sectional View

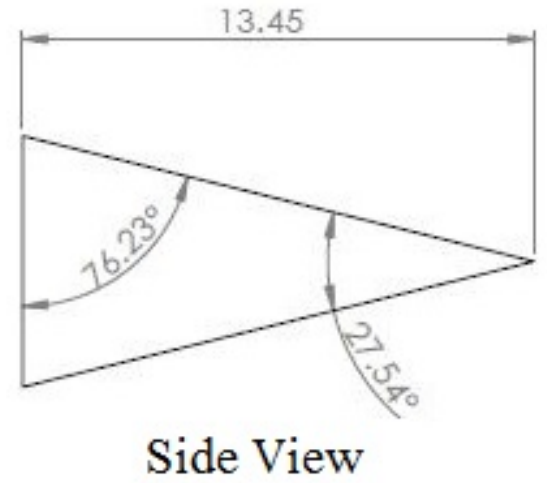

Side View

Figure 7: Original boat-tail dimensions proposed by Toyota, in inches 


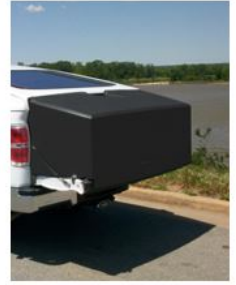

Rigid Panel

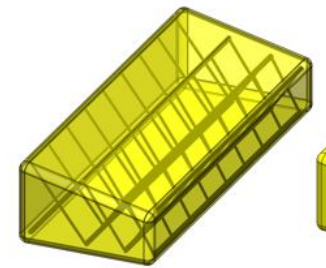

Mechanical Fold

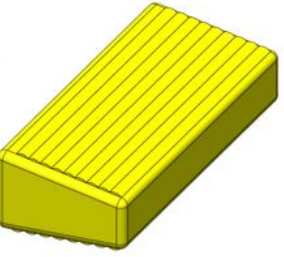

Baffled

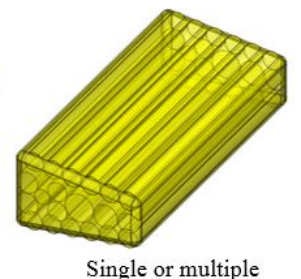

Inflatable Airbeam

\begin{tabular}{r|r|r|r|}
\hline Design & $\begin{array}{r}\text { Compactness } \\
\text { (stowed) }\end{array}$ & Maintain Shape \\
\hline Rigid Panel & 3 & 1 Panel Shape \\
Mechanical Fold & 4 & 3 & Skin Tension \\
Baffled & 1 & 2 & Air Pressure \\
Multi-Beams & 2 & 4 & Air Pressure
\end{tabular}

Figure 8: Initial boat-tail concepts

\subsubsection{Objectives}

The main goal of this research project is to prove inflatable technology as a drag reduction device. Successful application of inflatable technology allows for extremely lightweight designs that can be deployed at any moment a vehicle is in motion. The following objectives are set to establish a plan of action for this investigation of the design, manufacture, and testing of the inflatable boat-tail for drag reduction. Surveys will be taken of existing inflatable technologies, and design specifications for the inflatable boat-tail will be developed. Multiple iterative steps and processes are expected during the design and manufacturing stages of boat-tail systems to determine the most optimized designs. According to proposed model sizes by Toyota in Fig. 7, a 1/5 ratio of actual vehicle size, 3D models will be developed along with 2D fabric design drawings. Inflatable fabrics will be evaluated by heat sealability, UV resistance, and peel strength of adhesive bonds testing, of which test articles will be manufactured. Burst testing will be completed for experimental evaluation of peel strength as a function of internal pressure and multiple test systems will be developed for wind tunnel testing. 2D wake surveys will be performed while varying Reynolds number and boat-tail geometries, and coefficient of drag will be determined for various systems. 
- Survey existing inflatable structure elements and concepts including system envelope, internal structure, materials, and support systems, and recognize design specifications

- Investigate how to design ideal shapes and sizes of inflatable structures

- Develop 3D models of inflatable boat-tails and 2D fabric layouts and drawings for 3D construction

- Compare the different designs and their load carrying capability to determine the design variables and how they are connected including but not limited to pressure, tensile strength, elasticity, geometry etc

- Evaluate inflatable fabric options through testing by ASTM International specifications and determine the best fabrics and how to avoid failure

- Design, fabrication, and assembly of a demonstration article to illustrate the concept of using inflatable structures for future vehicles and show the effect of pressure on performance

- Establish construction techniques for inflatable boat-tails

- Develop test system for wind-tunnel wake surveys

- Conduct wake surveys following conservation of momentum theory and back out drag coefficients for various boat-tail models

- Discuss results 


\section{Background, Literature Review, Theory}

\subsection{History of Drag Reduction Concepts and Boat-Tails}

Reducing fluid-dynamic drag through unique shaping has been exercised by boat-designers for hundreds of years. Since approximately 1914 there have been proposals to reduce aerodynamic drag of ground vehicles. This was when horse-drawn vehicle speeds began to be exceeded. It took several more decades before serious attempts to reduce aerodynamic drag were adopted [3]. During the oil crisis of the early 1970s, NASA Dryden Flight Research Center began studying ground vehicle aerodynamics. During this time few vehicle designers regarded aerodynamic considerations when determining vehicle shape. Ease of manufacture and inside volume of vehicles held a higher priority, which resulted in box-like configurations. It was during this time that great opportunity for aerodynamic refinement of vehicles was perceived. Over the next couple of decades, Department of Transportation (DOT) and the Department of Energy placed increasing attention on aerodynamic efficiency of ground vehicles, primarily heavy-duty trucks and buses [3].

The majority of drag results from pressure differences, as seen in Fig. 9. Throughout the history of drag reduction, many methods have been proposed. One such method involves control of boundary layers through what is known as tangential blowing. This technology is also known as the Coanda Effect, after Henri Coanda, and provides that slow airflow will separate over a surface, see Fig. 10. Through this method, slots are made at strategic points on a vehicle allowing airflow to become energized with high velocity flow, therefore becoming attached to a curved surface, see Fig. 11. Results showed moderate decrease in drag coefficients depending on slot configurations. Rounding of corners also became an interesting factor in drag reduction and several combinations of slots with controlled blowing and rounded corners were combined. Boat-tail configurations were added, and multiple tests showed that adding a boat-tail independently had the largest effects on drag coefficients. This determined that the most beneficial configuration was the boat-tail, as seen in Fig. 12. Results for CFD calculations are shown in Fig. 13 [1].

Nasa Ames Research Center studied the configuration of an aerodynamic boat-tail compared to an ordinary or rigid boat-tail. This aerodynamic boat-tail is created by the addition of what are known as boat-tail plates, see Fig. 14 and 15. The idea of boat-tail plates is to trap a vortex in 


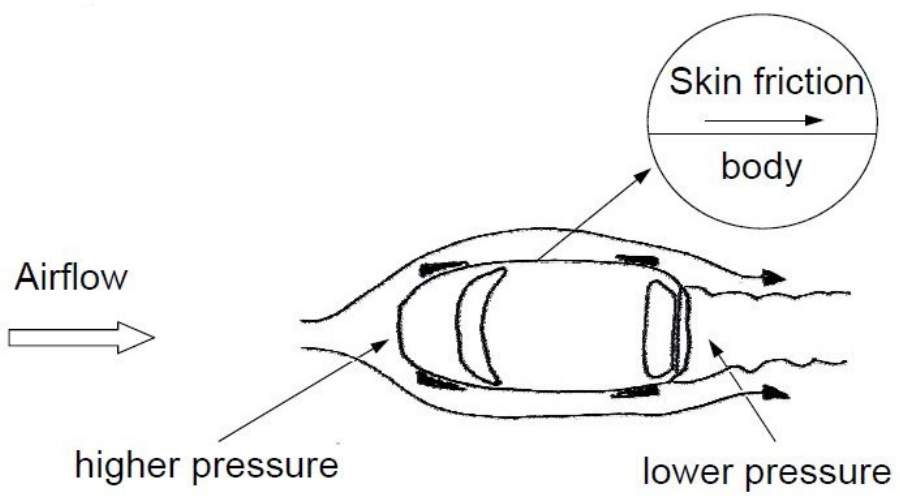

Net pressure force

drag coefficient, dependent upon shape

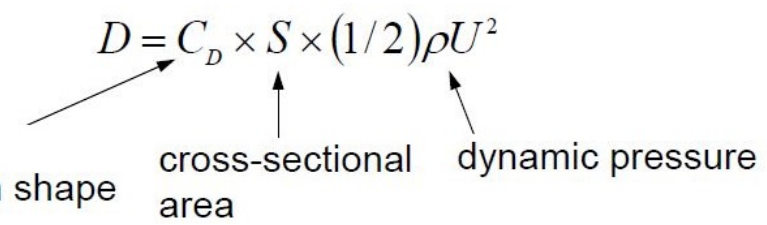

Figure 9: General representation of pressure differences on vehicle [1]

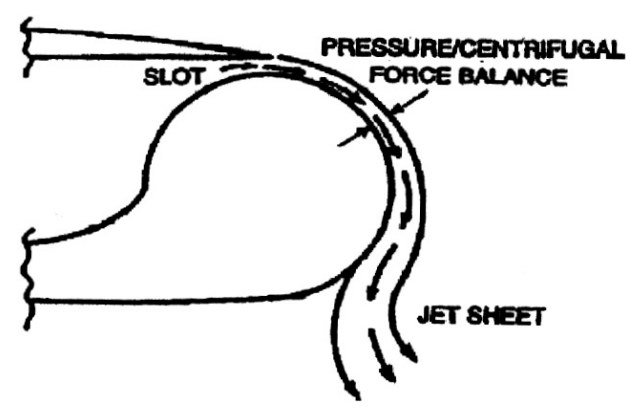

Figure 10: The Coanda effect demonstrated on a trailing edge [1]

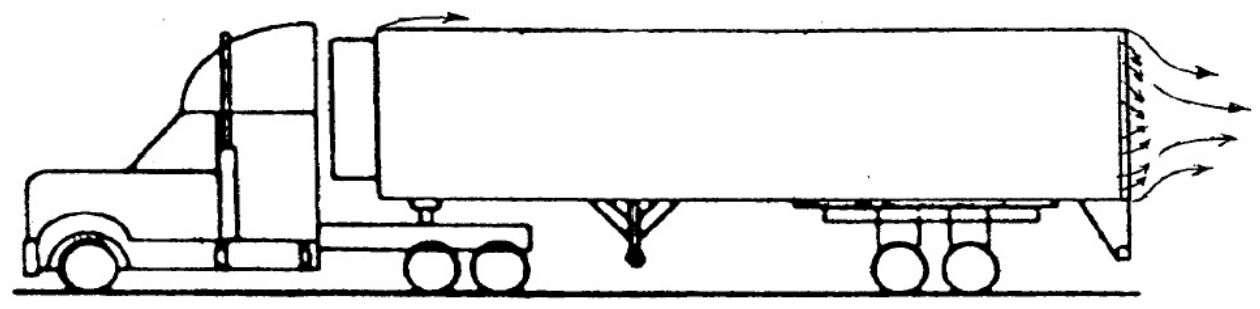

Figure 11: Trailer configuration simulated at Georgia Tech Research Institute [1] 


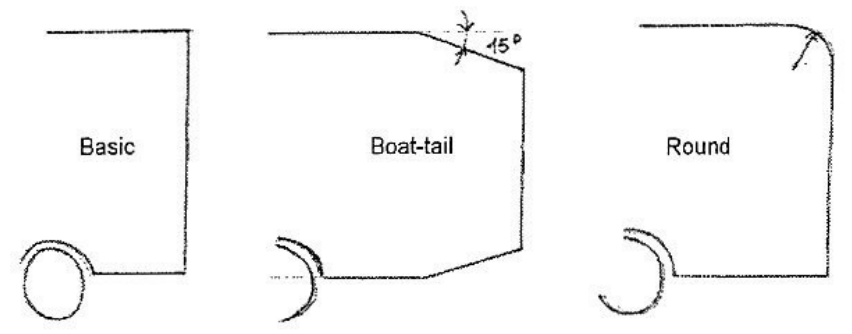

Figure 12: Different configurations simulated at KTH [1]

\begin{tabular}{|l|l|l|l|}
\hline Configuration & & & $\mathrm{C}_{\mathrm{d}}$ \\
\hline Basic & & & 0.326 \\
\hline Boat-tail & Length $=0.1 \mathrm{~m}$ & Basic & 0.285 \\
\hline & & Blowing & $\begin{array}{l}0.287, \mathrm{U}=0.4 \mathrm{~m} / \mathrm{s} \\
0.275, \mathrm{U}=0.004 \mathrm{~m} / \mathrm{s}\end{array}$ \\
\hline & Length $=0.25 \mathrm{~m}$ & Basic & 0.271 \\
\hline & & Blowing & $0.291, \mathrm{U}=2 \mathrm{~m} / \mathrm{s}$ \\
& & & $0.338, \mathrm{U}=33 \mathrm{~m} / \mathrm{s}$ \\
\hline & Length $=0.5 \mathrm{~m}$ & Basic & 0.23 \\
\hline & & Blowing & $0.25, \mathrm{U}=0.4 \mathrm{~m} / \mathrm{s}$ \\
\hline & Radius $=0.1 \mathrm{~m}$ & Basic & 0.293 \\
\hline & & Blowing upper & $0.278, \mathrm{U}=0.04 \mathrm{~m} / \mathrm{s}$ \\
\hline & & Blowing upper + & $0.27, \mathrm{U}=0.04 \mathrm{~m} / \mathrm{s}$ \\
& & lateral & \\
\hline & & Punctual Blowing & $0.28, \mathrm{U}=0.04 \mathrm{~m} / \mathrm{s}$ \\
\hline & Radius $=0.2 \mathrm{~m}$ & Basic & 0.28 \\
\hline & & Blowing & $0.27, \mathrm{U}=0.04 \mathrm{~m} / \mathrm{s}$ \\
\hline
\end{tabular}

Figure 13: Results for CFD calculations at KTH when blowing boundary layers [1] 


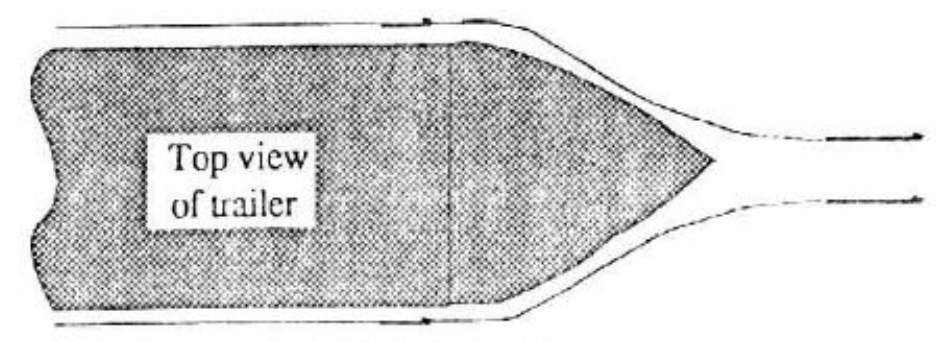

Fizure 12. Rigid boattail

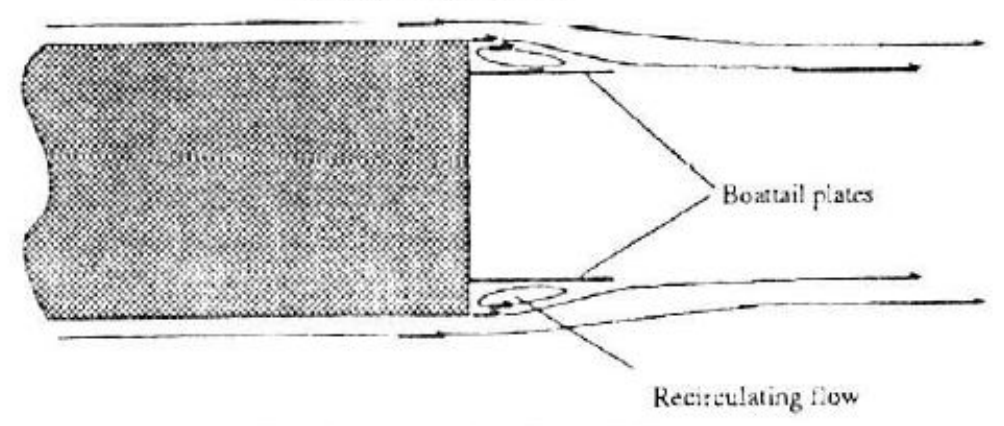

Figure 1b. Aerodynamic boattial

Figure 14: Rigid and Aerodynamic boat-tails [1]

the corner between the plates and rear of the trailer. The eddy's created between the plates and trailer cause the flow that would normally become separated to turn inward. This creates a virtual boat-tail, thus increasing the pressure acting on the rear of the vehicle. Therefore reducing the total aerodynamic drag of the vehicle. By adjusting configurations, results showed drag reductions in the range of $10 \%$.

Other drag reduction technologies such as transverse and swept grooves, as well as vortex generators have been tested as drag reduction devices. Yet above all drag reduction technologies, the most common way of reducing rear end drag on vehicles is by rigid boat-tailing, also known as rear end tapering. Previous research through wind tunnel investigation was performed on how varying tail shape affects drag coefficient, yet the most optimal configuration for drag coefficient is not practical from a design perspective, as seen in Fig. 16 [2]. 


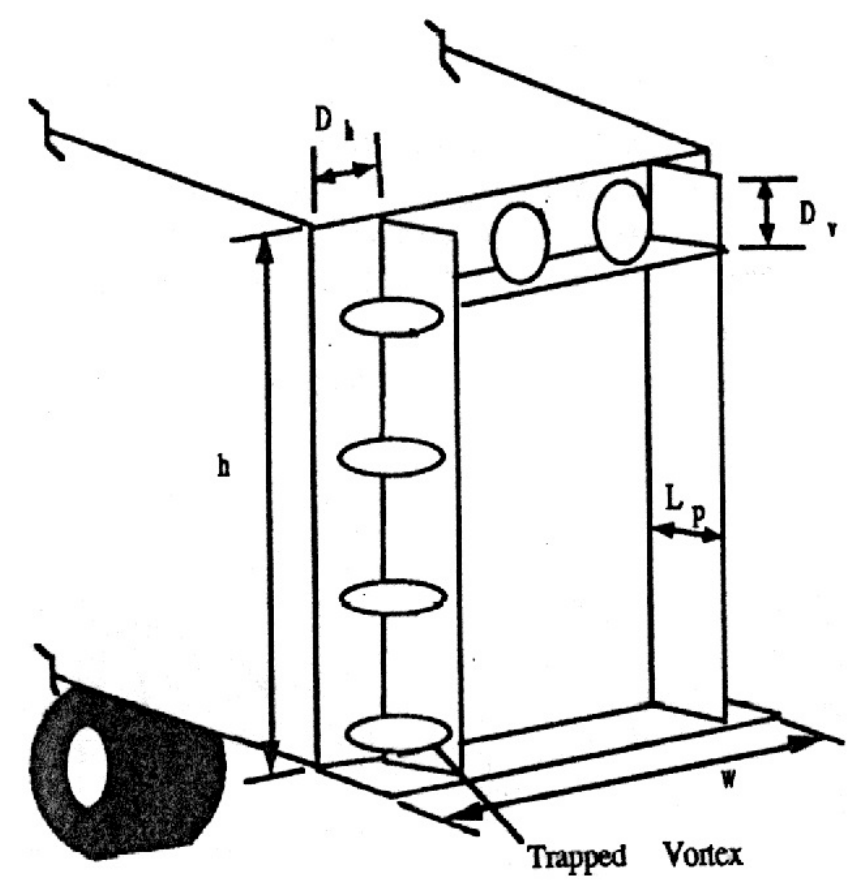

Figure 15: Rear end configuation for Nasa Ames Research Center wind tunnel tests [1] 

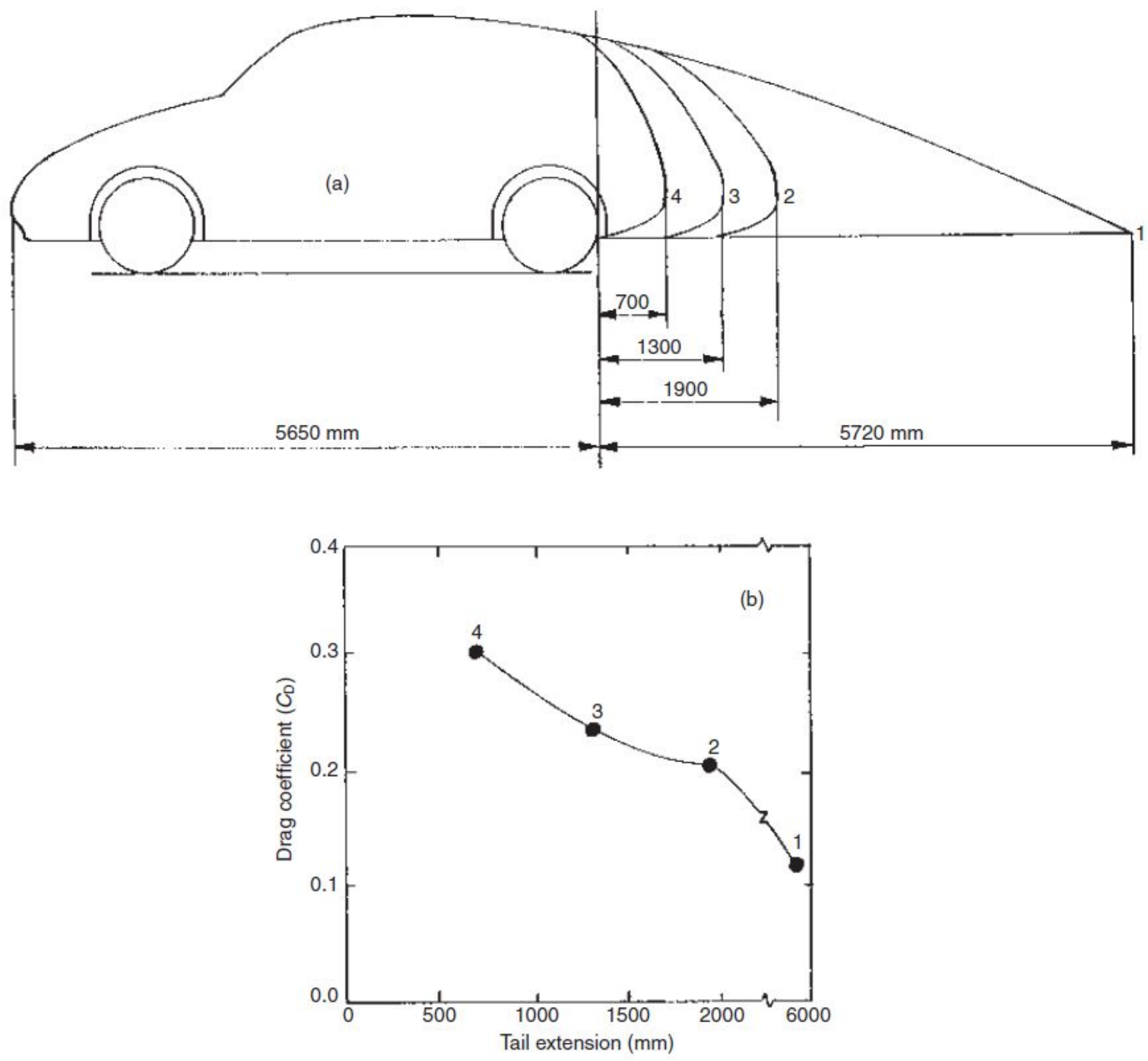

Figure 16: Effect of rear end extension on drag coefficient [2] 


\subsection{Inflatable History}

Due mostly to ease of fabrication, ability to span distances, and carry loads, interest in inflatable structures has been growing since Frei Otto's Tensile Structures was first published in 1962. Especially with regards to space, inflatable structures are quite an interest because of their ability to be packed to a low volume and launched into space in the non-inflated state. Over the last several decades structural analysis of inflated circular-cylindrical beams has been developed using a number of different strategies. Comer and Levy studied inflatable cantilever beams using the Euler-Bernoulli kinematics, while Fitchter gave the first solutions having inflation pressure in the deflection expressions. John A. Main et al. developed bending models for inflated fabric beams which showed their bending behavior is identical to conventional solid elastic beams, given that the inflatable beam fabric remain unwrinkled $[4,5]$. More recently, inflatable technologies have widely expanded for medical uses, inflatable antenna reflectors, inflatable dams, and many other interesting and creative inflatable solutions and ideas. Through this many relationships have been developed by mathematical and numerical models along with extensive areas of experimental research.

Most recently, investigation over deployment dynamics of inflatable wings was performed. Since 1970, ILC Dover has been a leading manufacturer of inflatable technology, specifically that of inflatable wings. These designs allow for multi-function aircraft as inflatable wings are developed to change shape during flight. Other than variation of functionality, inflatable aircraft offer many benefits including low cost, long storage life, shape recovery after buckling and bending due to load, and a high packing efficiency (low volume). Other factors may limit inflatable technology such as potential leaking due to puncture, lower stiffness when compared to more solid structures, and low atmospheric pressure in high altitude leading to a larger volume of gas for inflation. Yet these drawbacks can be made up for through rigidization technology using materials that would become rigid after deployment [6]. Multiple inflatable wing systems have been designed, tested, and evaluated, these include the Goodyear Inflatoplane, ILC Dover Apteron, NASA Dryden I2000, Pnewing by Prospective Concepts, and AIRCAT and BIG BLUE by University of Kentucky in Lexington. Successful application and testing of these varying projects helps prove inflatable technologies for many different applications [6]. 


\subsection{Peel Strength Theory}

In the case of developing an inflatable boat-tail for motor vehicles, the testing of fabrics through peel strength theory was completed to determine the best off-the-shelf fabric for heat sealed inflatable applications. Optimum fabrics include those which provide a strong, quality heat seal and can hold pressures above 7 psi. For this investigation, the ASTM International test method ASTM D90398(2017) Peel Strength of Adhesive Bonds, was chosen for its relation to pouch burst pressure. By testing for a fabrics heat seal peel strength, related burst pressure can be found, giving insight to maximum pressures for heat sealed inflatables built of these fabrics. Figure 17 shows a pouch restrained by two parallel plates with a distance of $2 \mathrm{R}$. As the pouch is inflated, balanced forces act upon the upper and lower pouch by the plates, and as air pressure increases, increasing tensile forces are exerted on the seal area. Summing the y-component forces around the seal area leads to the following equations [7].

$$
\begin{gathered}
d F_{y}=P R \sin (\theta) d \theta \\
F_{y}=\int_{0}^{\pi / 2} P R \sin (\theta) d \theta=P R \\
S=P_{b} R
\end{gathered}
$$

Where $F_{y}$ is the force peeling the seal, $\mathrm{P}$ is the internal pressure, $\mathrm{R}$ is the half-plate separation distance, and $\Theta$ is the angle shown in Fig. 18 [7]. At time of rupture, $F_{y}$ and $\mathrm{P}$ can be replaced by the seal strength $\mathrm{S}\left(l b_{f} / i n\right)$ and burst pressure $P_{b}(\mathrm{psi})$, respectively.

To verify this theory, standard peel tests and burst tests were performed. Following ASTM D90398 Standard Test for Peel Strength of Adhesive Bonds, using an Instron Universal Testing machine with constant head speed peel strength tests were completed. Details are discussed in Chapters 3 and 4 . 


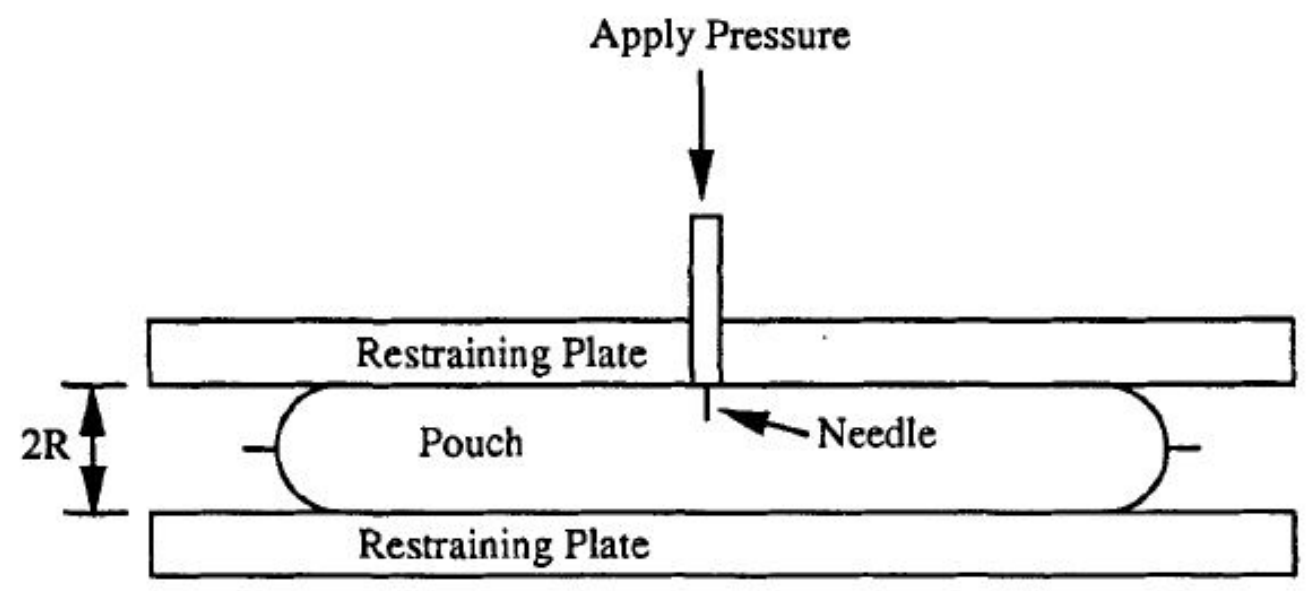

Figure 17: Internal burst test schematic for flexible pouch

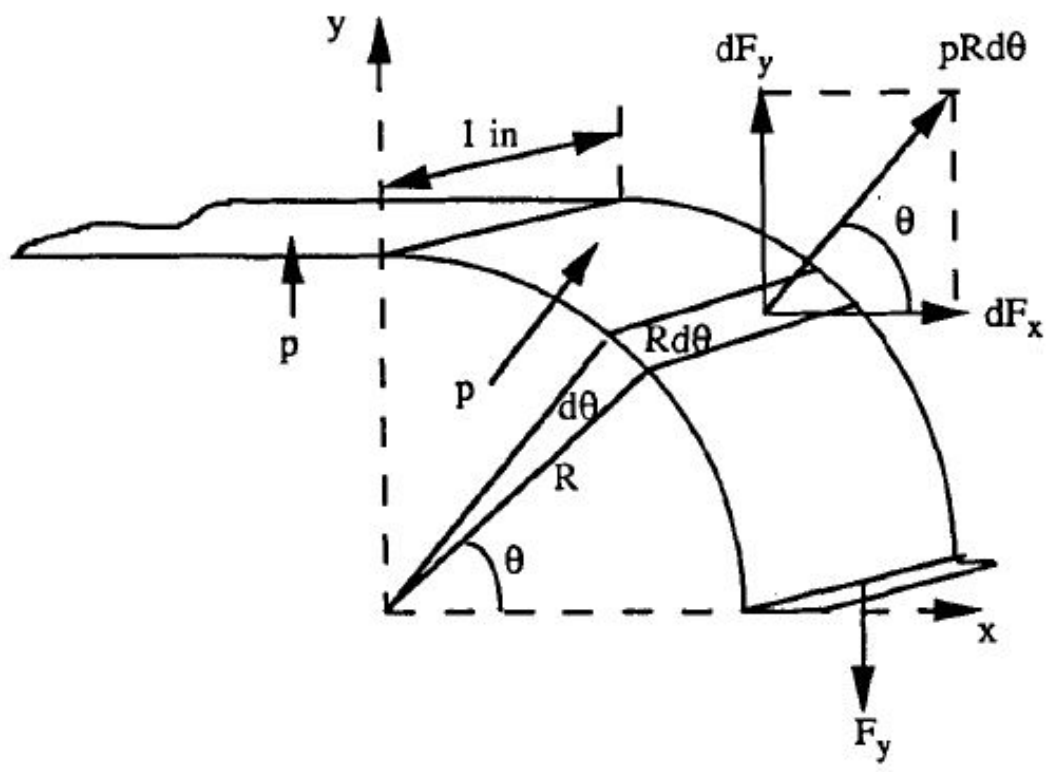

Figure 18: Analysis of force near the seal area 


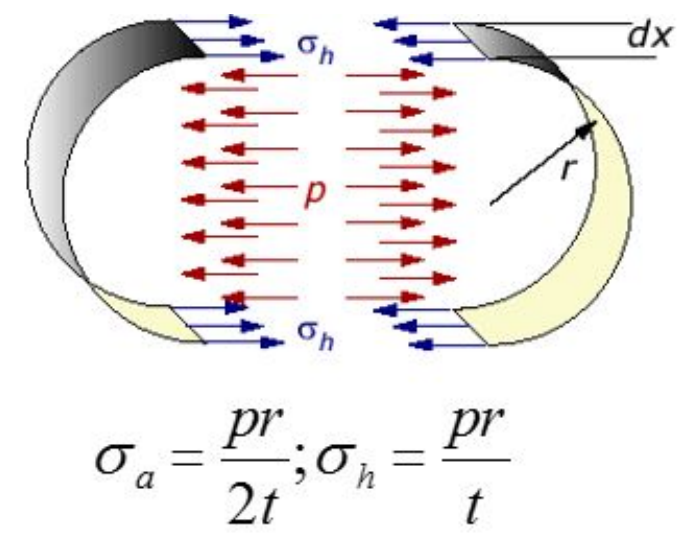

Figure 19: Inflatable structure modeled as a thin wall pressure vessel

\subsection{Burst Tests Theory}

For burst testing, inflatable tubes are considered as thin walled pressure vessels, where pressure is required to maintain tension and shape, and to resist loading. From thin walled pressure vessel theory, hoop stress $\sigma_{h}$ is twice that of axial stress, $\sigma_{a}$. Tests were performed on eight total inflatable tubes of 3 inch and 5 inch diameters. Experimental set-up and Results are discussed in Chapters 3 and 4 , respectively.

\section{$2.5 \quad$ Failure Consideraions}

The primary consideration for failure in an inflatable structure is the maximum sustainable bending moment. For an inflatable structure solution to be practical for a drag reduction device, the inflation pressures required to sustain the root bending and other associated forces on the structure (such as twist) must be small enough that the design does not impose severe inflation and material requirements. This limit is somewhat arbitrary since it is dependent on the wing design and the inflation system. In reality, this limit must be balanced with other constraints, such as packing requirements and available weight. Naturally, higher pressures will increase design risk by reducing the reliability of inflatable components through increased chances of leaks. While leakage effects can be countered with make-up gas and onboard compressors, these must be factored in as increased weight during the trade study portion of the system design.

To determine the load carrying capability of an inflatable solution, we begin with the well known 
Euler-Bernoulli beam equation that relates the beam deflection with applied moment and material properties on a cantilever beam [8];

$$
\frac{d^{2} y}{d x^{2}}=\frac{M(x)}{E_{w} I}
$$

where $M$ is the applied moment, $E_{w}$ is the Young's modulus of the material, and $I$ is the crosssectional moment of inertia. Main et al. modified this with respect to an inflated fabric tube to develop a relation for the bending moment equation for a single inflated fabric spar for space based inflated structures $[4,9]$.

$$
\begin{gathered}
\frac{d^{2} y}{d x^{2}}=\frac{M}{E_{l} \pi r^{3}} \text { for } M<\frac{\pi p r^{3}}{2}\left(1-2 \nu_{t}\right) \\
\frac{d^{2} y}{d x^{2}}=\frac{M-2 \nu_{t} p r^{3} \sin \theta_{0}}{E_{l} r^{3}\left[\left(\pi-\theta_{0}\right)+\sin \theta_{0} \cos \theta_{0}\right]} \text { for } M>\frac{\pi p r^{3}}{2}\left(1-2 \nu_{t}\right)
\end{gathered}
$$

where $M$ is the bending moment, $E_{l}$ is the longitudinal fabric tensile modulus, $r$ is the beam radius, and $\theta_{0}$ is the wrinkle angle. The relation includes the impact of wrinkling and accounts for the biaxial stress in the beam fabric and the impact that it has on the wrinkling threshold of the beam as well as the beam's postwrinkling bending behavior. The model was well validated against experimental data of fabric beams under loads. The essential behavior of the model is presented in Fig. 20. As the load increases, the beam deflects in a linear manner. Once the wrinkling threshold is reached, the relation becomes non-linear, soon after, the beam buckles. This will scale depending upon the type of structure involved. While buckling is the failure mode, the onset of wrinkling indicates the maximum design load and will be used for the design limit. It should be noted that unlike metal or composite rigid structures that will either plasticly deform or crack, respectively, once the yield stress is reached, the inflatable beam will bend, but then will return undamaged to its original state after the load is reduced or removed. Inflatable sections can either be made out of plastic or fabric material with fabric tubes either woven or braided, the latter typically referred to as "airbeams" [10].

In terms of required inflation pressure for a given bending moment, the equation can be written as

$$
P=\frac{2 M_{0}}{\pi r^{3}}
$$

While $P$ is linear with $M_{0}$, doubling the tube radius reduces $P$ by a factor of 8 . Thus, larger diameter 


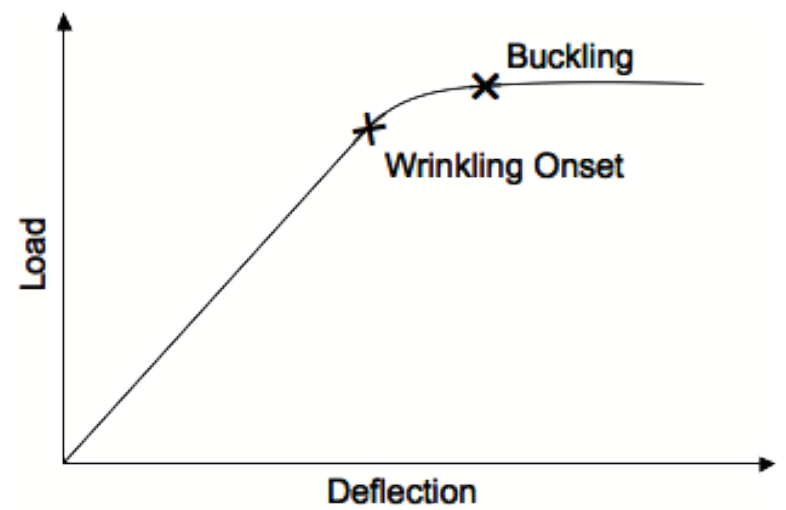

Figure 20: Load versus deflection for generic inflatable structure.

tubes are extremely beneficial when used on thicker rather than thinner structures.

The required pressure can be reduced by $1 / 2$ by using a braided beam that groups the active axial fibers to double the moment of inertia in the bending direction [10].

$$
P=\frac{M_{0}}{\pi r^{3}\left(1-2 \tan ^{2} \beta\right)}
$$

where $\beta$ is the angle of the bias braid. Further increases in the allowable bending load can be made by applying the principle of tensairity where tension and compression elements are designed integrally with the airbeam [11]. While not extensively tested, it has the potential to increase the allowable load by an order of magnitude. Other methods to increase allowable bending moment include increasing the material's elastic modulus and the wing's cross-sectional moment of inertia. Multiple spars or baffles accomplish the latter.

\subsection{Drag Measurements - 2D Wake Survey Theory}

The aerodynamic drag on an object depends on several factors, including shape, angle of attack, and flow conditions. The $2 \mathrm{D}$ wake survey experiment is based on the momentum balance performed over a control volume, see Fig. 21, where the flow is assumed to be two-dimensional and upstream flow uniform. From measured velocity profiles in the wake, drag force is determined by means of the law of conservation of linear momentum. Below is the x-momentum balance performed over the 


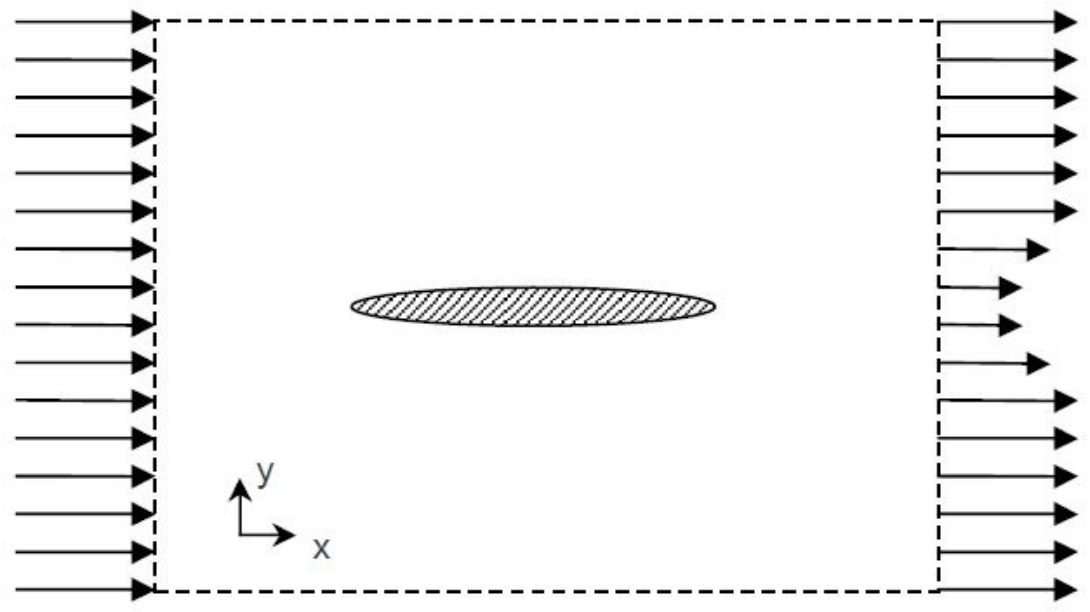

Figure 21: Control volume for drag estimation by momentum balance

control volume [12].

$$
\frac{d}{d t} \int_{V} \rho u d V+\int_{S} \hat{n} \cdot V u d S=\int_{S} \hat{n} \cdot \tilde{T} \cdot \hat{i} d S+\int_{V} b_{x} d V-D
$$

Where $\mathrm{V}$ is the control volume, $\mathrm{S}$ is the control surface area, $\mathrm{W}$ is width, $\rho$ is the fluid specific mass, $\mathrm{V}$ is local velocity vector, $\mathrm{u}$ is the velocity component in the $\mathrm{x}$-direction, $\mathrm{n}$ is the external unitary vector locally normal to the surface $\mathrm{S}, \mathrm{T}$ is the stress tensor, $b_{x}$ is the body force per unit volume acting on the fluid in the $\mathrm{x}$-direction, $\mathrm{dV}$ is the control volume element, $\mathrm{dS}$ is the control surface element, and D is the force in the x-direction exerted by the fluid on the airfoil [12]. Now using the steady two-dimensional flow hypothesis, assume that time averaged quantities do not vary in time in the z-direction; neglect body forces and assume all important contributions of the stress tensor are those due to its spherical part, the pressure p. With these assumptions,

$$
\langle D\rangle=\left\langle\int_{S}(\rho \hat{n} \cdot \hat{i}-\rho \hat{n} \cdot V u) d S\right\rangle
$$

where angle brackets represent time averaging. Now, letting the control surface be a rectangular prism with cross section as shown in Fig. 21, where control surfaces are far enough from the body and downstream momentum flow is uniform (equal to $\rho U_{\infty}^{2}$ ) and specific mass and pressure are 
uniform along the control surface, then

$$
\langle D\rangle=\left\langle W \rho \int_{-\infty}^{\infty}\left(U_{\infty}^{2}-u^{2}\right) d y\right\rangle=W \int_{-\infty}^{\infty}\left(\rho\left\langle U_{\infty}^{2}\right\rangle-\left\langle u^{2}\right\rangle\right) d y
$$

The integration is performed only over the downstream face of the control volume, which is extended above and below the airfoil y-position until the specific momentum flux on that surface equals $U_{\infty}^{2}$, making the integrand null. Some subtleties of turbulent flow are disregarded and mass conservation is used to rewrite the above equation in terms of a velocity deficit [12].

$$
D=W \rho \int_{-\infty}^{\infty} u\left(U_{\infty}-u\right) d y
$$

Below is the general conservation law, letting $\mathrm{W}=\mathrm{b}$.

$$
D_{f}=\rho b \int_{-\infty}^{\infty} u\left(U_{\infty}-u\right) d y
$$

Where $\mathrm{b}$ is the width of the body, $\mathrm{u}$ is the velocity profile, and $U_{\infty}$ is the freestream velocity.

$$
D_{f}=\rho b \int_{-\infty}^{\infty} u\left(U_{\infty}-u\right) d y=\rho b \int_{- \text {wall }}^{+ \text {wall }} u(y)(U-u(y)) \Delta y
$$

By pairing this with the drag equation, individual coefficient of drag values for varying cases can be solved. The drag equation may be derived by the method of dimensional analysis [13]. Where involved variables are speed $\mathrm{u}$, viscosity of the fluid $\nu$, fluid density $\rho$, cross-sectional area of body A, and drag force $F_{d}$. By Buckingham Pi Theorem, these five variables are reduced to two dimensionless parameters, drag coefficient $C_{d}$ and Reynolds number Re, where

$$
\begin{gathered}
R e=\frac{u \sqrt{A}}{\nu} \\
R e=\frac{F_{D}}{\frac{1}{2} \rho A u^{2}}
\end{gathered}
$$


Thus,

$$
f_{b}\left(\frac{F_{D}}{\frac{1}{2} \rho A u^{2}}, \frac{u \sqrt{A}}{\nu}\right)=0
$$

or

$$
F_{D}=\frac{1}{2} \rho A u^{2} f_{c}(R e)
$$

and with

$$
C_{D}=f_{c}(R e)
$$

Then,

$$
\begin{gathered}
F_{D}=D_{f}=\frac{1}{2} \rho V^{2} A C_{D} \\
\frac{D_{f}}{b}=\rho \int_{- \text {wall }}^{+ \text {wall }} u(y)(U-u(y)) \Delta y=\frac{1}{2} \rho V^{2} h C_{D}
\end{gathered}
$$

where $\mathrm{A}=\mathrm{bh}$

Therefore, by summing $(\mathrm{U}-\mathrm{u}(\mathrm{y})) \Delta \mathrm{y}$ for each data set, and knowing wind tunnel air density, free stream velocity $\mathrm{U}$, and boat-tail height $\mathrm{h}$, one can solve for dimensionless drag coefficient, $C_{D}$, where $\mathrm{h}=6$ inches for this study [13]. Following wake survey, wind tunnel experiments were performed and coefficient of drag was found for multiple cases. Initially, 2D wake surveys were performed at the middle section of each boat-tail system, at varying Reynolds numbers of approximately $1.59 \mathrm{E}+5$, $2.30 \mathrm{E}+5,3.15 \mathrm{E}+5$, and $3.96 \mathrm{E}+5$. These Reynolds numbers span the limits of the wind tunnel system, providing results for a variety of cases. All three of these cases were performed at $0^{\circ}$ angle of attack. Inflatable sections were kept at an average internal bladder pressure of $\mathrm{P}=0.5 \mathrm{psi}$ throughout testing. Multiple other tests were performed using wake survey theory, and more details are described in Ch. 3 and 4. 


\section{Experimental Arrangement}

Towards the beginning of the design process it was clear that in order to build inflatable boattails properly, the correct fabric must be selected. Several factors influenced final fabric choices, including heat seal ability, UV resistance, weight, material strength, and heat seal peel strength. Initially, six fabrics were bought for testing, Heat Sealable Taffeta, 200 Denier Coated Oxford, Polyurethane Coated Ripstop, Heat Sealable Oxford, Heat Sealable 30 D Nylon Ripstop and Heat Sealable Packcloth, all purchased from SeattleFabrics, Inc. and are shown in Fig. 22. Each fabric was tested for heat seal ability. Four fabrics were successfully heat sealed and chosen for peel strength tests to investigate heat seal strength and performance. For proper manufacture, peel strength tests were completed following the Peel Strength Theory and a primary fabric was chosen for heat seal strength and UV resistant properties. Results of Peel Strength testing are discussed in Chapter 4. After manufacture of different designs, wind tunnel tests were set-up following theory of 2D Wake Survey.

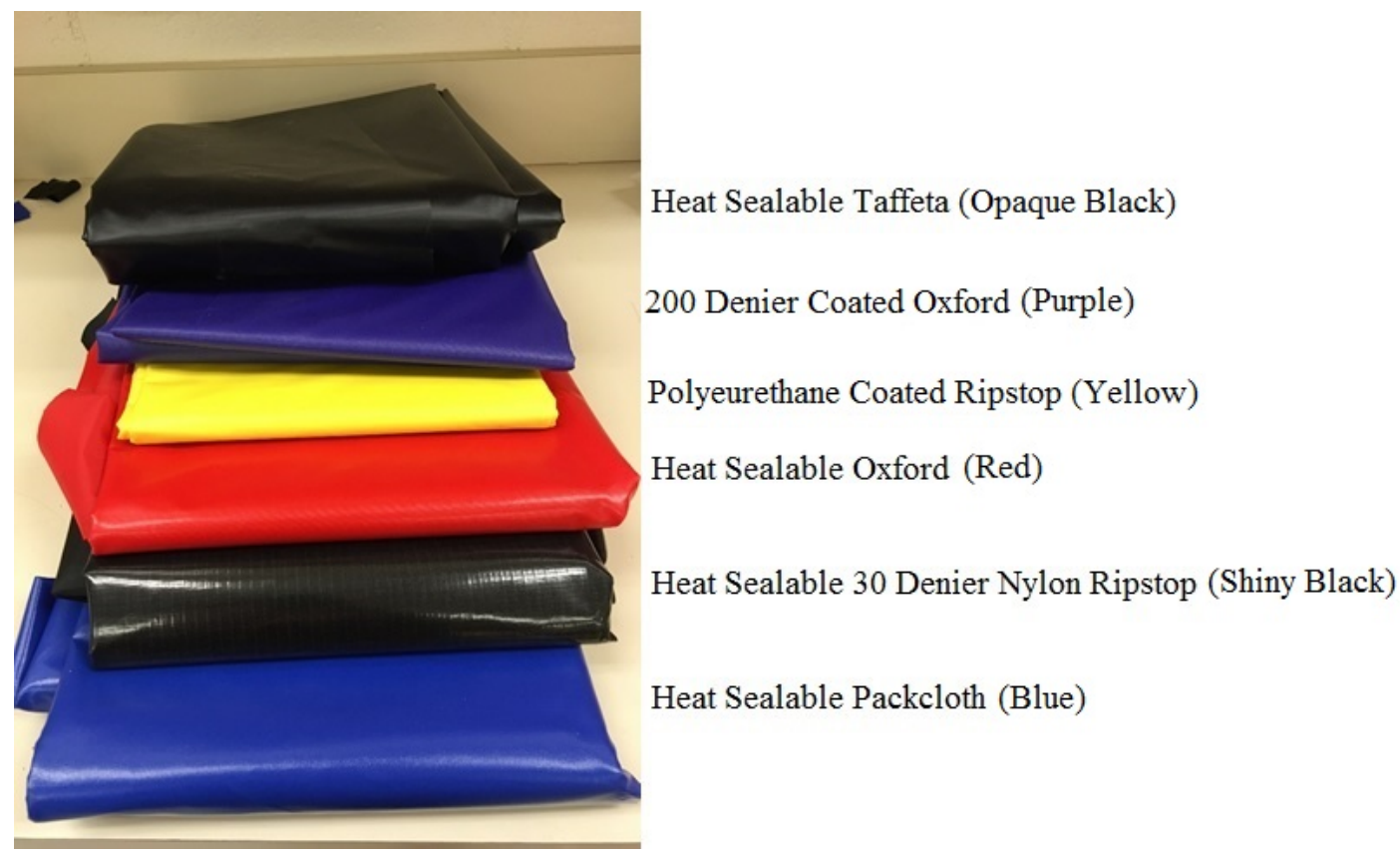

Figure 22: Six fabrics tested for heat seal ability 


\subsection{Peel Strength Test Set-up}

Following ASTM International specifications for D903-98(2010) Standard Test Method for Peel or Stripping Strength of Adhesive Bonds, see Fig. 23 [14], the four heat sealable fabrics discussed previously were tested. Individual tests were completed on six test specimens per fabric, see Fig. 24. These specimens consisted each of one $1 \times 12$ inch strip of fabric heat sealed over a six inch length section to a $1 \times 8$ inch piece of fabric. Prior to testing, specimens were heat sealed using a handheld heat sealer made by UL Heat Seal Model S seen in Fig. 25. Testing was completed on an Instron Universal Testing Machine with System ID Number: 5582R3202, with a capacity of $100 \mathrm{kN}$ and DOM August 2009. The Instron UTM is shown in Fig. 26 and fabric samples were individually clamped into the device as shown in Fig. 27. During peel strength testing, the universal testing machine pulls each end of the heat-sealed fabric, at a constant head speed with travel rate of $6 \mathrm{in} / \mathrm{min}$. During this time both the heat seal and the material are under tension, and tests are monitored using Instron Bluehill Universal Software. Loading continues as the heat seal and fabric are strained, and failure happens with rupture of the heat seal area or fabric tearing. Results are plotted as Load $\left(l b_{f}\right)$ vs Extension (in) and certain types of failure are discussed in Chapter 4.

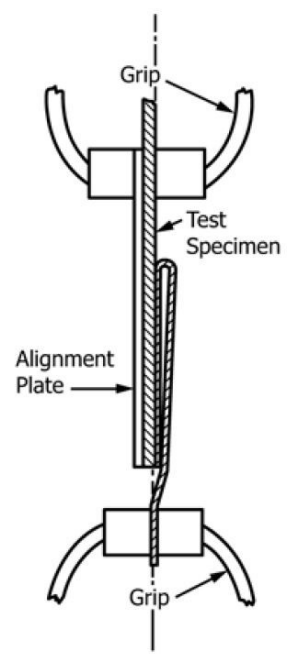

Figure 23: Peel strength test diagram [14] 


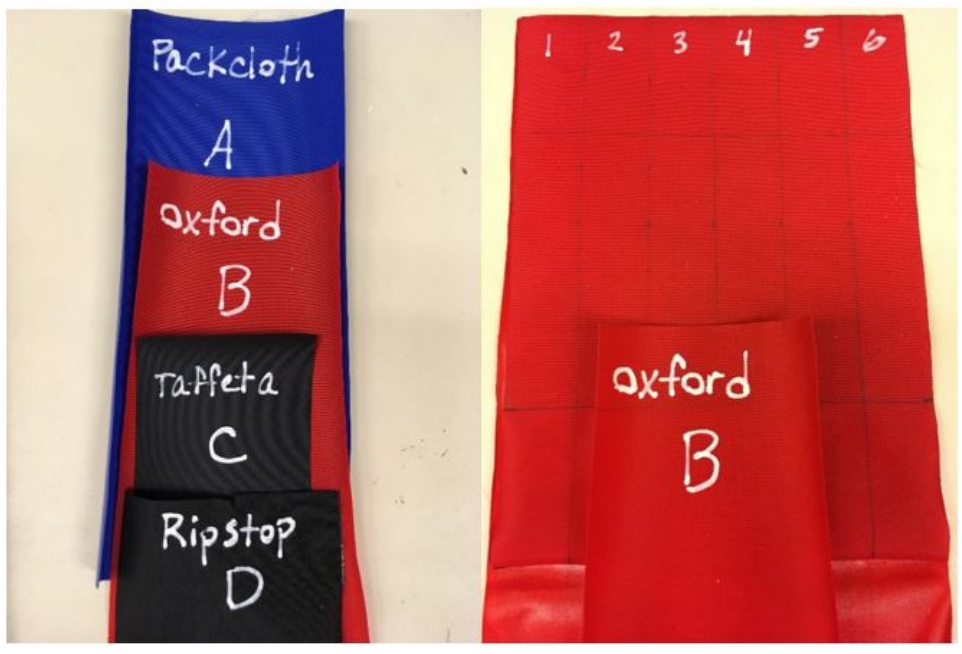

Figure 24: Peel strength test fabrics
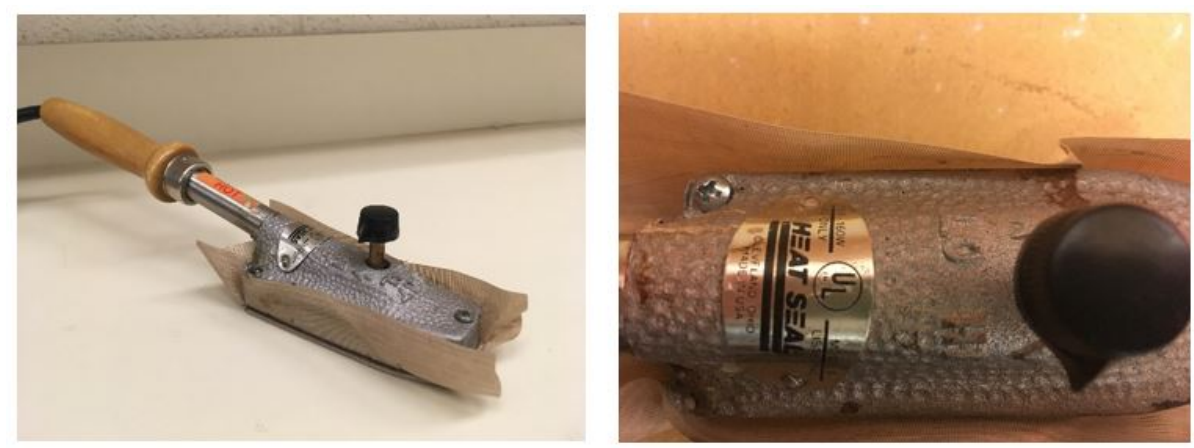

Figure 25: Handheld heat sealer 


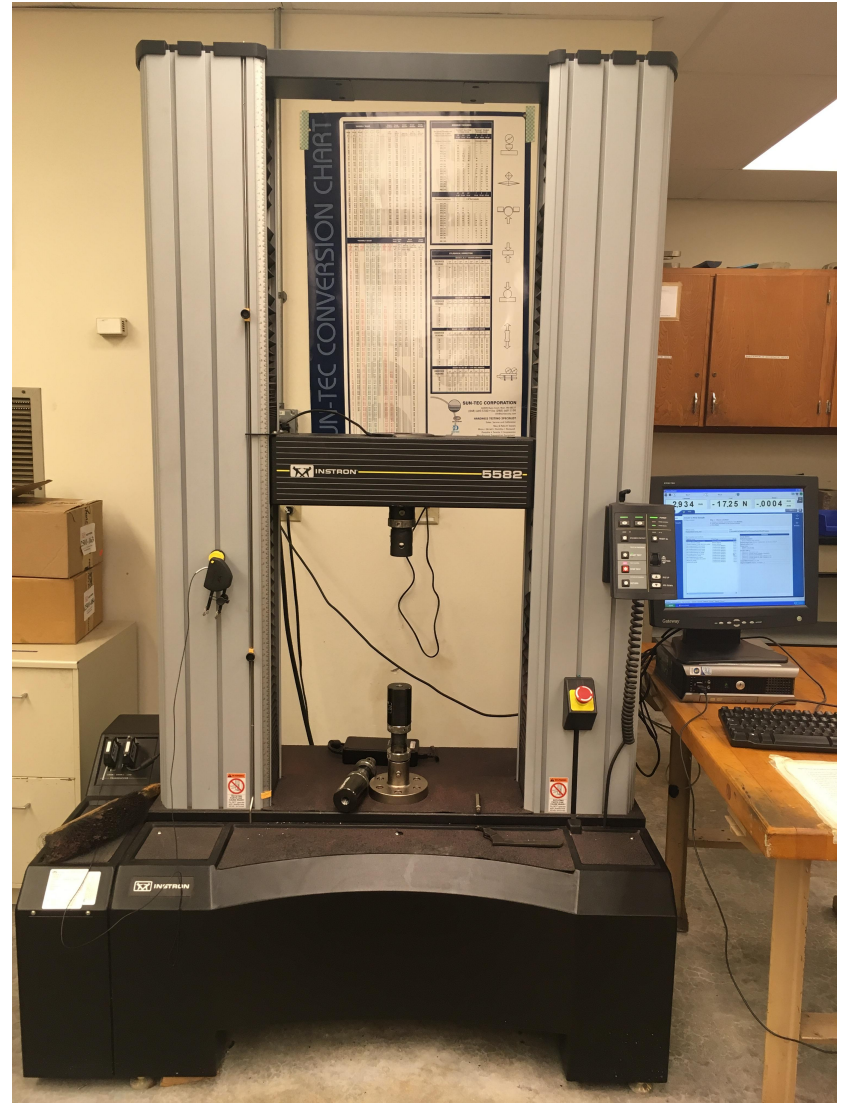

Figure 26: Instron Universal Testing Machine

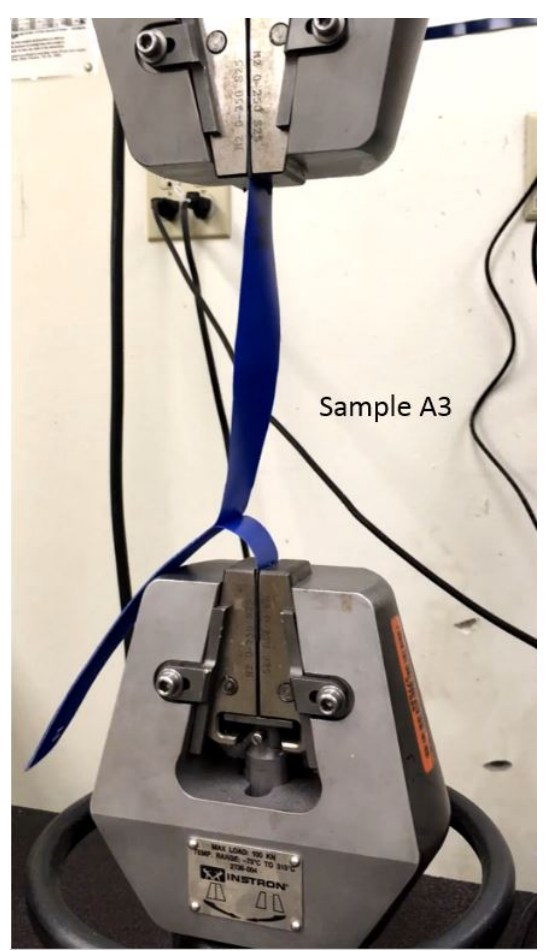

Figure 27: Peel strength testing 


\subsection{Burst Test}

Burst tests were conducted on 3 inch and 5 inch diameter tubes to determine maximum inflation pressure before rupture. To perform a burst test, ideally the inflatable tube is inflated at a uniform rate. Tests tubes were built from Oxford fabric, first by cutting four 10.42 in x 43.37 in rectangles from the fabric. These dimensions were used so that the tube would have a 3 inch diameter and 0.5 inch heat seal area, and would be approximately 0.5 meters long when inflated. Similarly, 5 inch tubes were cut from 16.71 in x 43.37 in rectangles. Four tubes of each size were built by adding a tube coupling for inflation and then heat sealing around three edges. For testing, a Bostich 150 psi, 6 gallon, 2.6 SCFM air compressor was used. This was not optimal since the pressure regulator on the compressor did not have a high enough resolution. Small pressure increments would be better, to have more control over inflation pressures. During burst tests, a $3 \mathrm{ft} \times 3 \mathrm{ft}$ wood section with a reinforced 8 inch gap was used to keep burst specimens contained during testing, see Fig. 28. A Vernier Pressure Sensor 400 Model: PS4003515R1, and Vernier Barometer Model: BAR4314R2 were tied into the line, approximately 2 feet from the test station. Pressure was monitored throughout testing using a Vernier LabQuest Mini Interface and LoggerPro software and each tube was slowly inflated until rupture, or sudden drop in pressure. Maximum pressures were recorded, and then averaged for 3 inch and 5 inch cases [15].

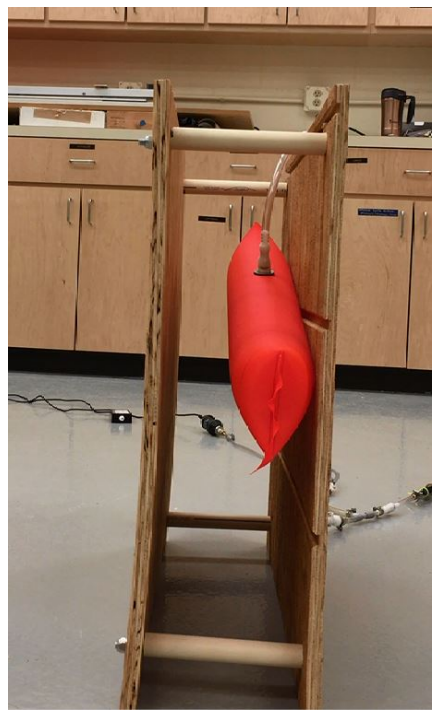

Figure 28: Burst test frame 


\subsection{Design of Inflatable Boat-Tail}

\subsubsection{Three Piece Design}

Initial designs for inflatable boat-tail consisted of a three piece design as seen in Fig. 29. This three piece design was one rectangular piece, heat sealed to two triangular pieces, around three edges. This design left for one side to be opened and heat sealed later. This design became the outer inflatable cover of the next generation baffled boat-tail.

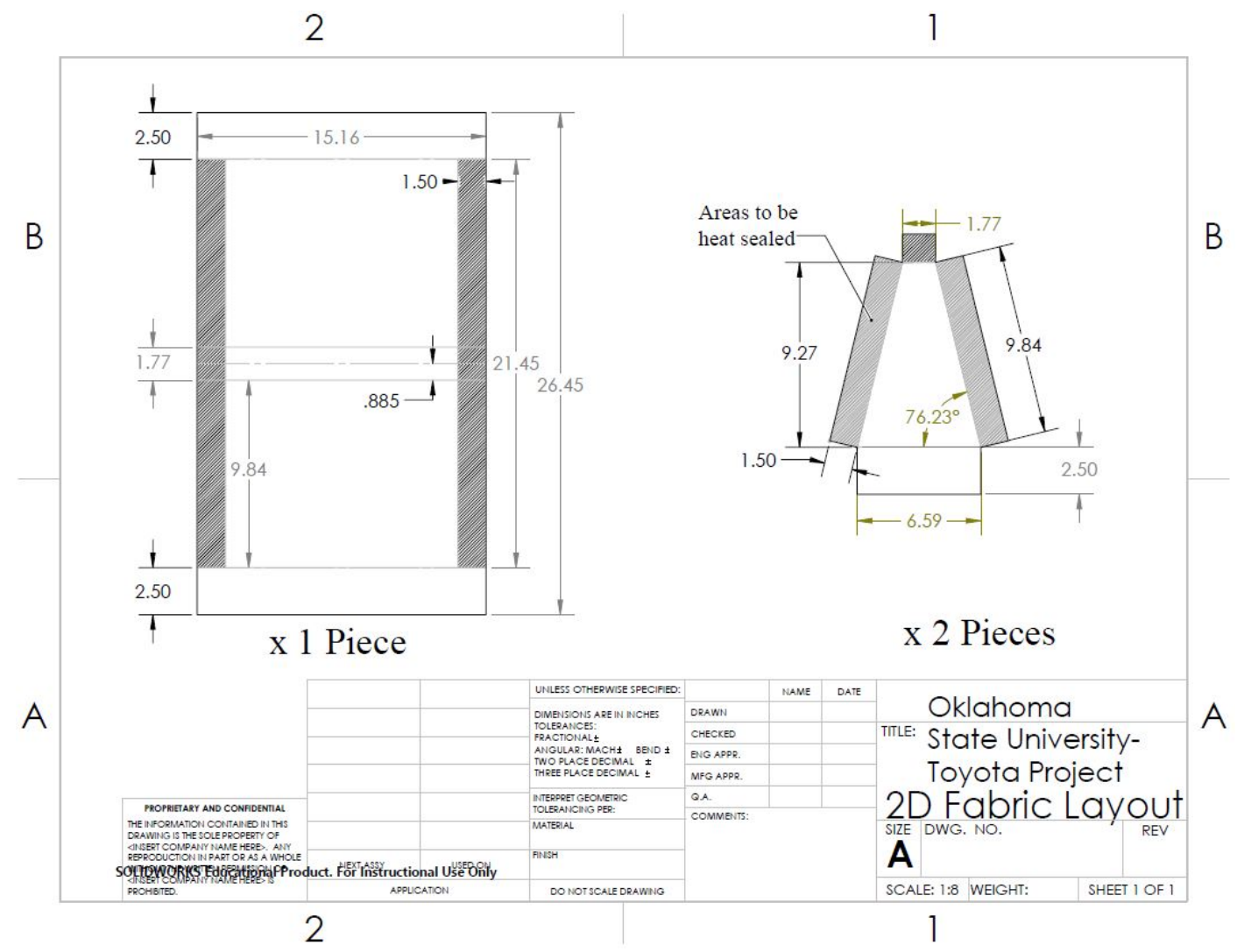

Figure 29: Solidworks drawing for inflatable cover design 


\subsubsection{Baffled Boat-Tails}

Next, a baffled boat-tail design was created. This new design allowed for only one piece of material to be the entire inflatable boat-tail, rather than three parts as considered previously. Having only one piece of material resulted in less heat seal area, leading to easier manufacturing and better heat seal ability. Four different designs for inflatable boat-tails were made with a varying number of baffles. Adding baffles to the internal structure provides a more defined shape. The zero-baffle, two-baffle, four-baffle, and six-baffle designs are shown in Figures 30, 32, 34, and 35, respectively. Inflated boat-tails become rigid at pressures of around 0.3 psi. 


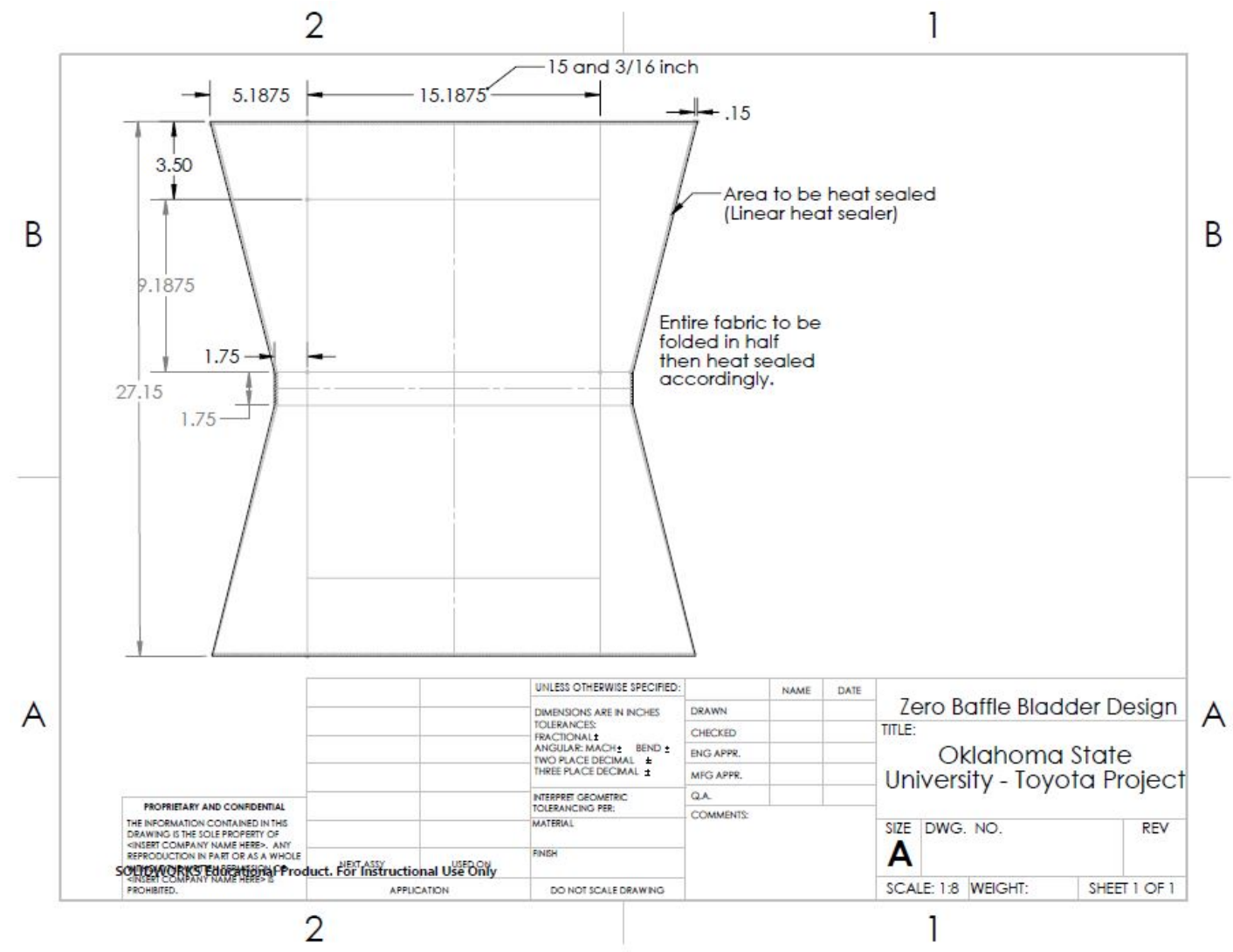

Figure 30: Zero-baffle design

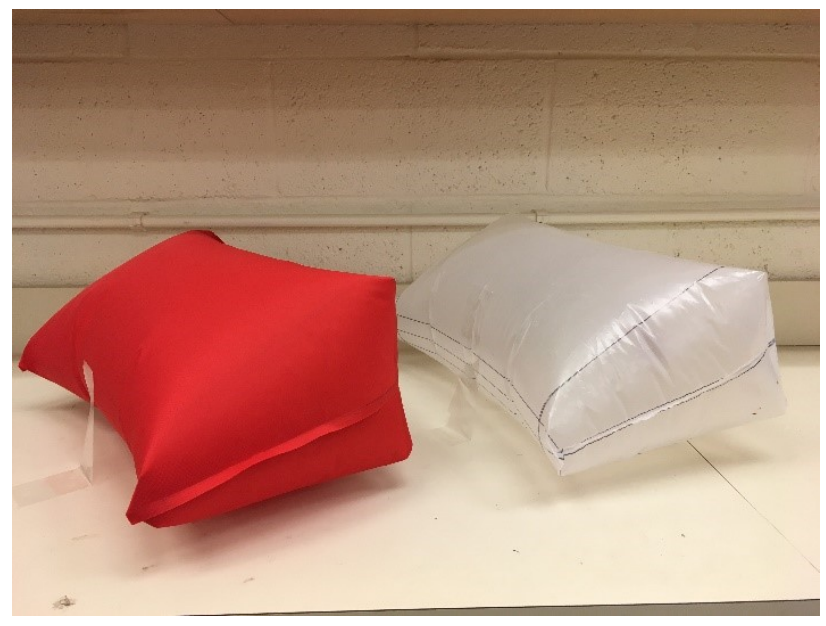

Figure 31: Inflated zero-baffle boat-tail, HS Oxford and HS plastic sheeting 


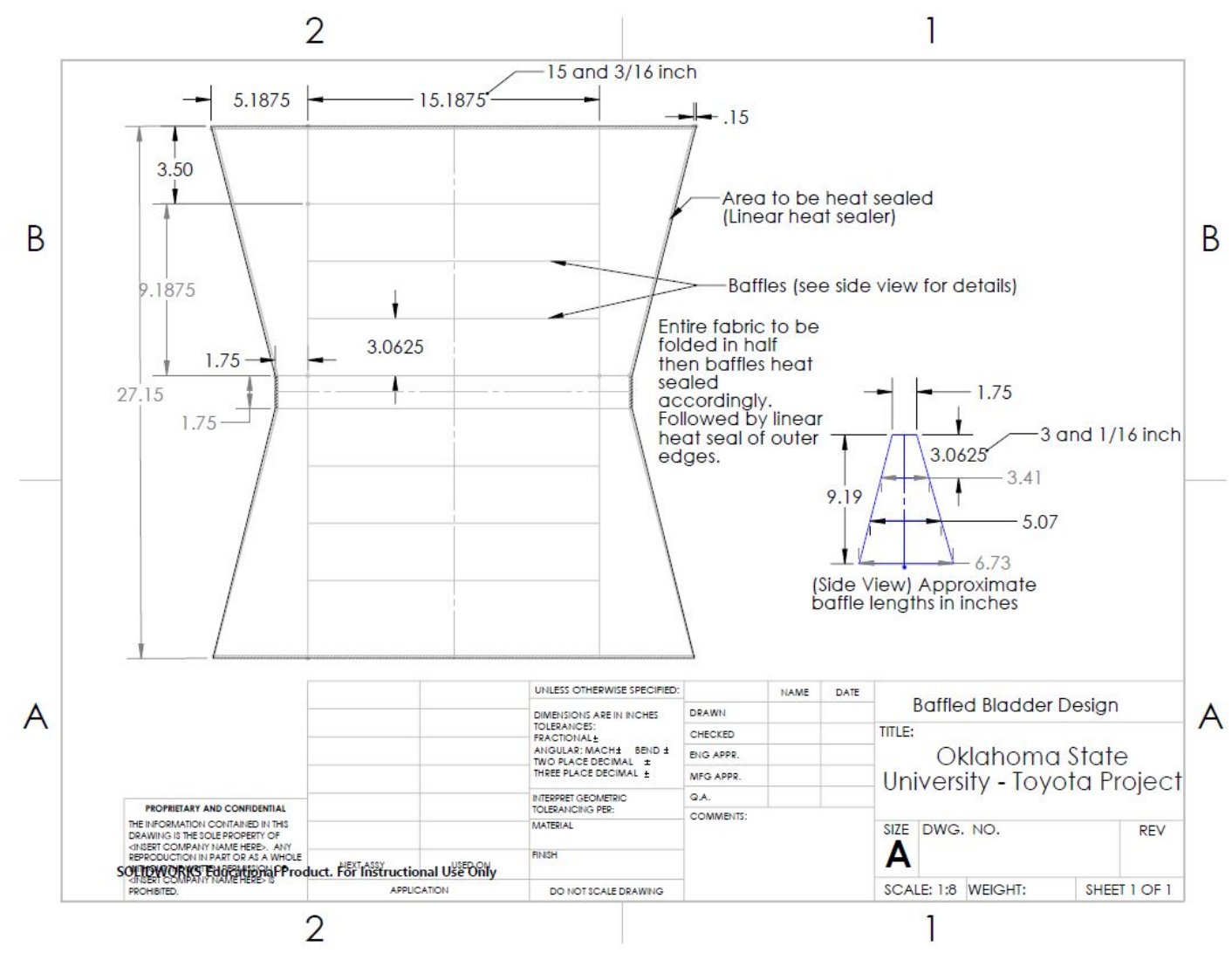

Figure 32: Two-baffle design

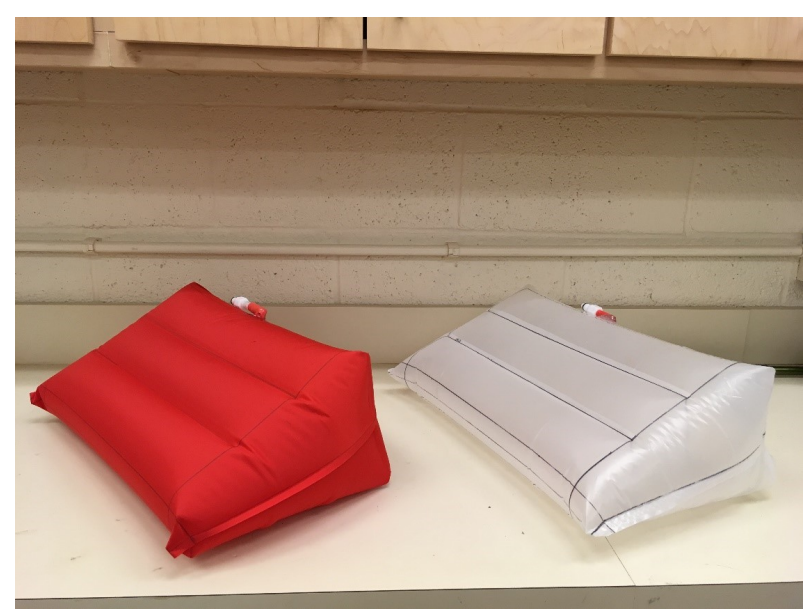

Figure 33: Inflated two-baffle boat-tail, HS Oxford and HS plastic sheeting 


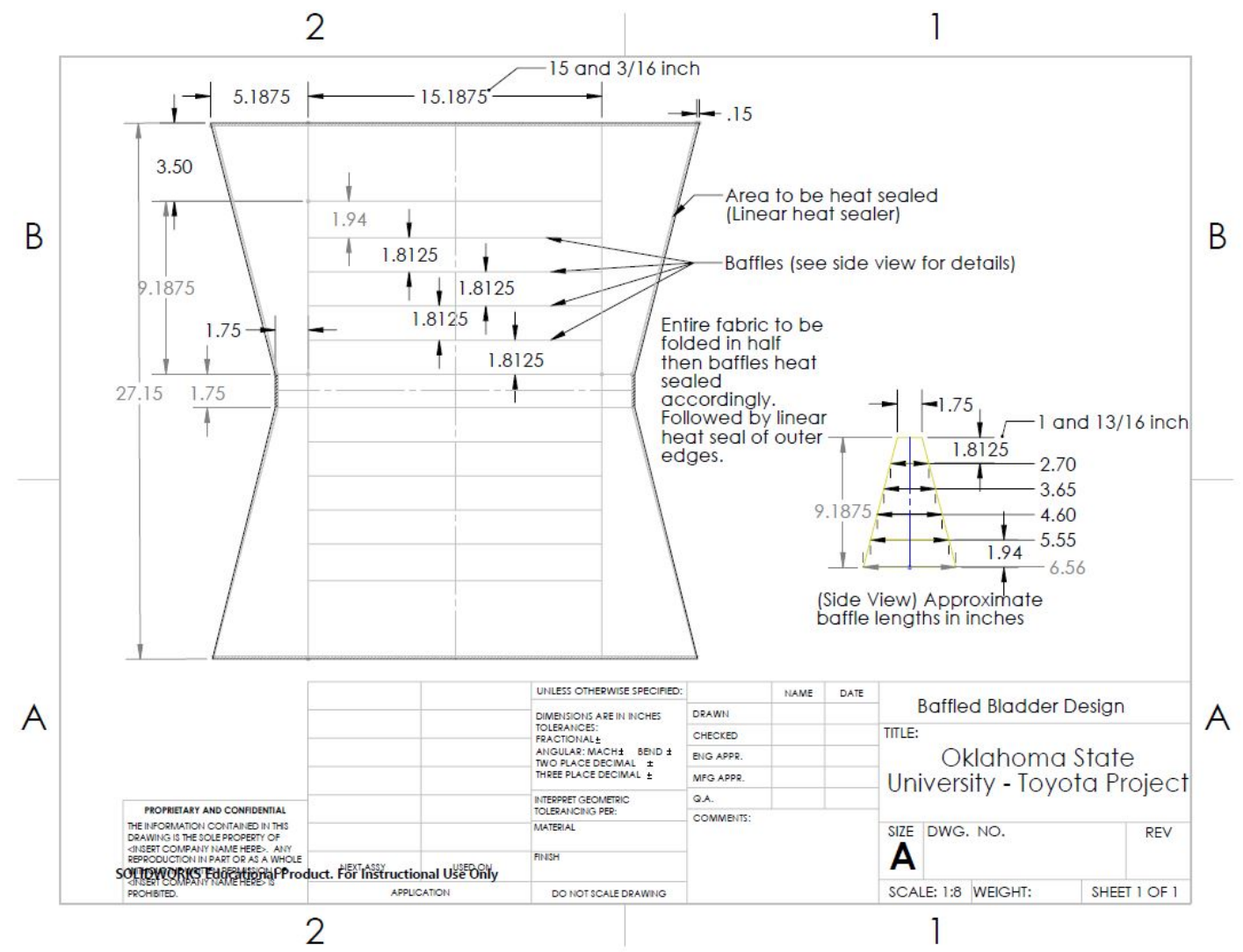

Figure 34: Four-baffle design 


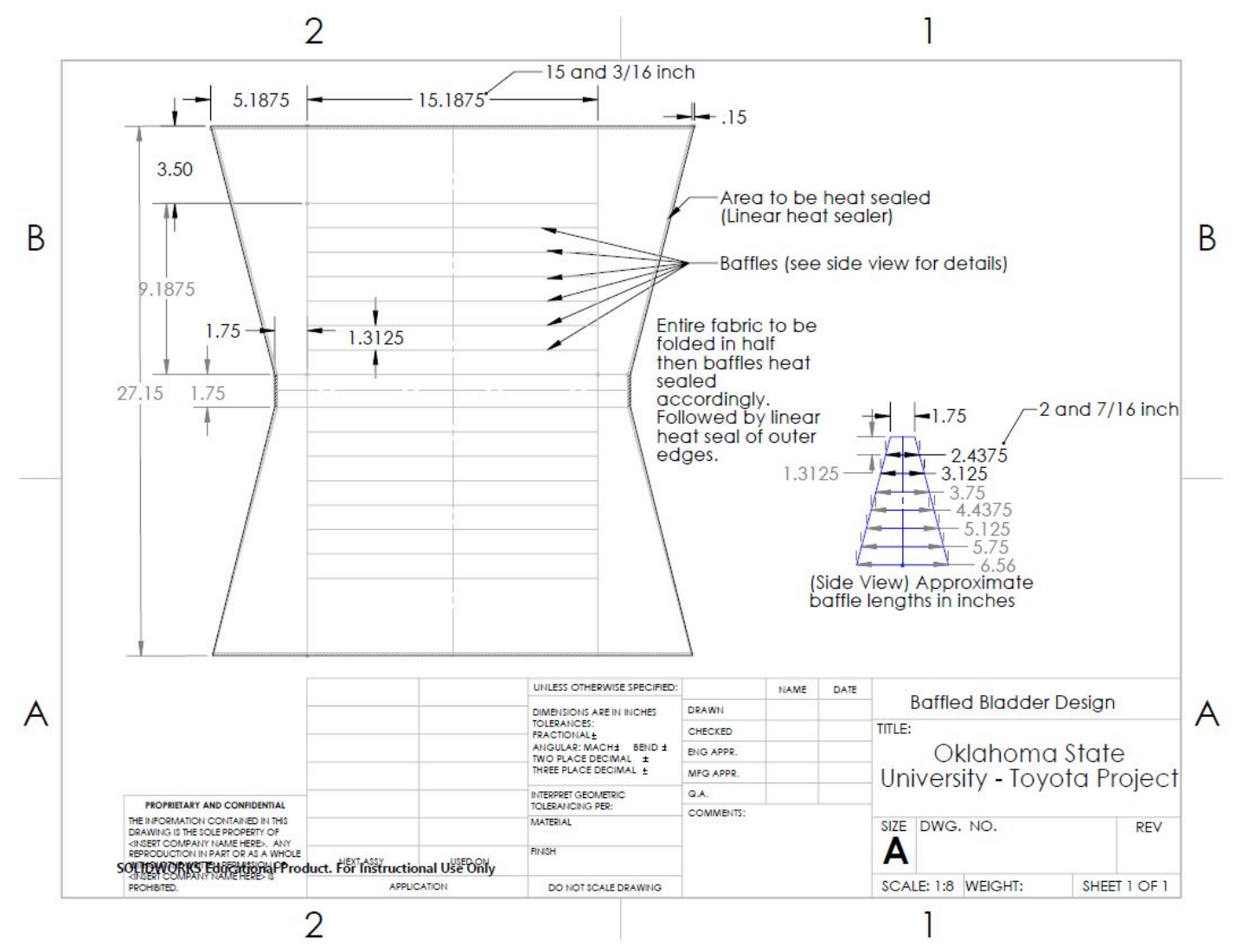

Figure 35: Six-baffle design

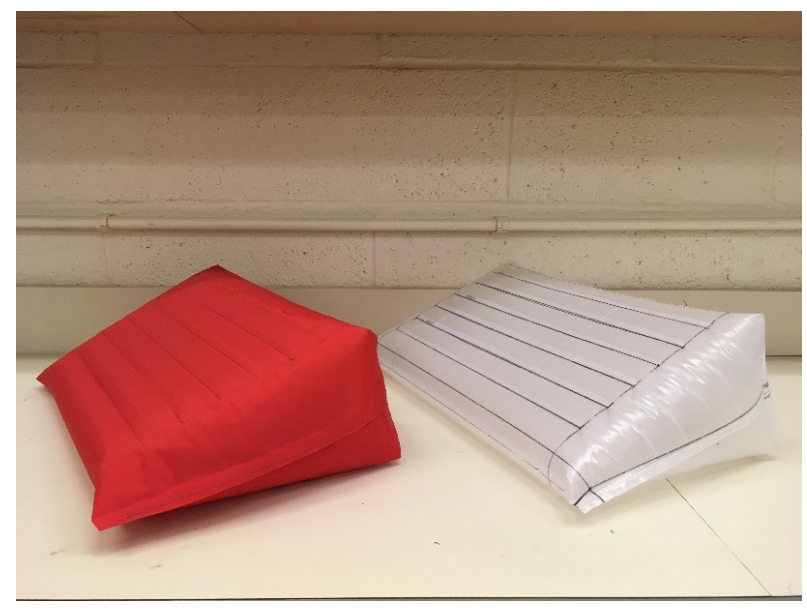

Figure 36: Inflated six-baffle boat-tail, HS Oxford and HS plastic sheeting 


\subsection{Construction Basics}

For construction of baffled boat-tails, it is necessary to have proper heat sealing equipment. For this project, both a retrofitted linear heat sealer and hand held heat sealer were used as seen in Fig. 25 and Fig. 37. Starting with the appropriate heat sealable fabric (in experiments, HS Oxford), the fabric should be measured and marked according to boat-tail type: zero, two, four, or six-baffle. For simplicity and view-ability, the boat-tail provided in this example is built with simple plastic sheeting. Once measurement and markings are complete as shown in Fig. 38 and Fig. 39, a small X should be cut where the plastic quick-disconnect tube coupling, seen in Fig. 40 and Fig. 41, will be inserted. Plastic Quick Disconnect Tube Couplings were purchased from McMaster-Carr, product \# 5012K58. This tube coupling should include sealing washers. These Hot-Dipped Galvanized Steel with Neoprene Sealing Washers were also purchased from McMaster-Carr, product \# 94708A517. After the coupling is inserted into the fabric with sealing washers, RTV high temperature gasket maker should be used to coat the threads of the plastic coupling thoroughly and the small metal nut should be threaded and tightened. Wait 24 hours for the coupling system to dry before beginning the heat sealing process.
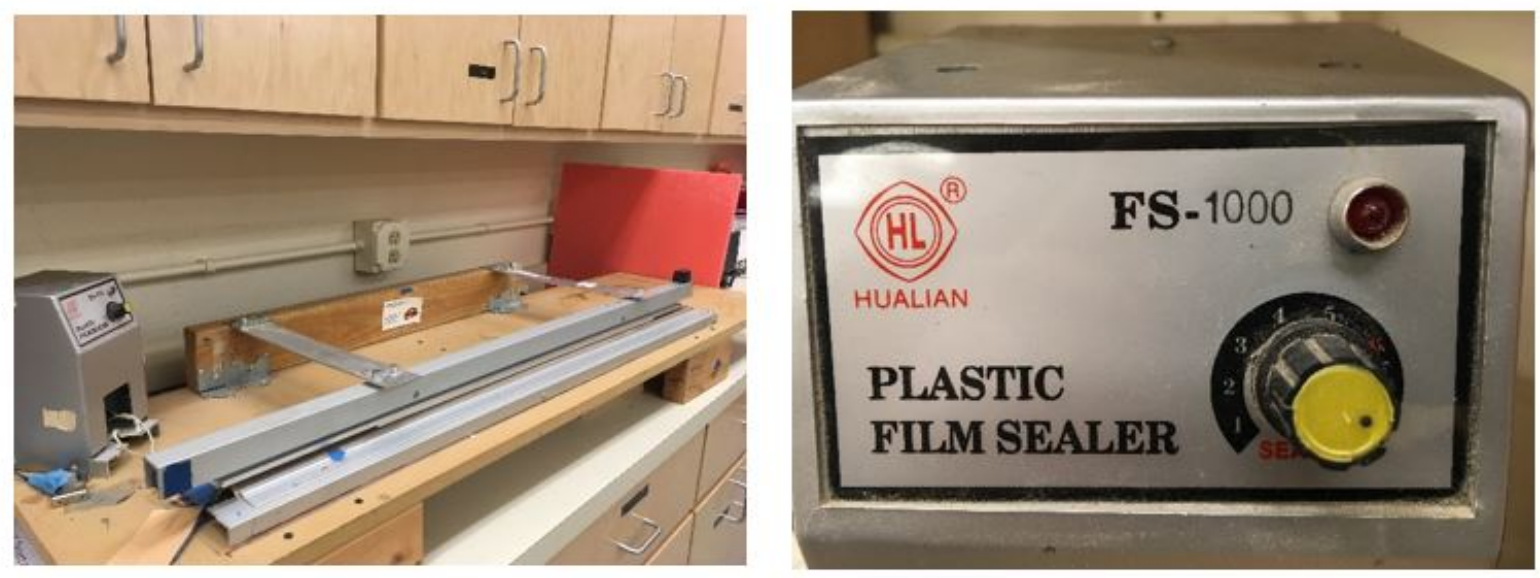

Figure 37: Linear heat sealer 


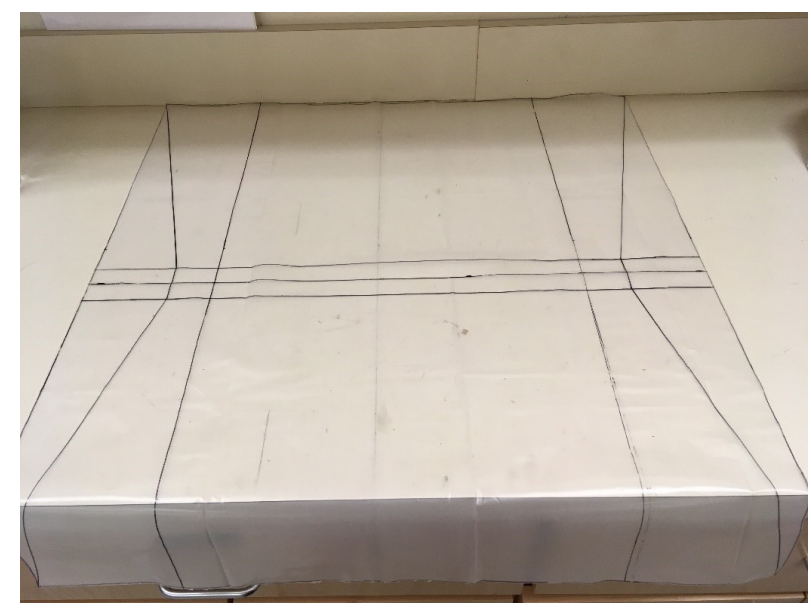

Figure 38: Initial measurements and markings for a baffled boat-tail

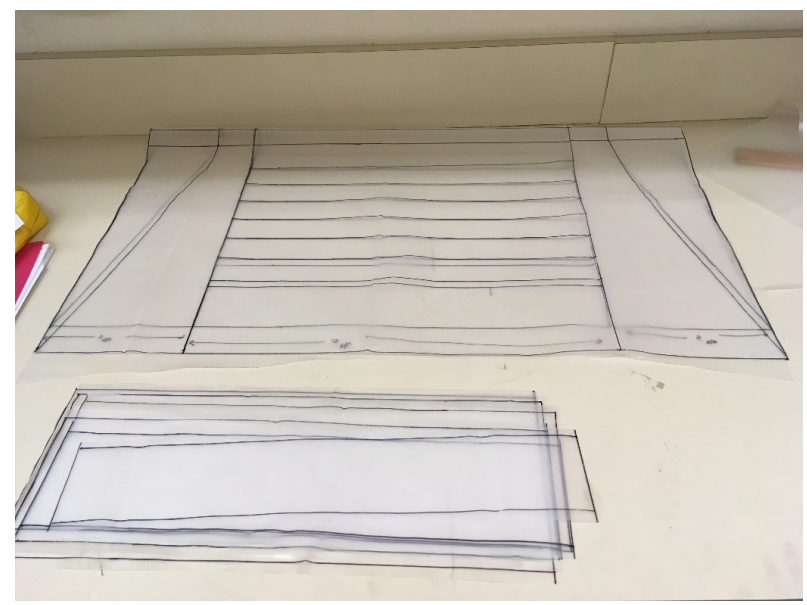

Figure 39: Complete measurement and markings for a six-baffle bloat-tail 

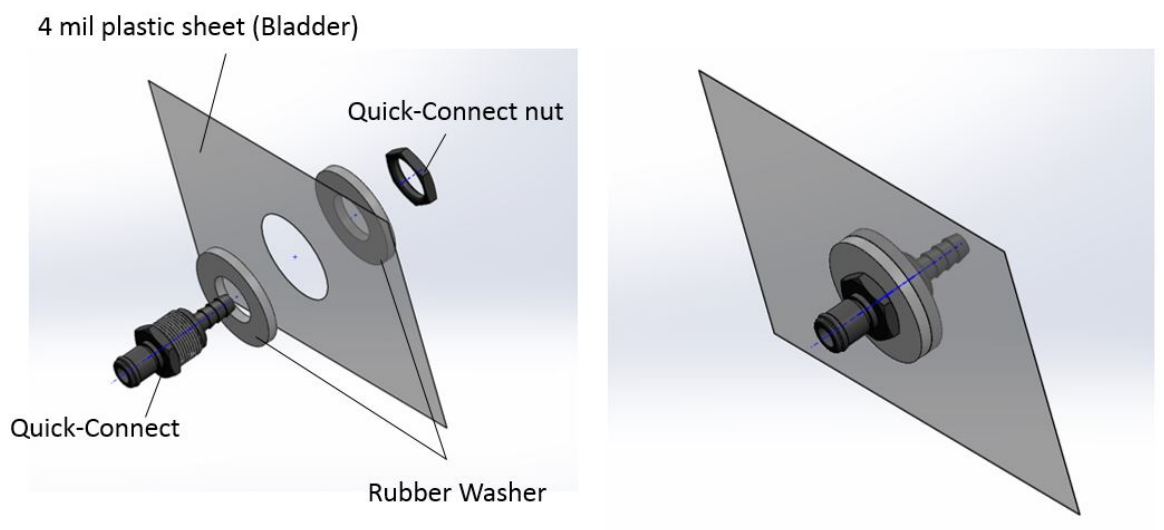

Figure 40: Tube couplings

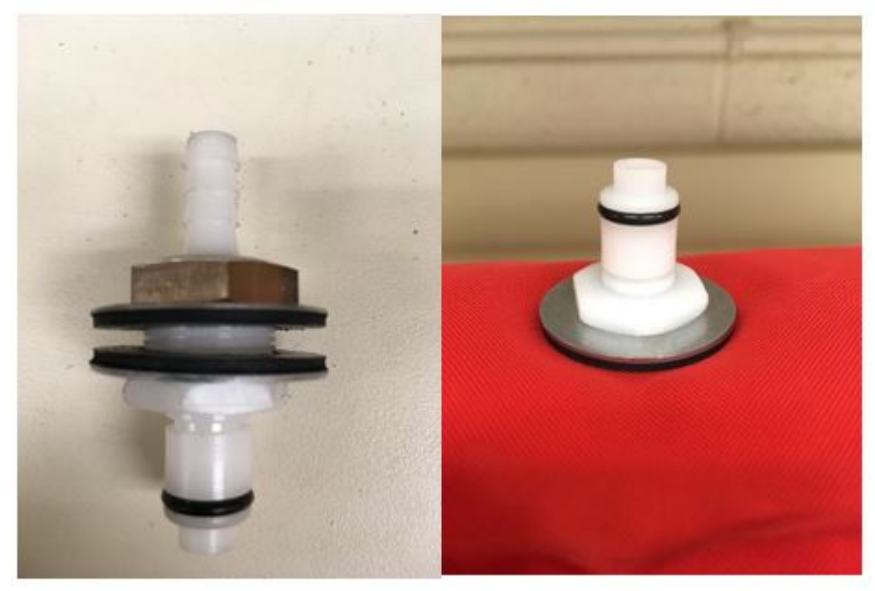

Figure 41: Tube couplings 


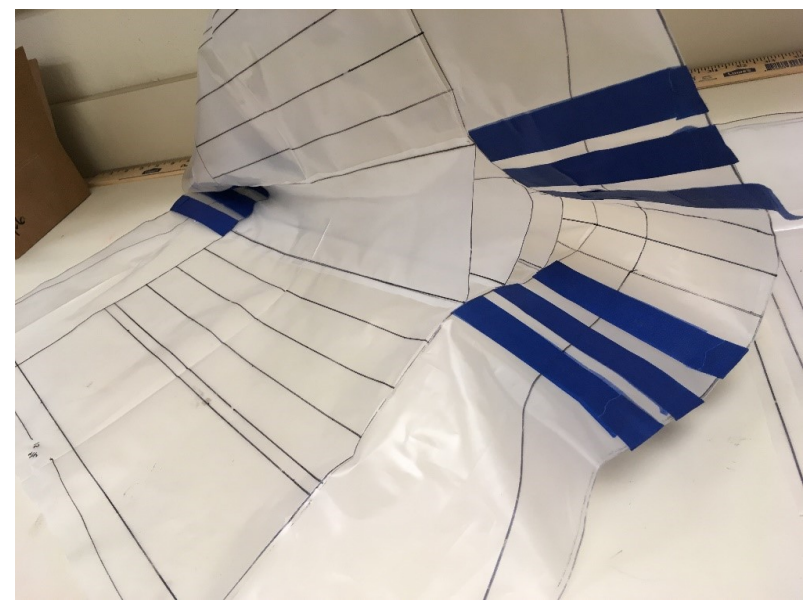

Figure 42: Initial heat sealed baffles

Once the tube coupling and glue are set into place, begin heat sealing baffles starting with the smallest sized baffle towards the back of the boat-tail. When using a linear heat sealer, for some materials, it is best to use tape as temporary insulation to ensure that the heat from the heat sealer does not affect unwanted areas of the fabric. After sealing the first and smallest baffle, move to the next largest size, and so on. Examples of this process are shown in Fig. 42 and Fig. 43. Once all the baffles have been heat sealed appropriately, remove the tape and heat seal the outer edges of boat-tail. To heat seal outer edges first use the linear heat sealer and then use the handheld heat sealer over the wider outside edges. Next, add air with pump to slightly inflate the boat-tail. Heat seal the corners of the boat-tail as seen in Fig. 45, and then inflate to approximately 0.5 psi. Check the baffled boat-tail for holes or leaks in the heat sealed areas.

Construction is similar for each boat-tail type, and only changes according to how many baffles will be added. Fig. 48 shows zero, two, four, and six-baffle boat-tails side-by-side for shape comparison. From this it is clear that a higher number of baffles creates more shape definition. 


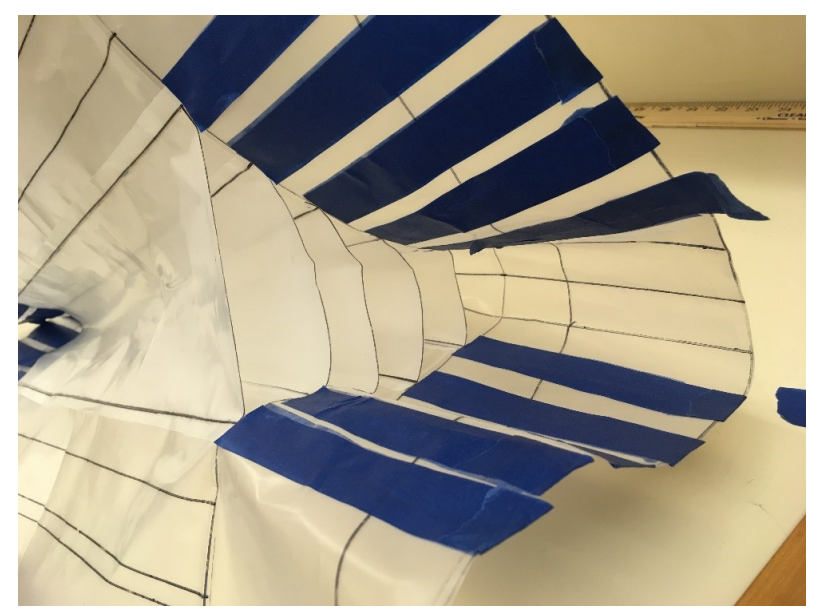

Figure 43: Heat sealed baffles

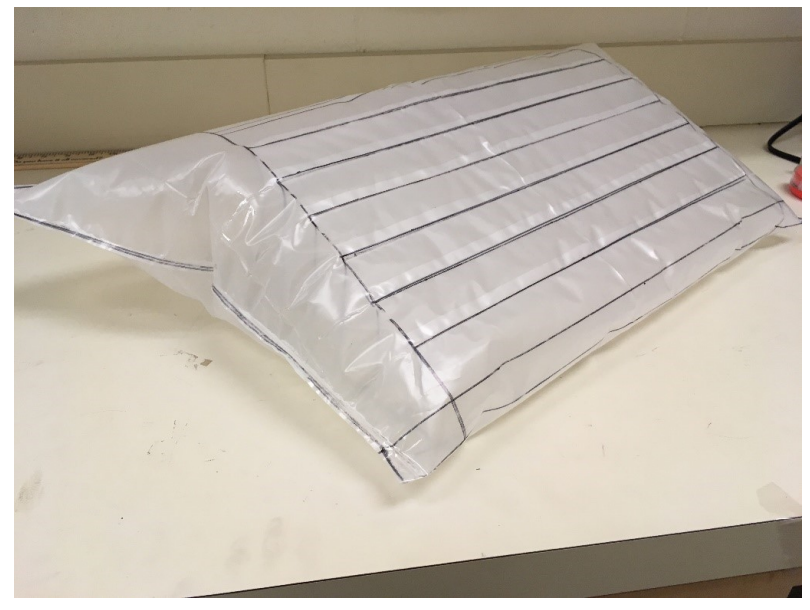

Figure 44: Edges heat sealed, partially inflated 


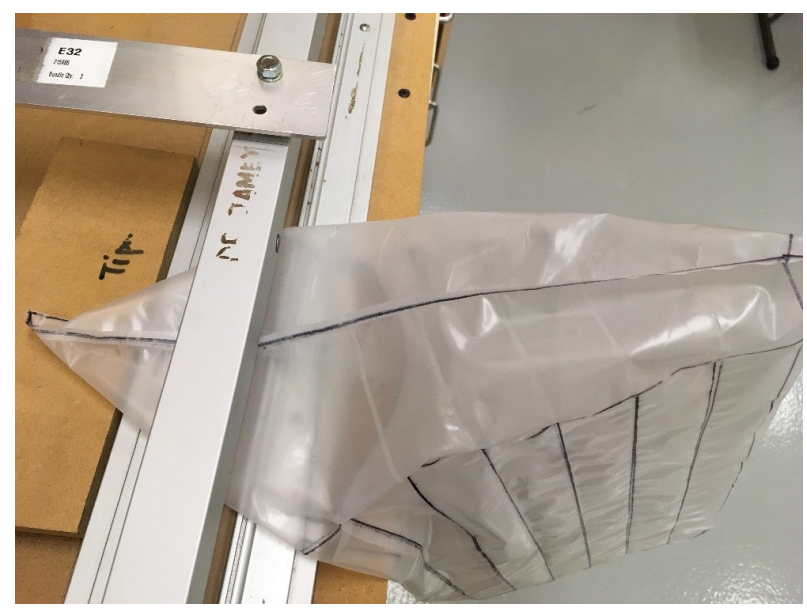

Figure 45: Heat sealing corners for proper shape

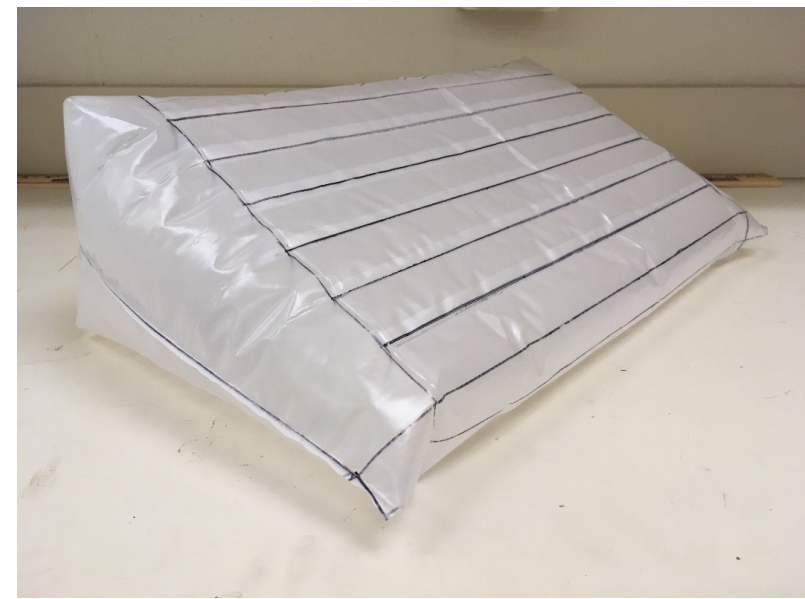

Figure 46: Isometric view of fully constructed and inflated six-baffle boat-tail 


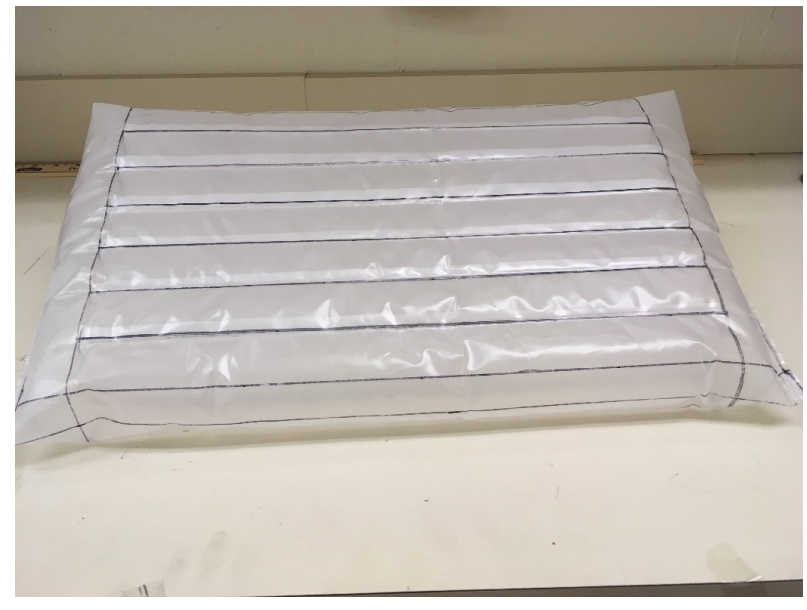

Figure 47: Fully constructed and inflated six-baffle boat-tail

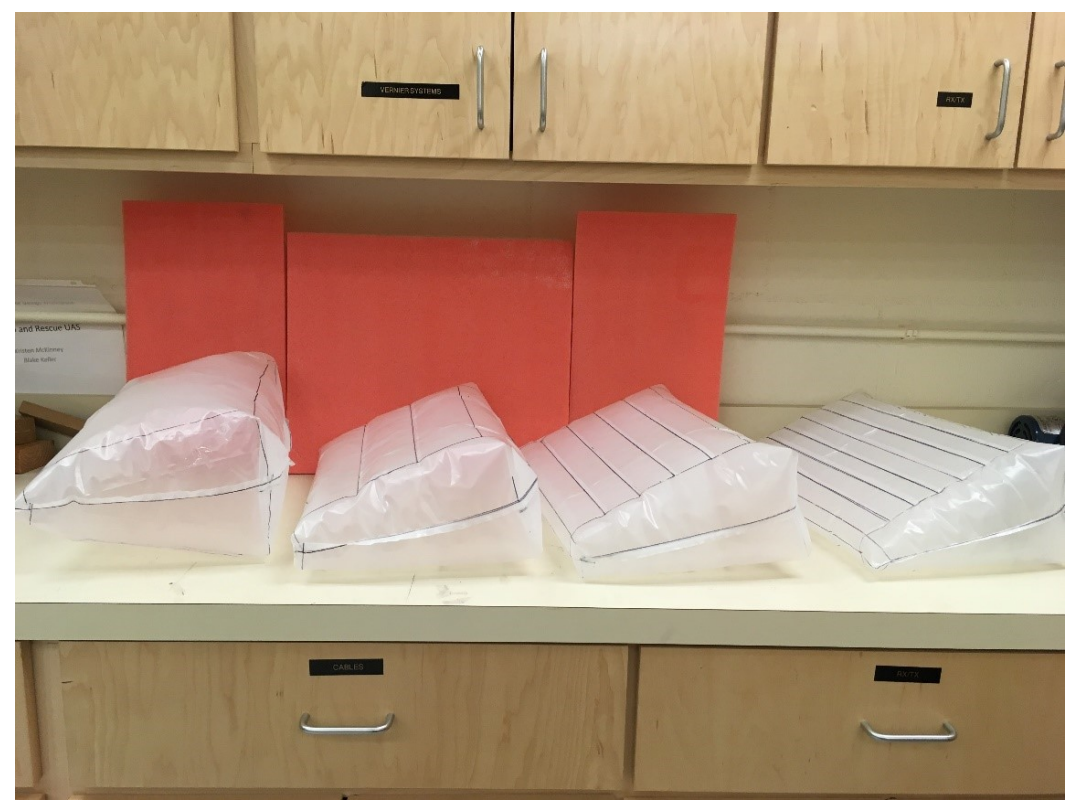

Figure 48: Comparison of shape for zero, two, four, and six-baffled boat-tails 


\subsection{Wind Tunnel Wake Survey Experimental Set-up}

The Oklahoma State University large wind tunnel, located in the lower basement of the Advanced Technology Research Center is a 16:1 contraction ratio open loop tunnel. Air is pulled in from outside through the inlet and test section by a 125 HP Centrifugal Fan. Test set-up and monitoring is completed in the central portion of the wind tunnel as shown in Fig. 49. The test section is a $1 \mathrm{~m} \times 1 \mathrm{~m}(3.28 \mathrm{ft} \times 3.28 \mathrm{ft})$ cross section that is $2.44 \mathrm{~m}(8 \mathrm{ft})$ long and consists of a large $1 \mathrm{~m} \times 1.22 \mathrm{~m}$ (3.28ft x $4 \mathrm{ft})$ door, supported by hydraulic arms attached to the side of the wind tunnel.

In the upstream portion of the test section is an upstream pitot probe. This pitot probe is connected to a Dwyer Flextube manometer, shown in Fig. 50. This pressure gauge changes in height according to upstream tunnel pressure difference caused by the freestream velocity. The upstream pitot probe is also connected to an Omega 10" water column pressure transducer, shown in Fig. 51. These systems allowed upstream velocity to be monitored and recorded during testing.

Downstream of the test section is the traverse pitot probe. This pitot probe is a one hole probe with automatic traverse system that is implemented to allow velocity measurements at specific positions behind the boat-tail system and does not provide information about the flow directionality. The traverse system used was a IselGermany 2D-Traverse 1010 Model. During testing the traverse system can move in the $\mathrm{x}$ and $\mathrm{y}$ directions over the cross sectional area of a single plane inside the wind-tunnel. The traverse pitot probe was also connected to an MKS pressure transducer, Model\# 223BD. This model provides $0.01 \%$ resolution and $+-0.5 \%$ accuracy, with maximum line pressure of 40 psig. Pressure transducers are connected to a central breadboard powered by a National Instruments $+24 \mathrm{~V}$ Power Supply. This system is connected to a National Instruments NI cDAQ 9188 which transfers data to the computing system where it is processed and output as velocity. Implementing LABview, the VI converts readings from the pressure transducer to psi using the programmed linear calibration curve of the pressure transducer. The VI displays real time velocity data of both upstream and downstream pitot probes in both numerical output and plot form. This information is recorded and outputs of time, voltage, upstream and downstream velocities, and $\mathrm{x}$ and y positions of the downstream pitot probe are displayed in stored files.

In this experiment, drag estimation by wake survey is completed. A wake survey is an experimental technique useful for measuring disturbance in the velocity field. During testing, the upstream 


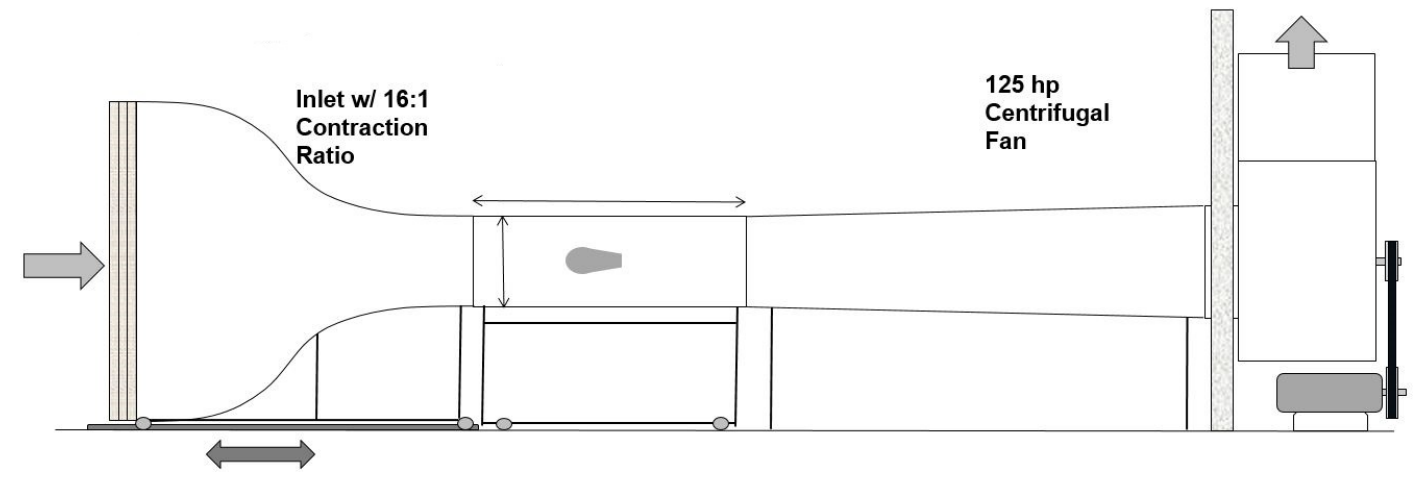

Figure 49: A basic schematic of the wind tunnel

velocity is monitored over time while downstream velocity is measured on a point to point basis. Testing involved three different systems, one baseline system for comparison and two inflatable systems, see Fig. 52. General setup is shown in Fig. 53.

Testing procedures consisted of multiple conditions involving the different inflation systems at varying Reynolds numbers. 2D wake survey velocity measurements were taken behind the boat-tail at every 0.25 inches. Wind tunnel wake surveys were completed on the baseline, zero-baffle, and sixbaffle models. Internal pressure of inflatable boat-tails was kept at an average of 0.5 psi throughout testing by a Barnant Company Vacuum-Pressure Pump Model: 400-1901. Pressure was monitored throughout testing using a Vernier LabQuest Mini Interface and LoggerPro software. Using the pre-cut hole in the bottom of the wind tunnel, 0.25 inch ID air hose was connected to the boattail system using plastic quick-disconnect tube couplings, purchased from McMaster Carr, product number 5012K58. This allowed for constant pressure supply connection to the boat-tail system.

The baseline system was set up as a rounded front rectangle with a flat back, built of white poster board and attached permanently with glue, see Fig. 54. An acrylic plate was modeled then cut by CNC, and attached as a flat back plate to the baseline system, see Fig. 55. This double thick acrylic plate allowed for the interchangeable attachment of the baffled boat-tail systems by attachment of the outer cover which bolted between the acrylic plates. This system assured the inner inflatable baffled boat-tail would not move, and also allowed for a smoother and more consistent outer surface. The six-baffle boat-tail design, in the non-inflated state, is seen in Fig. 56 and 57. Once the outer cover was bolted into place, clear tape was used to cover the small gap between the baseline system 


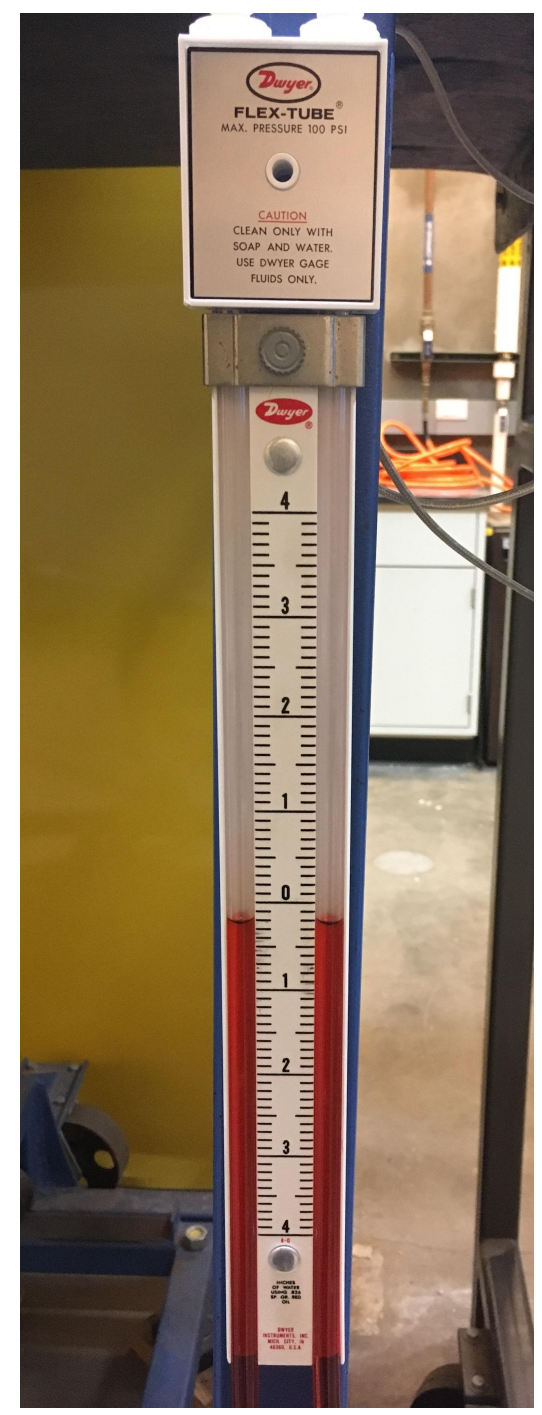

Figure 50: Flex-tube manometer 


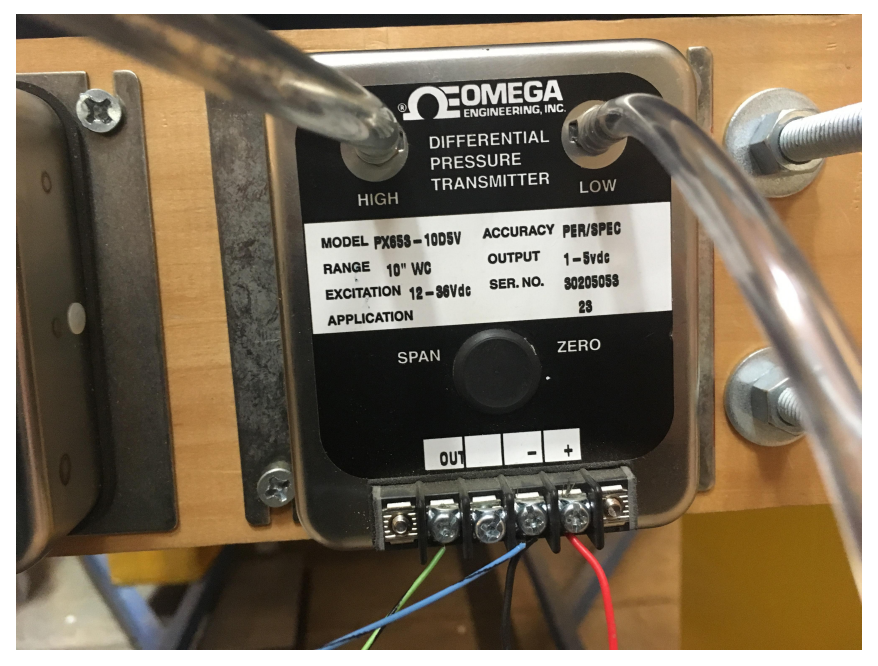

Figure 51: Omega 10inch pressure transducer

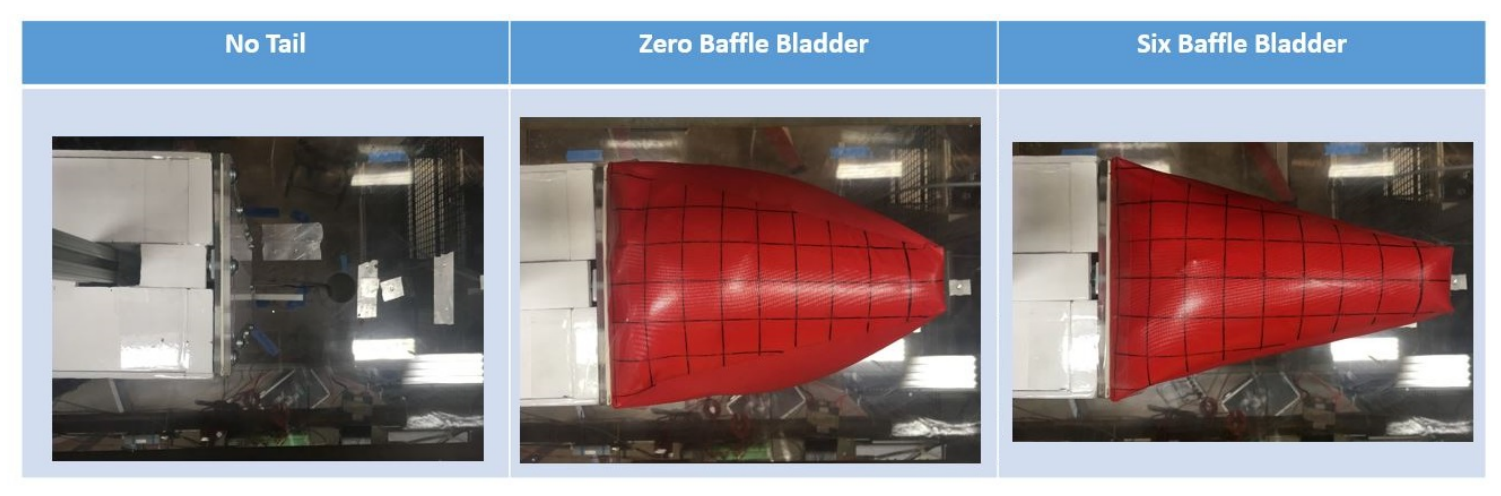

Figure 52: Three wind tunnel test cases, top view: Baseline, Zero-Baffle, and Six-Baffle 


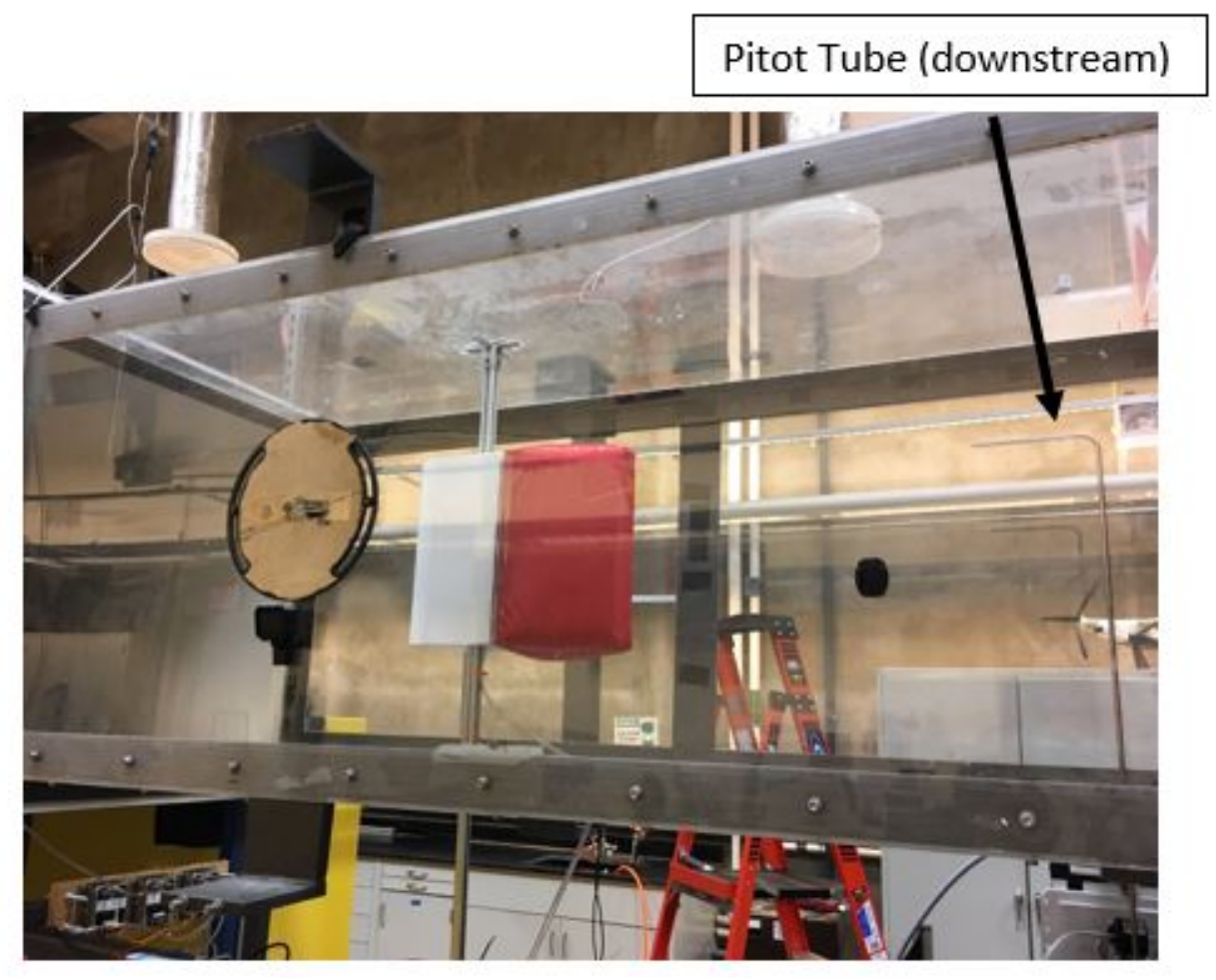

Figure 53: Wind tunnel setup with boat-tail and pitot tube 
and added boat-tail. Before testing, the boat-tail system was mounted into the wind tunnel using four L brackets on each end of the boat-tail support system, this included reinforcement using bolts, washers, and nuts from the outside top and bottom of the wind tunnel. Overall, the cross sectional area of the boat-tail took up a total of $6.0 \%$ of the entire wind tunnel cross-sectional area, see Fig. 58.

Data is processed using the supplemental Matlab code provided in Appendix A, which was created for this thesis. Pre-processing is necessary of which $\mathrm{u}(\mathrm{U}-\mathrm{u})$ must be computed for every velocity data point taken. Where $U$ is the averaged downstream freestream for individual tests, and $\mathrm{u}$ is the velocity for each data point in the set. The matlab code works by averaging many data taken at each specific x-position in the wind tunnel. The number of data points varies per tests, but averages at about 60 data points per $\mathrm{x}$-position. This shows that data taken at each point is approximately normally distributed. Tests were taken over a 30 inch span across the tunnel, at every 0.25 inches. Once pre-processing of tests data is complete, the matlab code provided is used. After plotting average curves, matlab trapezoidal rule is used to compute the area under the $\mathrm{u}(\mathrm{U}-\mathrm{u})$ curve, as discussed in Chapter 2. Respective coefficients of drag are backed out for each specific case. 


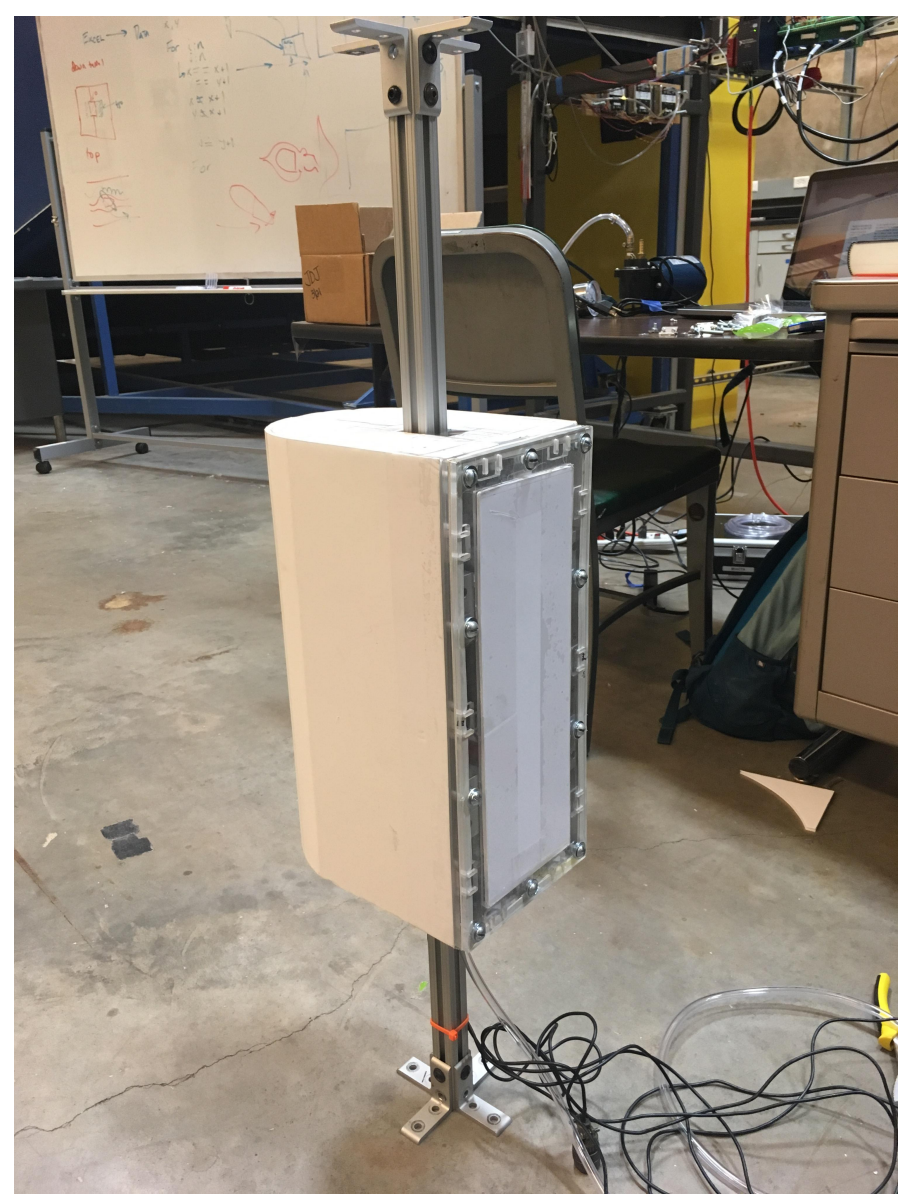

Figure 54: Baseline system for comparison

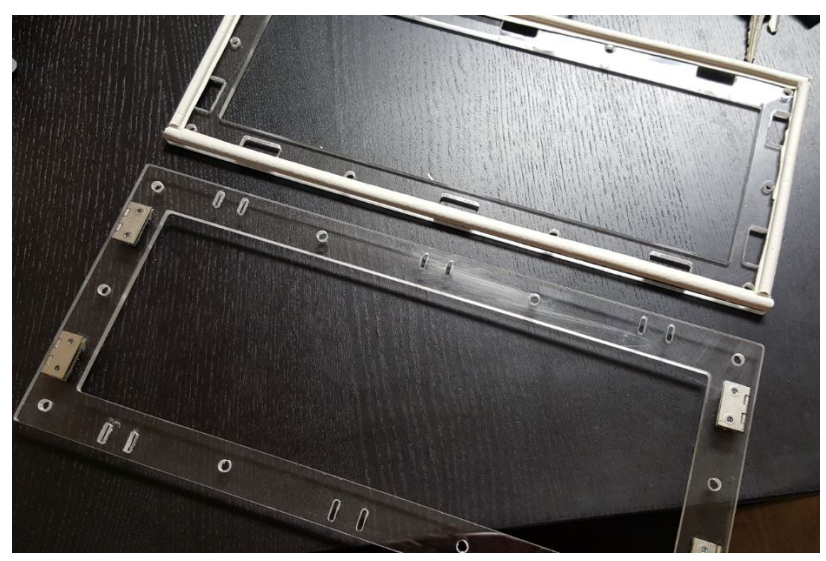

Figure 55: Baseline plate attachment frame 


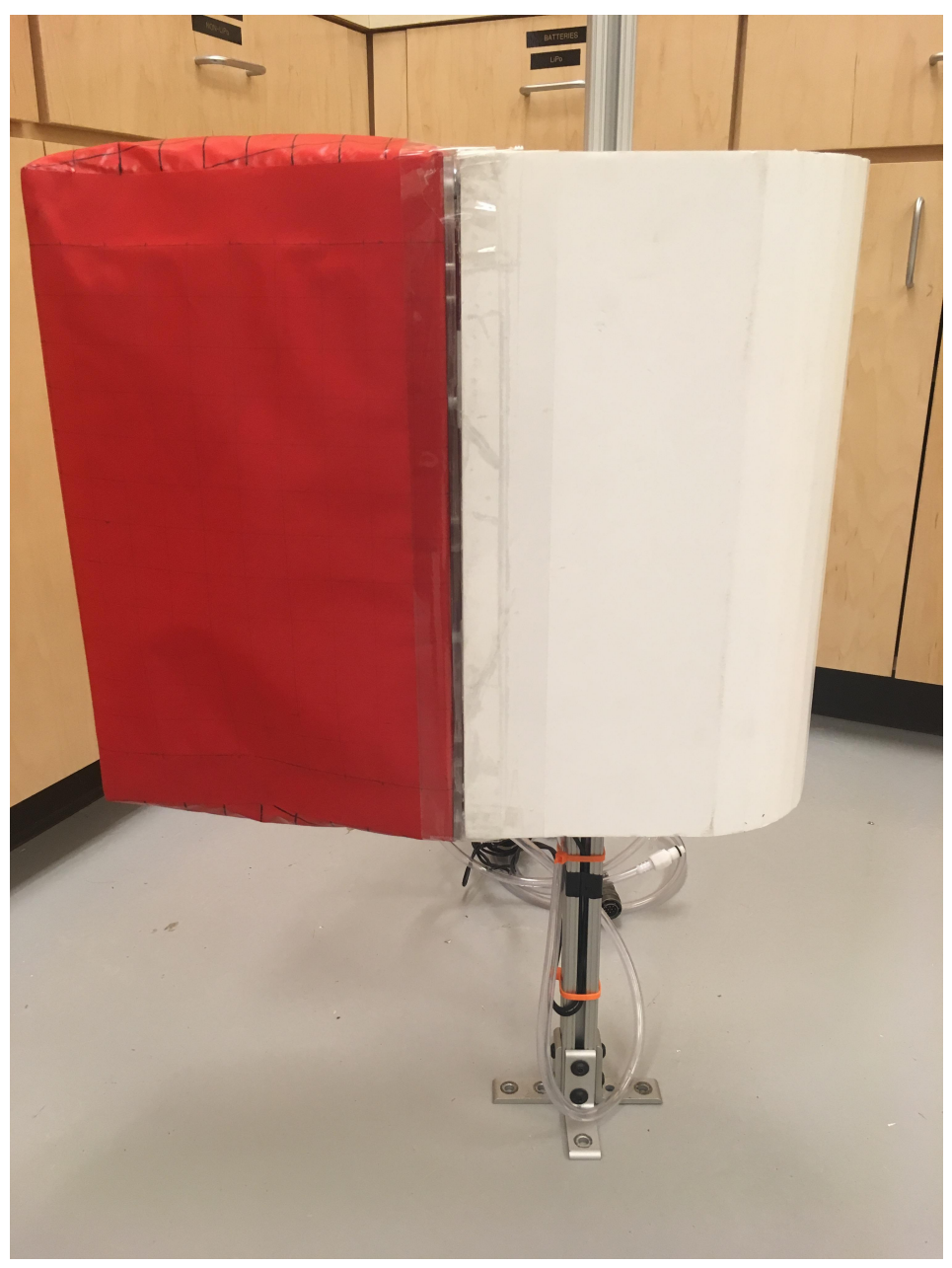

Figure 56: Six baffle system side view 


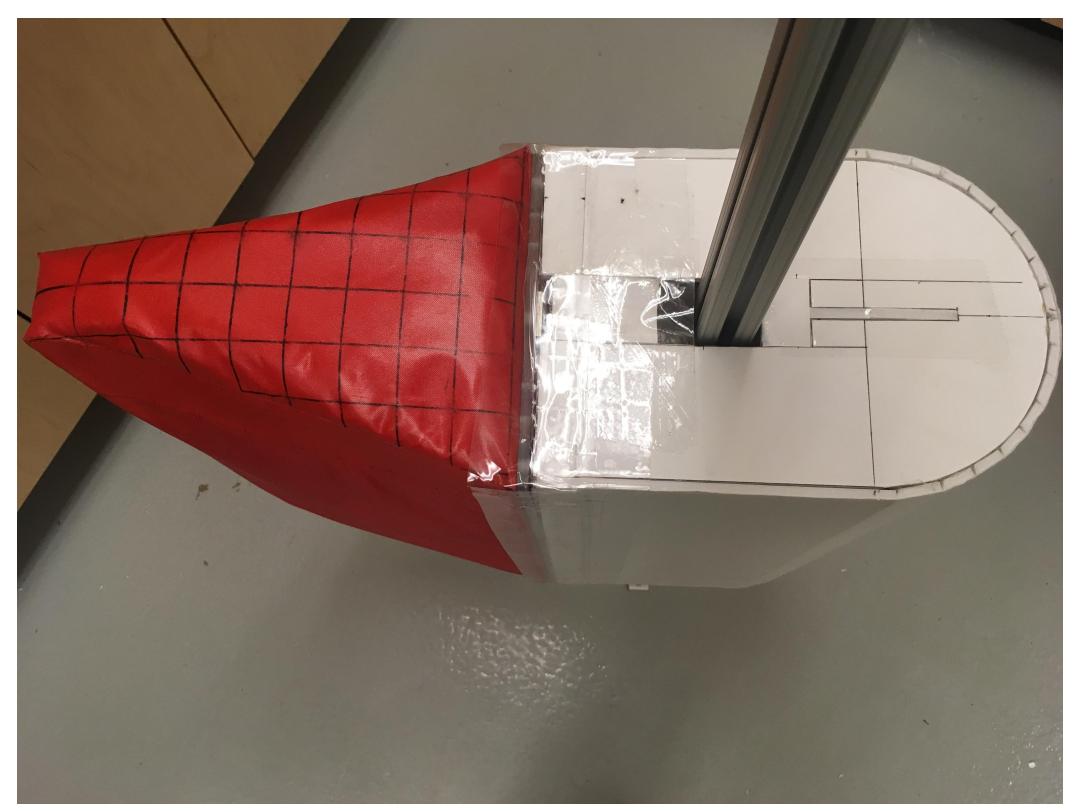

Figure 57: Six baffle system top view

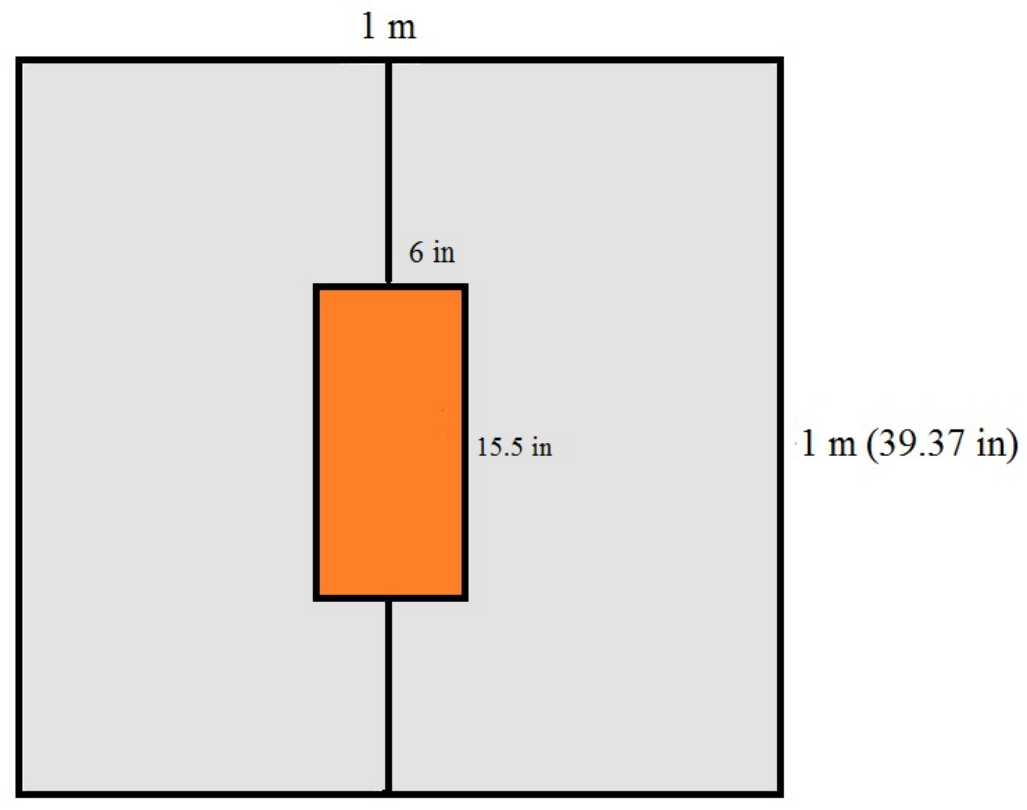

Figure 58: Wind tunnel cross section with boat-tail 


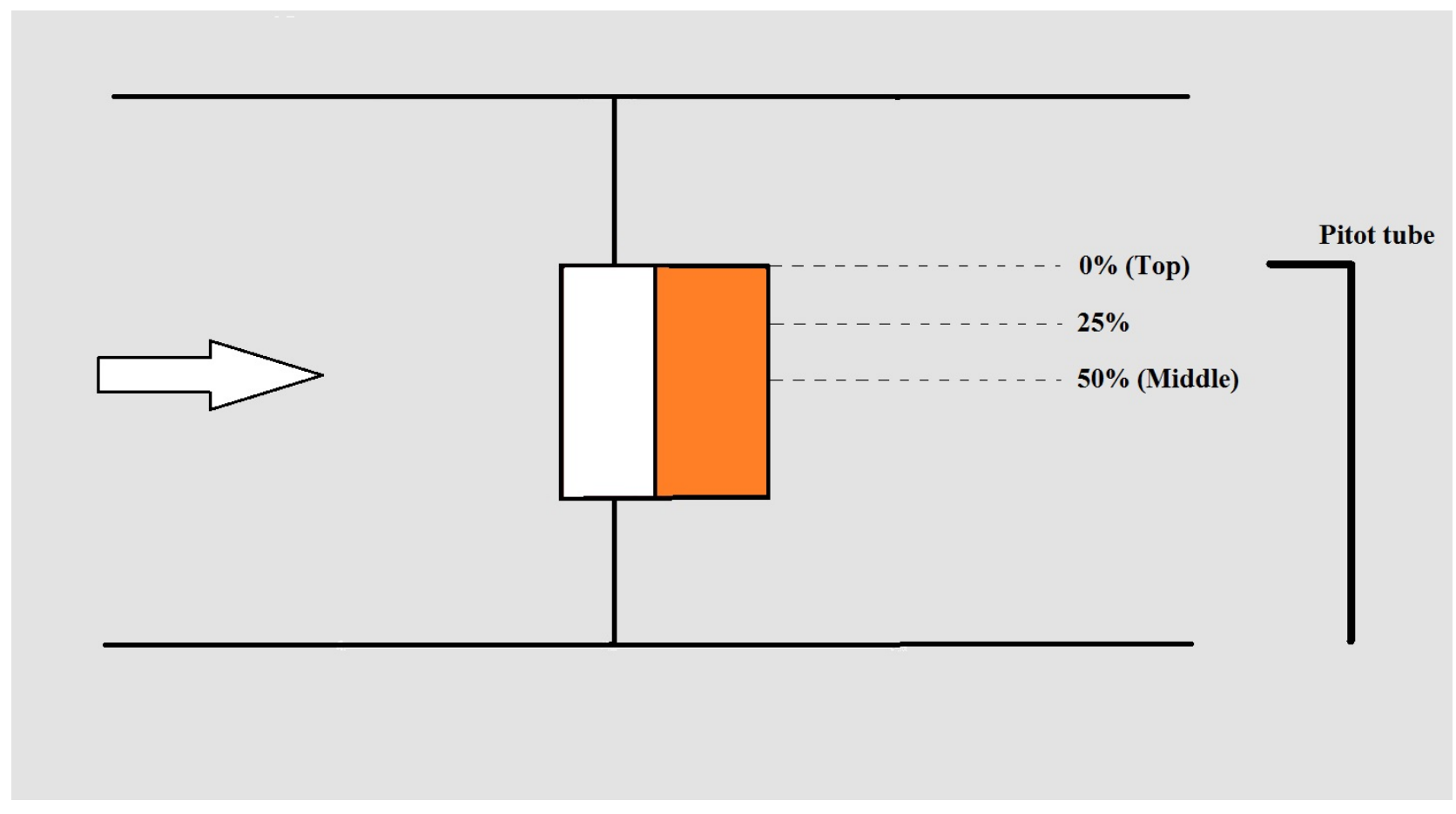

Figure 59: Variation of height for 2D wake surveys

\subsubsection{Varying profile height for 2D Wake Surveys}

Along with traditional center of boat-tail 2D-wake surveys, surveys were also performed at the top and $25 \%$ sections of the zero-baffle and six-baffle boat-tail systems. This allowed for a better understanding of how the velocity profiles vary behind the boat-tail depending on where the wake survey is performed relative to boat-tail width. Results in Chapter 4.8.1 show variation in velocity profiles of each system at $0 \%$ (top of boat-tail), $25 \%$ (between top and center of boat-tail), and center of boat-tail, see Fig. 59 for details.

\subsubsection{Variation of attack angles of boat-tail systems}

In addition to $2 \mathrm{D}$ wake surveys performed at $0^{\circ}$ angle, wake surveys were also completed at $5^{\circ}, 10^{\circ}$, and $15^{\circ}$ attack angles. These tests were performed in the same method as described above for $2 \mathrm{D}$ wake surveys, except that angle of attack was changed between tests. A clear thin 8x10 inch sheet with drawn angles was placed on the bottom of the wind tunnel, directly beneath the pivot point 


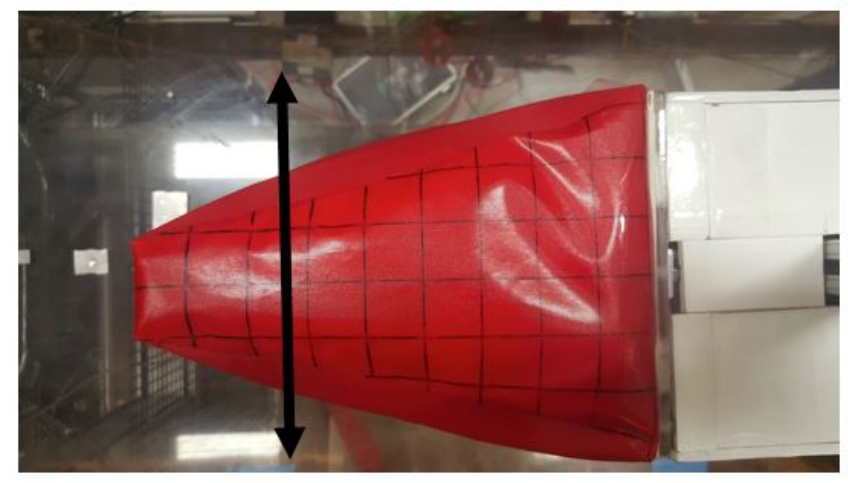

Figure 60: Study of deflection under dynamic pressure

of the boat-tail system. These degree lines were lined up with a yardstick from the pivot point to the center line of the boat-tail tip. After that bolts were tightened and the system was secured, the boat-tail was held at each specific angle throughout testing. Results are seen in Chapter 4.8.2.

\subsubsection{Boat-tail Systems Under Dynamic Pressure}

This test was developed to measure the reaction and any noticeable deformation of inflatable boattail systems under dynamic pressure, see Fig. 60. Deformation of the boat-tail was observed in wind tunnel experiments at two angles of attack, $0^{\circ}$ and $15^{\circ}$. Tests were performed at both atmospheric pressure (0 psi) and inflated pressure (0.5 psi), as well as free stream velocities of $0 \mathrm{mph}$ and $30 \mathrm{mph}$. Boat-tails were monitored by a camera held on top of the wind tunnel, directly above the boat-tail systems. Deflection was determined by comparison of photos taken throughout testing and results are discussed in Chapter 4.8.3. 


\section{Results and Discussion}

\subsection{Materials Testing, Selection, and Design}

Several factors influenced inflatable material choices, including heat seal ability, UV resistance, weight, material strength, and heat seal peel strength. Four materials were successfully heat sealed and chosen for peel strength tests to investigate heat seal strength and performance.

\subsubsection{Peel Strength of Adhesive Bonds}

Heat Sealable (HS) Packcloth, HS Taffeta, HS Oxford, and HS 30 Denier Nylon Ripstop were subjected to testing following ASTM D903-98 Standard Test for Peel Strength of Adhesive Bonds as discussed in Chapter 2, using an Instron Universal Testing machine with constant head speed peel strength tests were completed. Each specimen a 1 by 12 inch piece of fabric heat sealed for 6 inches at one end to another 1 by 8 inch piece of fabric of the same type, with the unbonded portions for each member being face to face [14]. Specimens were clamped into the Instron Universal Testing Machine. Six specimens were tested per fabric at a constant head speed with travel rate of 6 in $/ \mathrm{min}$ $[14]$.

After testing, data is plotted as load $\left(l b_{f}\right)$ versus extension $(i n)$. The first sign of failure for a heat seal bonded fabric is initial seal failure, this is when a sudden decrease in load can be seen in the load versus extension plot. Initial seal failure happens when a small area of the specimen has begun to fail which is caused by either failure of the heat seal or slight delamination. The second type of failure in peel strength tests is catastrophic failure or total failure of the specimen as load drops to zero. This is due to total failure of the heat seal (full delamination) or complete failure of the fabric under tensile stress. Initial failure is a good warning sign before catastrophic failure happens. Once initial failure has occurred the specimen is declared to be failed.

\subsection{Results of Heat Sealable Packcloth (Sample A)}

Plotted results of load $\left(l b_{f}\right)$ versus extension $(i n)$ for HS Packcloth show to be almost linear up to the first sign of initial failure, see Fig. 61. After initial failure, total fabric failure continues leading to catastrophic failure. Average peel strength for HS Packcloth was determined to be 45.1 
$l b_{f}$, calculated by averaging the initial failure point for each specimen.

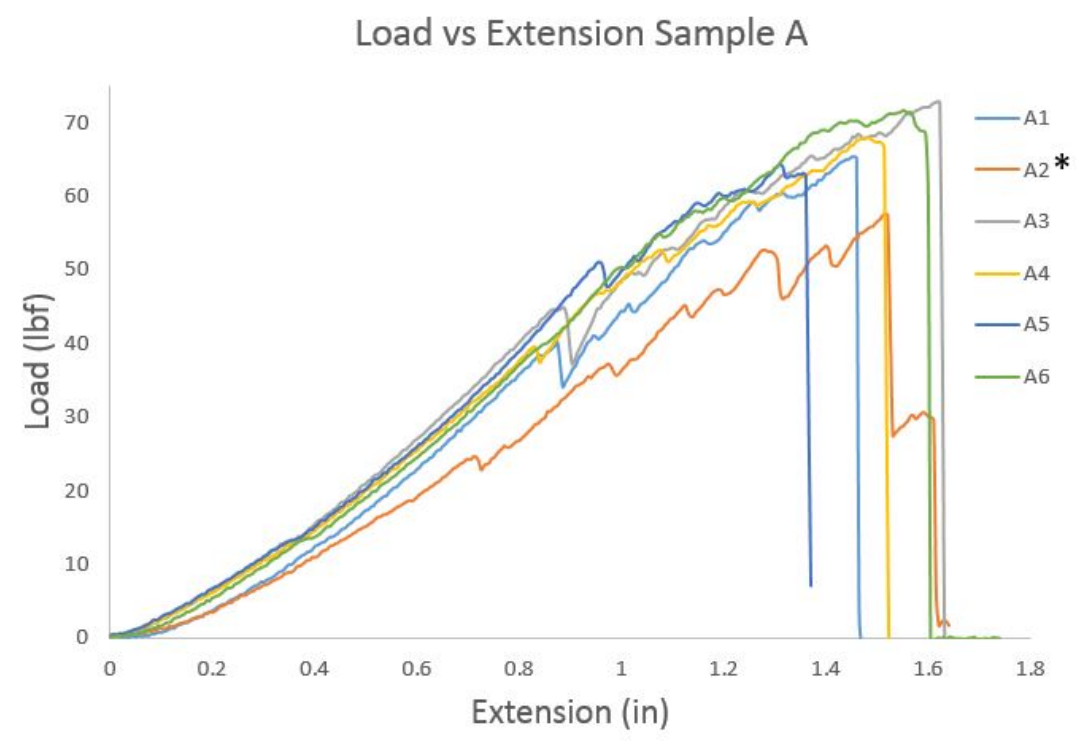

Figure 61: Peel strength test results for HS Packcloth (Sample A)

\subsection{Results of Heat Sealable Oxford (Sample B)}

Test results for HS Oxford show to be similar of that for HS Packcloth. Three out of six tests for HS Oxford gave no warning sign before catastrophic failure. Average peel strength for HS Oxford was determined to be $44.9 l b_{f}$, calculated by averaging the initial failure point for each specimen. Although average peel strength for HS Oxford is close to that of HS Packcloth, it is determined since HS Oxford gives no initial warning in $50 \%$ of tests, HS Packcloth is the better fabric between the two for cases where initial failure notification is necessary. If initial failure notification is not necessary, either fabric may be used. Both HS Packcloth and HS Oxford are suggested for use in inflatable heat sealed applications. 


\begin{tabular}{|c|c|c|}
\hline Sample Number & Initial Failure $\left(\mathrm{lb}_{\mathrm{f}}\right)$ & Catastrophic Failure $\left(\mathrm{lb}_{\mathrm{f}}\right)$ \\
\hline A1 & 40.2 & 65.4 \\
\hline A2 & 24.6 & 57.4 \\
\hline A3 & 44.8 & 72.6 \\
\hline A4 & 39.5 & 67.2 \\
\hline A5 & 50.7 & 62.7 \\
\hline A6 & 50.3 & 71.3 \\
\hline SUM & 225.1 & 396.6 \\
\hline MAX & 50.7 & 72.6 \\
\hline MIN & 39.5 & 57.4 \\
\hline Average (lbf) & 45.1 & 67.8 \\
\hline
\end{tabular}

Figure 62: Peel strength test results for HS Packcloth (Sample A) *A2 noted as outlier, not included in average calculations

\section{Load vs Extension Sample B}

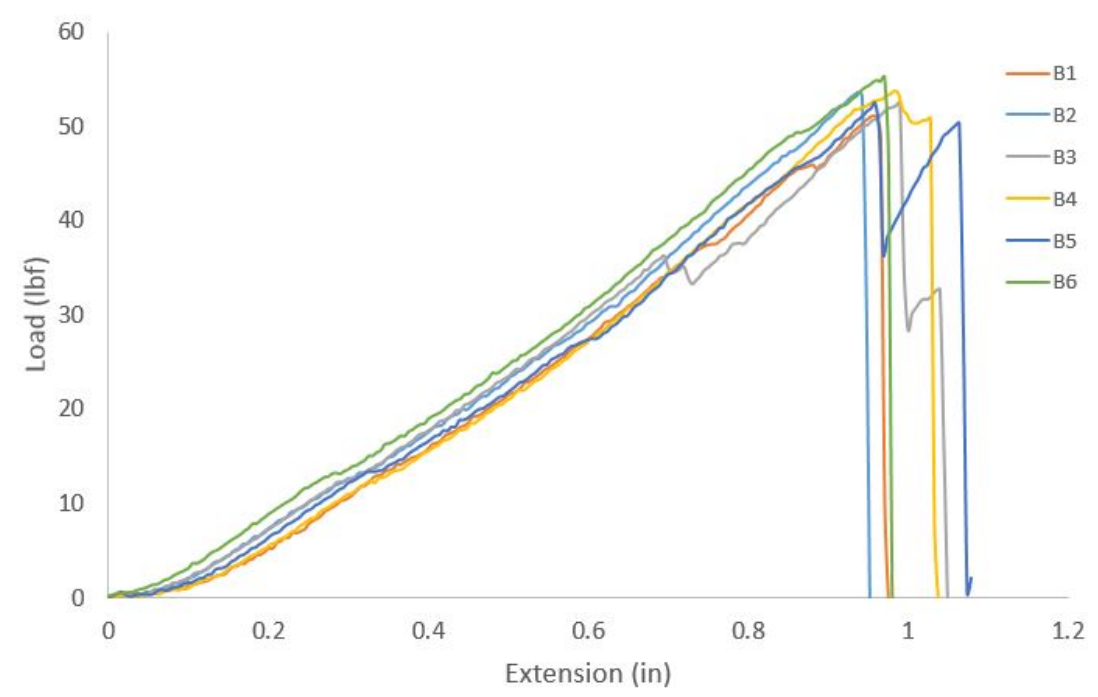

Figure 63: Peel strength test results for HS Oxford (Sample B) 


\begin{tabular}{|c|c|c|}
\hline Sample Number & Initial Failure & Catastrophic Failure \\
\hline B1 & 45.9 & 51.1 \\
\hline B2 & - & 53.7 \\
\hline B3 & 36.3 & 52.5 \\
\hline B4 & - & 53.7 \\
\hline B5 & 52.4 & 50.3 \\
\hline B6 & - & 55.2 \\
\hline SUM & 134.6 & 316.5 \\
\hline MAX & 52.4 & 55.2 \\
\hline MIN & 36.3 & 50.3 \\
\hline Average (lbf) & 44.9 & 52.8 \\
\hline Average Peel Strength (Ibf/in) & 44.9 & \\
\hline
\end{tabular}

Figure 64: Peel strength test results for HS Oxford (Sample B) 


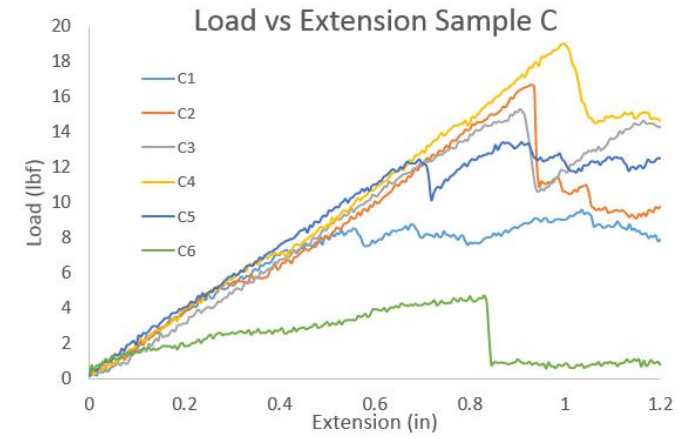

$[\mathrm{h}]$

Figure 65: Peel strength test results of HS Taffeta (Sample C)

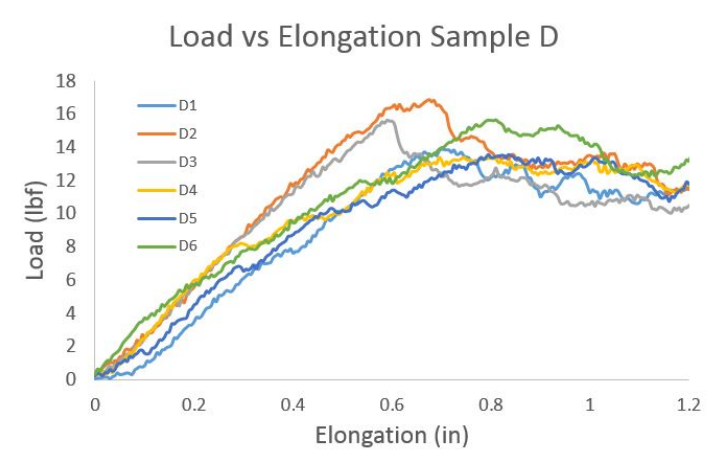

Figure 66: Peel strength test results of HS Ripstop (Sample D)

\subsection{Results of Heat Sealable Taffeta (Sample C)}

Initial failure for HS Taffeta happens at very low loads (commonly less than $2 l b_{f}$ ) due to sudden delamination of the two fabric layers. The heat seal continuously fails as areas peel away from each other. Due to failure happening at such low loads, HS Taffeta is not recommended for use in inflatable heat sealed applications.

\subsection{Results of Heat Sealable Ripstop (Sample D)}

Results for HS Ripstop show to be very similar to that of HS Taffeta. Initial failure happens through delamination at less than $2 l b_{f}$. Due to failure happening at such low loads, HS Ripstop is not recommended for use in inflatable heat sealed applications.

\subsection{Final Fabric Results}

Results show the best fabrics out of the four tested were Sample A, HS Packcloth and Sample B, HS Oxford. Both materials show average peel strength close to $45 \mathrm{lb}_{f}$, and prove to be dependable choices for heat sealed inflatable applications. HS Oxford is chosen for manufacturing since it has the lower density of the two fabrics and will result in a lighter weight boat-tail. Following the equations discussed in Chapter 2 and using results of peel strength tests, it is now possible to predict burst pressure depending on inflatable pouch radius. 


\begin{tabular}{|c|c|c|c|c|}
\hline & HS Packcloth (A) & HS Oxford (B) & HS Taffeta (C) & HS Ripstop (D) \\
\hline $\begin{array}{l}\text { Avg density } \\
\left(\mathbf{g} / \mathrm{cm}^{3}\right)\end{array}$ & 0.915 & 0.831 & 1.116 & 0.906 \\
\hline Thickness (in) & 0.0125 & 0.010 & 0.008 & 0.008 \\
\hline $\begin{array}{l}\text { Avg Initial Failure } \\
\left(\mathrm{lb}_{\mathrm{f}}\right)\end{array}$ & 45.1 & 44.9 & $<2$ & $<2$ \\
\hline $\begin{array}{l}\text { Avg Catastrophic } \\
\text { Failure }\left(\mathrm{lb}_{\mathrm{f}}\right)\end{array}$ & 67.8 & 52.8 & NA & NA \\
\hline $\begin{array}{l}\text { Avg Peel Strength } \\
\left(\mathbf{l b}_{\mathrm{f}} / \text { in }\right)\end{array}$ & 45.1 & 44.9 & NA & NA \\
\hline Failure Warning & $\begin{array}{l}\text { Fabric shows } \\
\text { warning signs before } \\
\text { failure }\end{array}$ & $\begin{array}{l}\text { Fabric shows } \\
\text { warning signs in } \\
50 \% \text { of cases }\end{array}$ & \multicolumn{2}{|c|}{$\begin{array}{l}\text { Fabric begins to fail under tension } \\
\text { immediately by delamination }\end{array}$} \\
\hline Failure Type & $\begin{array}{l}\text { Partial delamination, } \\
\text { followed by total } \\
\text { failure of fabric }\end{array}$ & $\begin{array}{l}\text { Partial } \\
\text { delamination in } \\
50 \% \text { of cases. }\end{array}$ & \multicolumn{2}{|l|}{ Delamination } \\
\hline Comments & \multicolumn{2}{|c|}{$\begin{array}{l}\text { Good heat sealability, delamination at } \\
\text { high loads. Approved for inflatable } \\
\text { applications. }\end{array}$} & \multicolumn{2}{|c|}{$\begin{array}{l}\text { Not suggested for use in heat } \\
\text { sealed inflatable applications }\end{array}$} \\
\hline
\end{tabular}

Figure 67: Final results of peel strength tests for Samples A, B, C, and D

\subsection{Burst Testing}

Oxford fabric was chosen as the primary fabric for manufacturing boat-tails, and burst testing was completed on heat sealed Oxford fabric tubes. Testing included tube sizes of 3 inch and 5 inch diameter, that were heat sealed along 3 edges at 0.5 inch width, and 0.5 meters in length. For $n=4$ tubes, preliminary results show an average burst pressure of 17.43 psi for the 3 inch diameter tube and 15.22 psi for the 5 inch diameter tube. Average results for burst pressure of the 3 inch tube are close to the prediction, but average results for the 5 inch tube are above the predicted burst pressure. Predicted burst pressure is plotted from the $S=P_{b} R$ relation discussed in Chapter 2 . Since a low number of tests were performed, more burst testing will provide better information on accuracy of the predicted burst pressure relation, see Fig. 68. The majority (75\%) of bursts tests resulted in failure due to sudden bursting. This caused the entire side of the inflated tube to burst, leaving a large opening. The other $25 \%$ resulted in failure due to slow leaking. This failure was less noticeable, but was observed due to a sudden drop in pressure. 


\section{Predicted Burst Pressure vs Tube Radius}

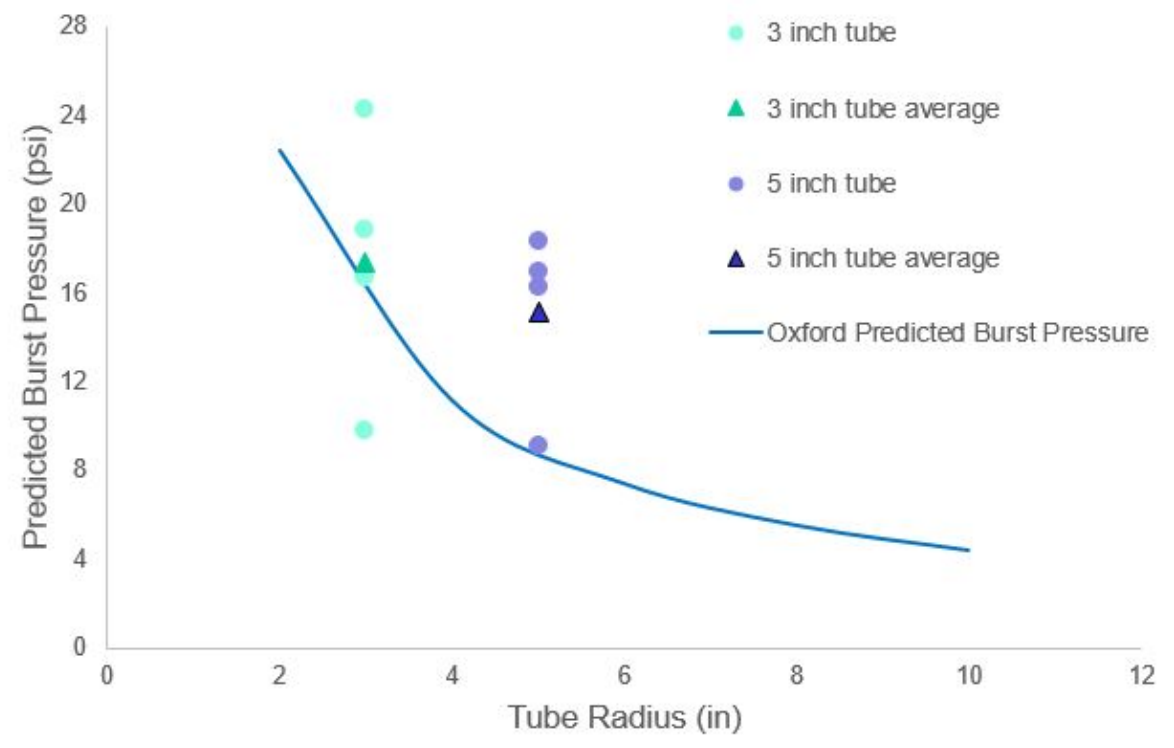

Figure 68: Predicted burst pressure versus pouch radius

\begin{tabular}{|l|l|l|l|l|}
\hline $\begin{array}{l}\text { Tube } \\
\text { Diameter }\end{array}$ & Average & Max (psi) & Min (psi) & $\begin{array}{l}\text { Average Hoop } \\
\text { Stress }\end{array}$ \\
\hline 3" Tube & 17.43 & 24.31 & 9.83 & 2614.5 \\
\hline 5" Tube & 15.22 & 18.39 & 9.16 & 3805.0 \\
\hline
\end{tabular}

Figure 69: Burst tests results 


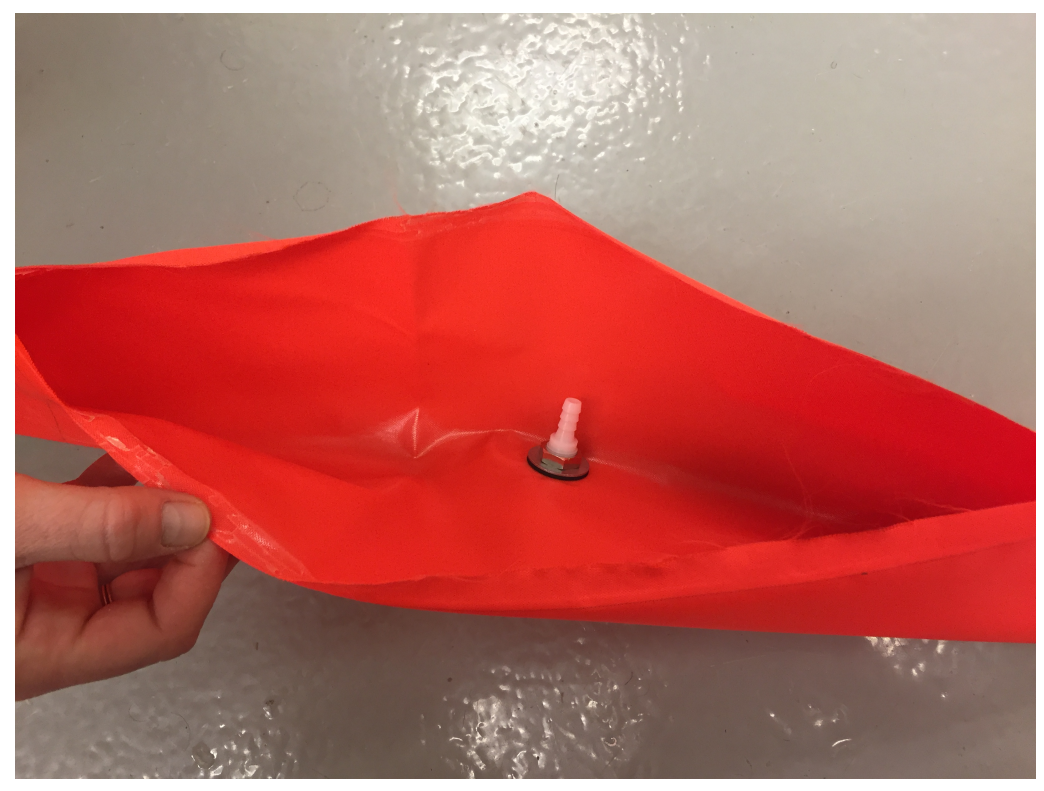

Figure 70: Burst test failure 


\subsection{Wind Tunnel Tests Results}

Wind tunnel experiments were performed and coefficient of drag was found for multiple cases. These cases include

1. Baseline System (rounded-front rectangle)

2. Zero-Baffle Boat-tail

3. Six-Baffle Boat-tail

Initially, 2D wake surveys were performed at the middle section of each boat-tail system, at varying Reynolds numbers of approximately $1.59 \mathrm{E}+5,2.30 \mathrm{E}+5,3.15 \mathrm{E}+5$, and $3.96 \mathrm{E}+5$. These Reynolds numbers span the limits of the wind tunnel system, providing results for a variety of cases. All three of these cases were performed at $0^{\circ}$ angle of attack. Inflatable sections were kept at an average internal bladder pressure of $\mathrm{P}=0.5$ psi throughout testing. The first tests results shown are the baseline (no tail), zero-baffle, and six-baffle systems at four different Reynolds numbers. Each are plotted comparing systems at respective Reynolds numbers. When comparing results of baseline, zero-baffle, and six-baffle systems it is important to remember $2 \mathrm{D}$ wake survey theory, and that the area under the velocity profile curve relates directly to coefficient of drag. Profiles with larger areas will result in systems that have much larger drag coefficients, due to large wake regions behind the system and low pressure regions, therefore increasing drag. By comparing velocity profiles and drag coefficients at varying Reynolds numbers, it is clear that the baseline system has the highest drag coefficient. The zero-baffle system shows a slight improvement when compared to the baseline system, but overall the six-baffle system results in the lowest drag coefficient and is therefore the best of the two inflatable boat-tail designs. This is due to the fact that the six-baffle system has a more defined and optimized shape when compared to the zero-baffle system, as shape is directly related to baffle number. Figure 75 shows the overall plot for Coefficient of Drag vs Reynolds number for the zero-baffle and six-baffle systems when compared to the baseline system at one standard deviation and further discussion in included in Chapter 5. 


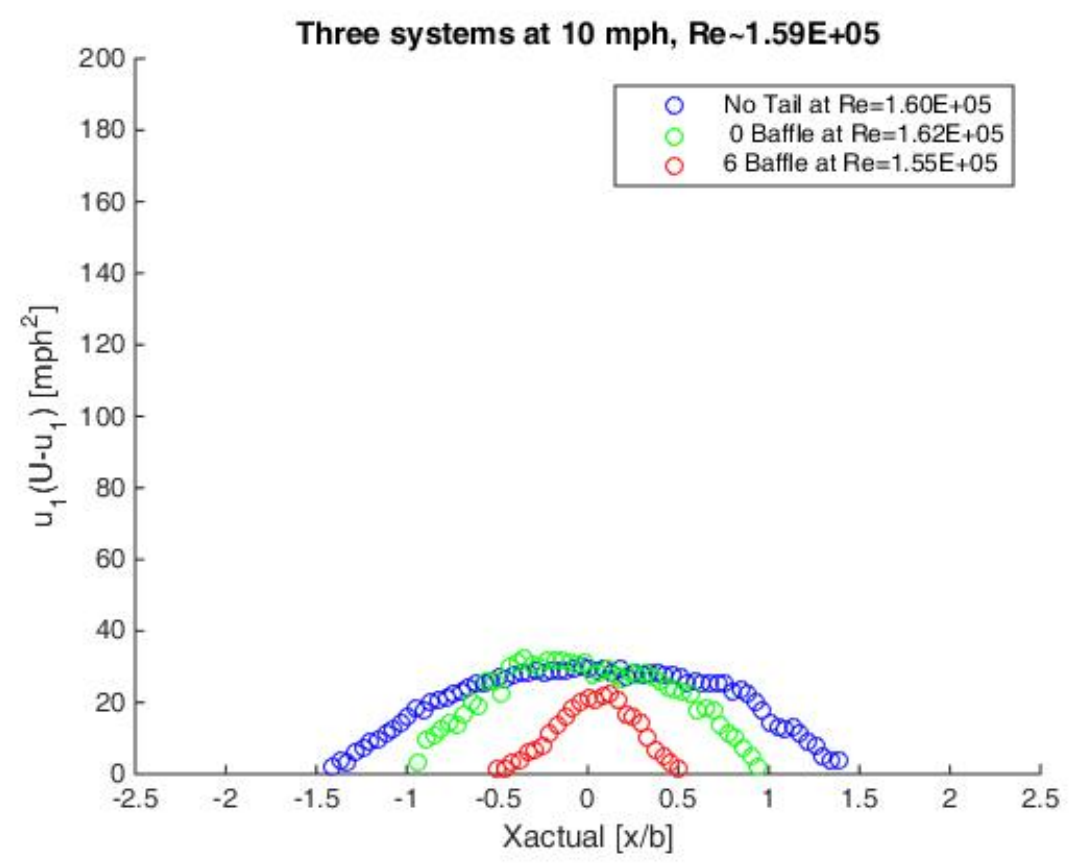

Figure 71: Three systems at $\mathrm{Re}=1.59 \mathrm{E}+5,10 \mathrm{mph}$

\begin{tabular}{|c|c|r|}
\hline System & $C_{D}$ & $\Delta C_{D} \%$ \\
\hline Baseline & 1.03 & - \\
\hline 0 Baffle Boat-tail & 0.73 & 29.1 \\
\hline 6 Baffle Boat-tail & 0.21 & 79.6 \\
\hline
\end{tabular}

Table 1: $C_{D}$ for Three Systems at $\mathrm{Re}=1.59 \mathrm{E}+5,10 \mathrm{mph}$

\begin{tabular}{|c|c|r|}
\hline System & $C_{D}$ & $\Delta C_{D} \%$ \\
\hline Baseline & 1.05 & - \\
\hline 0 Baffle Boat-tail & 0.59 & 43.8 \\
\hline 6 Baffle Boat-tail & 0.19 & 81.9 \\
\hline
\end{tabular}

Table 2: $C_{D}$ for Three Systems at $\mathrm{Re}=2.34 \mathrm{E}+5,15 \mathrm{mph}$

\begin{tabular}{|c|c|r|}
\hline System & $C_{D}$ & $\Delta C_{D} \%$ \\
\hline Baseline & 1.18 & - \\
\hline 0 Baffle Boat-tail & 0.98 & 17.0 \\
\hline 6 Baffle Boat-tail & 0.18 & 84.7 \\
\hline
\end{tabular}

Table 3: $C_{D}$ for Three Systems at $\mathrm{Re}=3.15 \mathrm{E}+5,20 \mathrm{mph}$ 


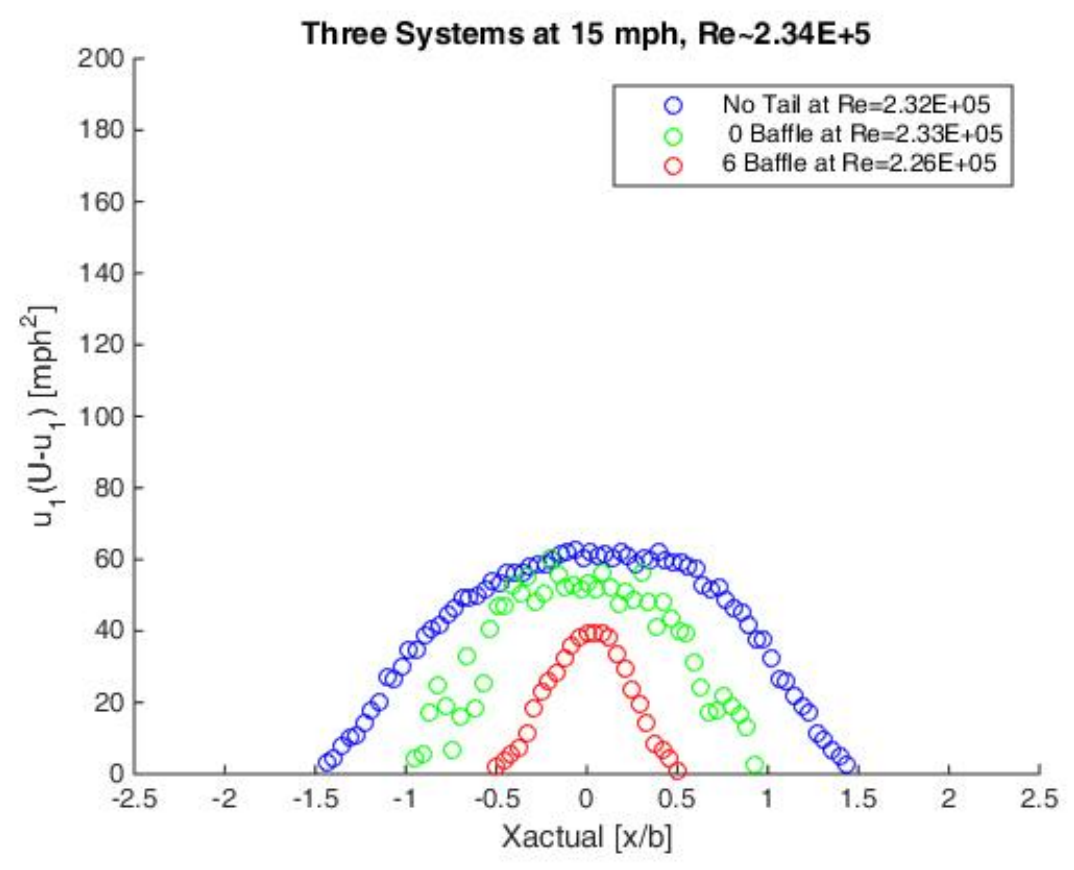

Figure 72: Three systems at $\operatorname{Re}=2.34 \mathrm{E}+5$

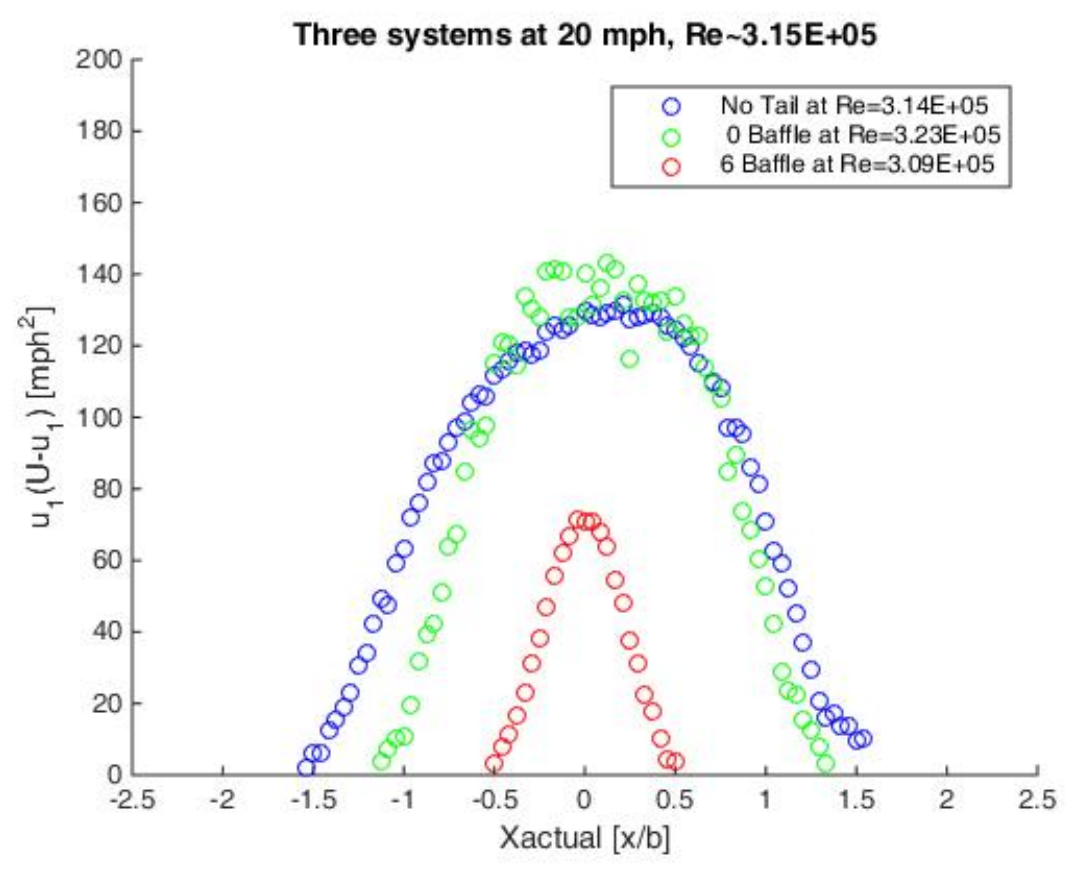

Figure 73: Three systems at $\mathrm{Re}=3.15 \mathrm{E}+5$ 


\begin{tabular}{|c|c|r|}
\hline System & $C_{D}$ & $\Delta C_{D} \%$ \\
\hline Baseline & 0.70 & - \\
\hline 0 Baffle Boat-tail & 0.63 & 10.0 \\
\hline 6 Baffle Boat-tail & 0.14 & 80.0 \\
\hline
\end{tabular}

Table 4: $C_{D}$ for Three Systems at $\mathrm{Re}=3.96 \mathrm{E}+5,30 \mathrm{mph}$

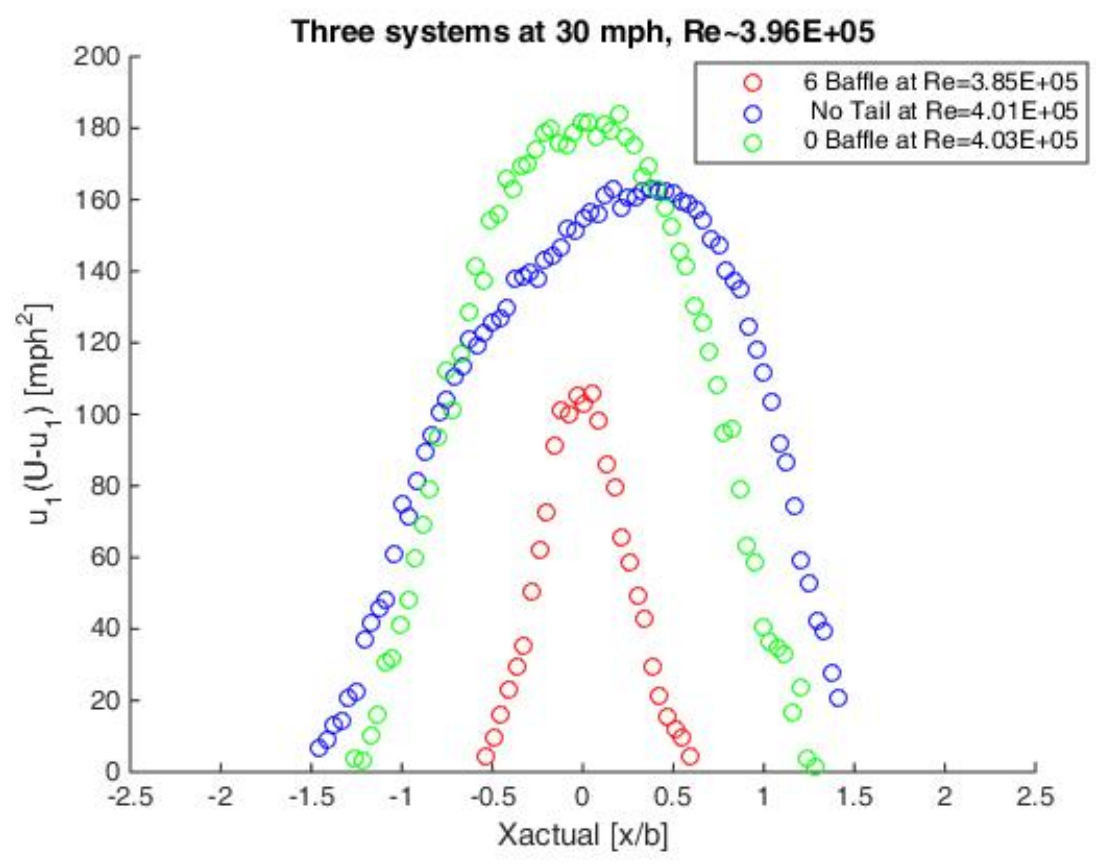

Figure 74: Three systems at $\operatorname{Re}=3.96 \mathrm{E}+5$

\begin{tabular}{|c|c|r|}
\hline System & $C_{D}$ & $\Delta C_{D} \%$ \\
\hline Baseline & 1.09 & - \\
\hline 0 Baffle Boat-tail & 0.77 & 29.4 \\
\hline 6 Baffle Boat-tail & 0.19 & 82.6 \\
\hline
\end{tabular}

Table 5: Overall average $C_{D}$ for each system 


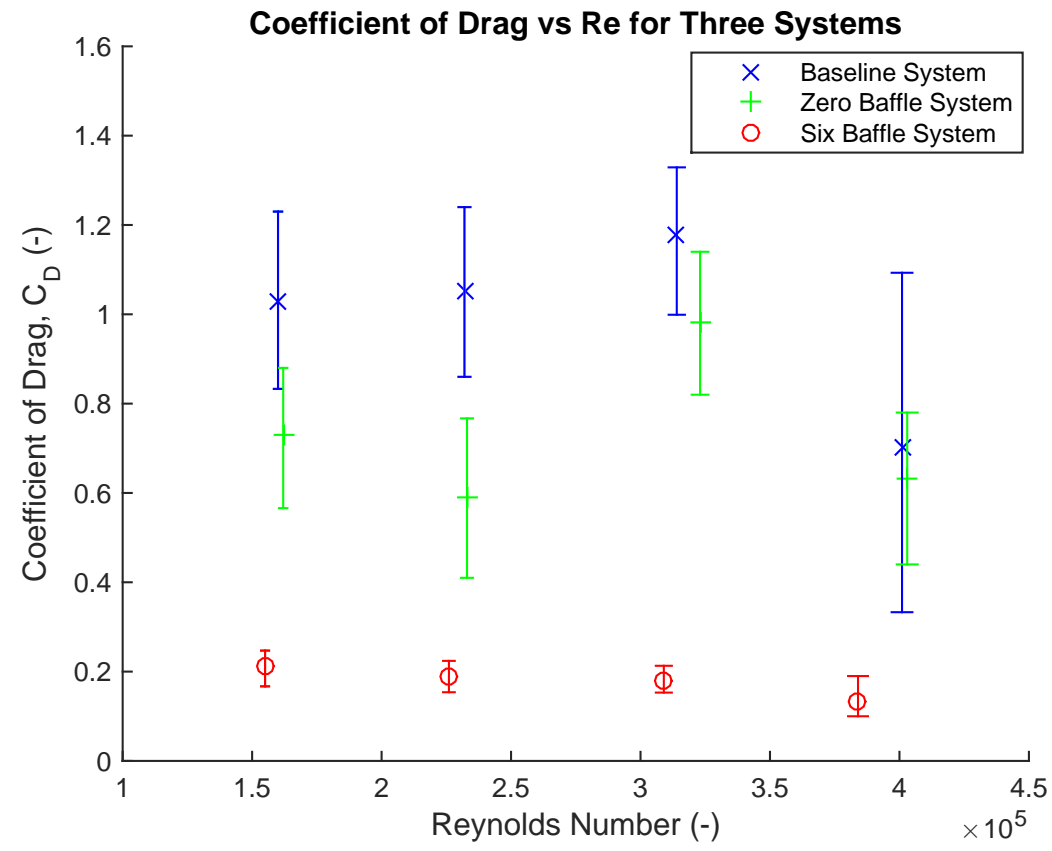

Figure 75: Coefficient of drag vs Reynolds number for three systems 


\subsubsection{Varying Height for 3D Profiles}

Since wake profiles are $2 \mathrm{D}$, it is interesting to take $2 \mathrm{D}$ profiles at different heights along the boat-tail section. This gives some idea about 3D aspects of the wake behind the boat-tail systems. Wake surveys were performed at the $0 \%$ (top), $25 \%$, and $50 \%$ (middle) sections of zero-baffle and six-baffle boat-tail systems, as shown previously in Fig. 59. For the zero-baffle system, there is decreased drag closer to the top of the boat-tail and increased drag towards the center of the boat-tail, due to the bowed center shape of the zero-baffle design. This is clear from Fig. 76 and 77 due to larger area under velocity profile curve for $25 \%$ and mid section tests. For the six-baffle systems, drag is slightly increased moving away from the boat-tail center for the higher velocity test of $20 \mathrm{mph}$. This minimal difference has to do with the six-baffle design having a much more consistent shape throughout the entire width. This slightly increased drag is most likely due to an area of higher turbulence at the edges of the boat-tail, see Fig. 78 through 81 .

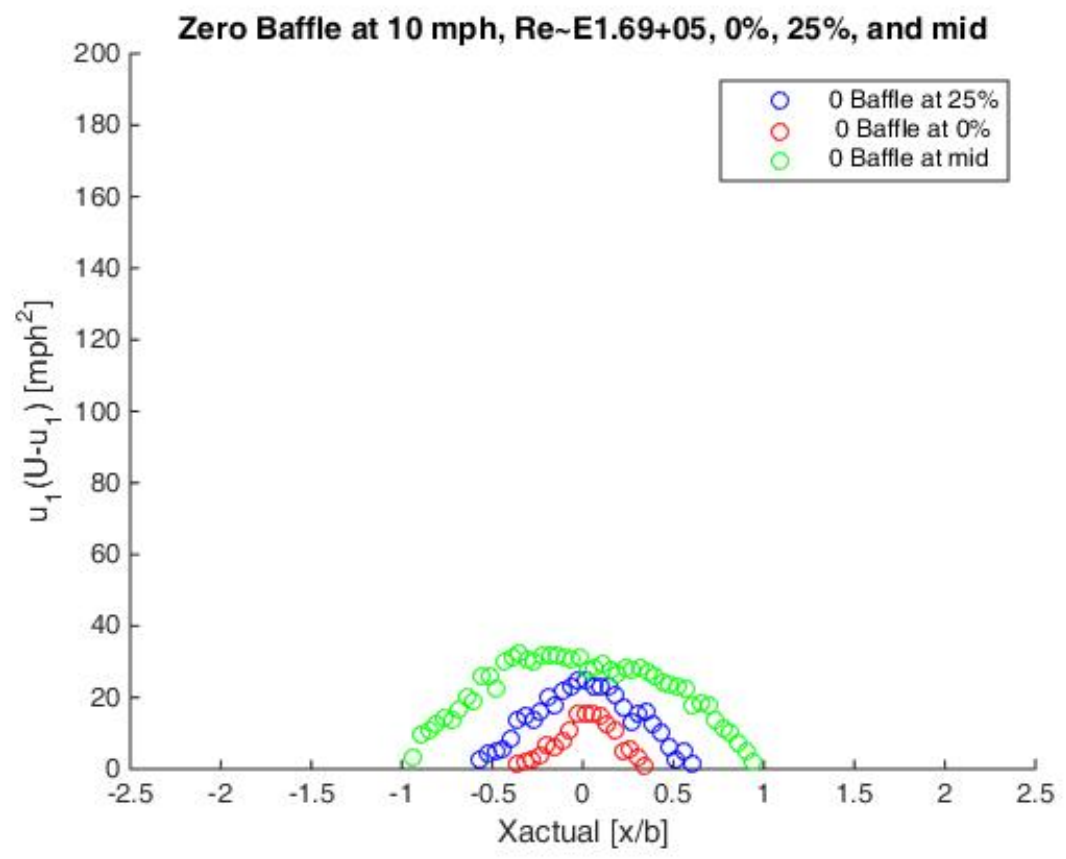

Figure 76: Zero-baffle boat-tail at $0 \%, 25 \%$ and mid 


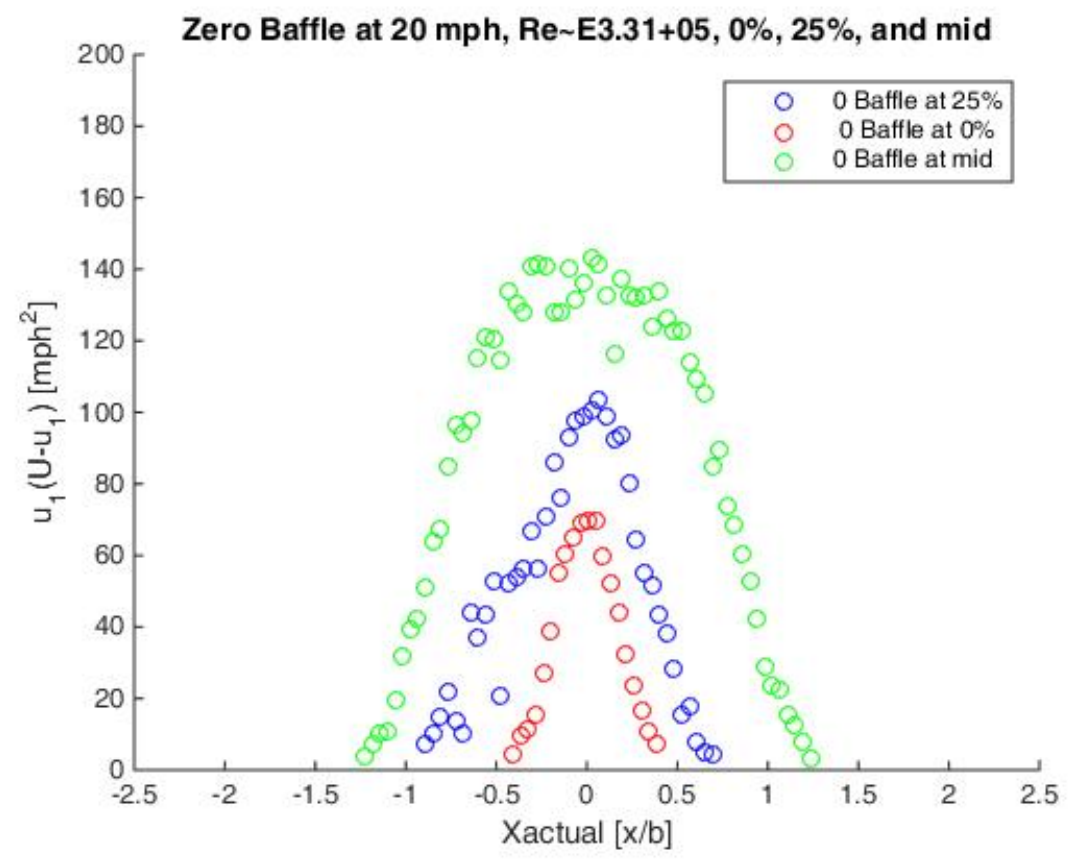

Figure 77: Zero-baffle boat-tail at $0 \%, 25 \%$ and mid

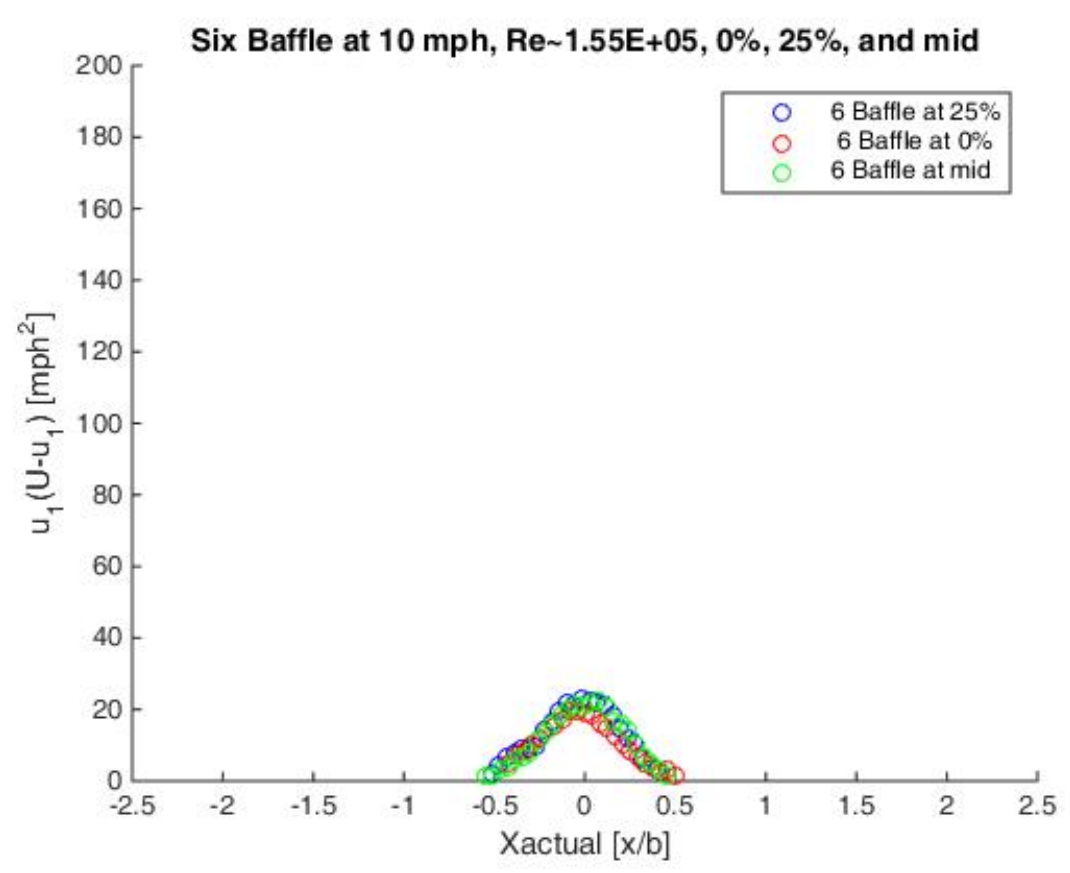

Figure 78: Six-baffle boat-tail at 0\%,25\% and mid 


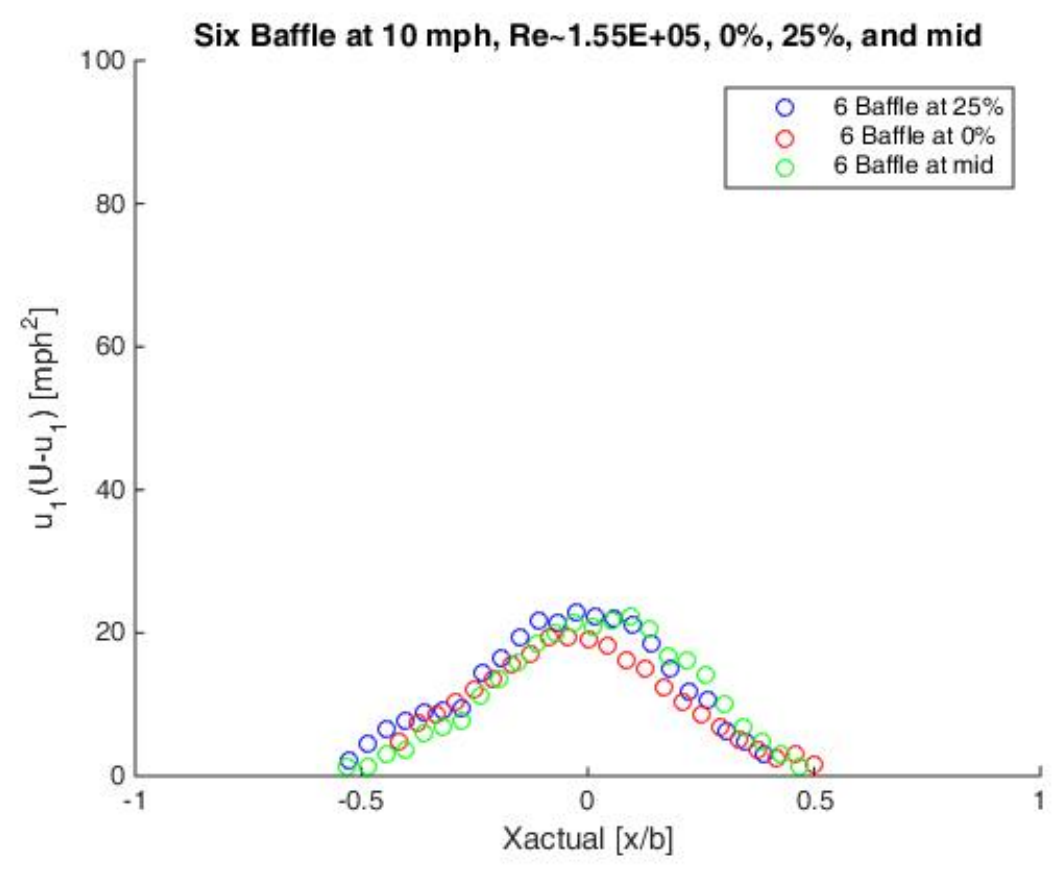

Figure 79: Six-baffle boat-tail at 0\%,25\% and mid

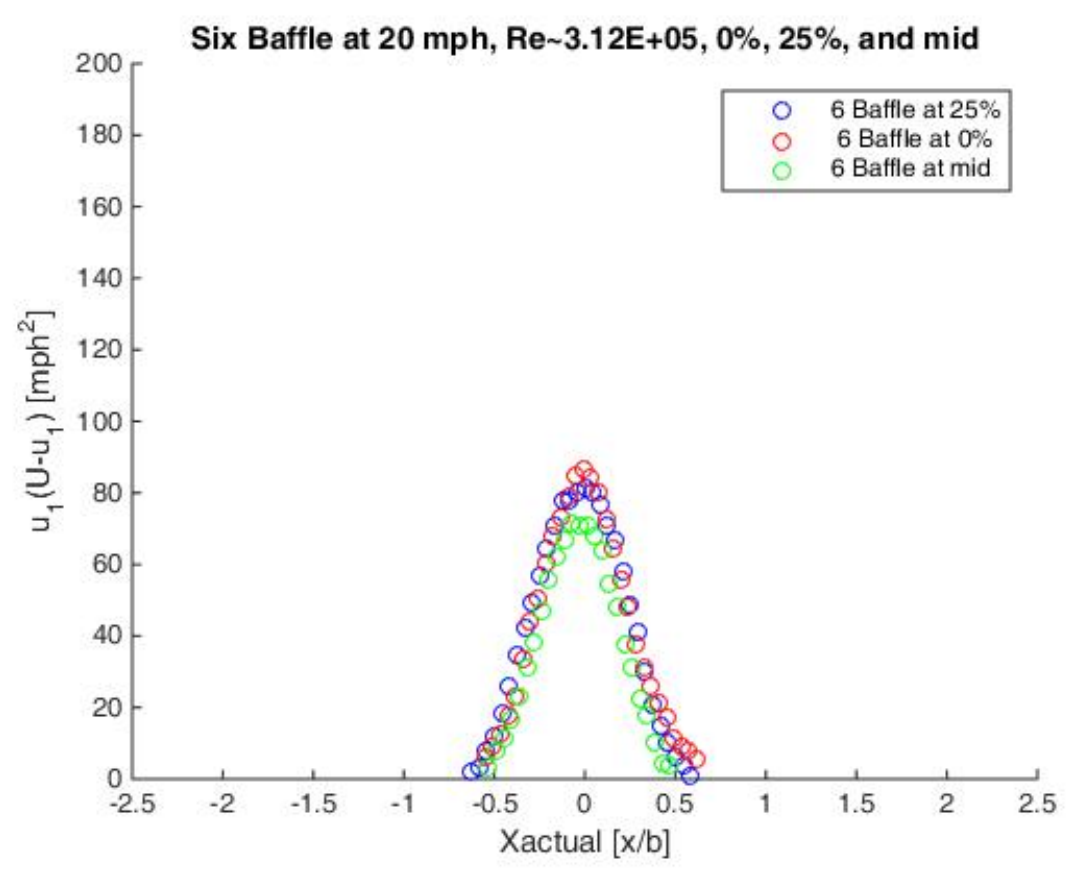

Figure 80: Six-baffle boat-tail at 0\%, 25\% and mid 


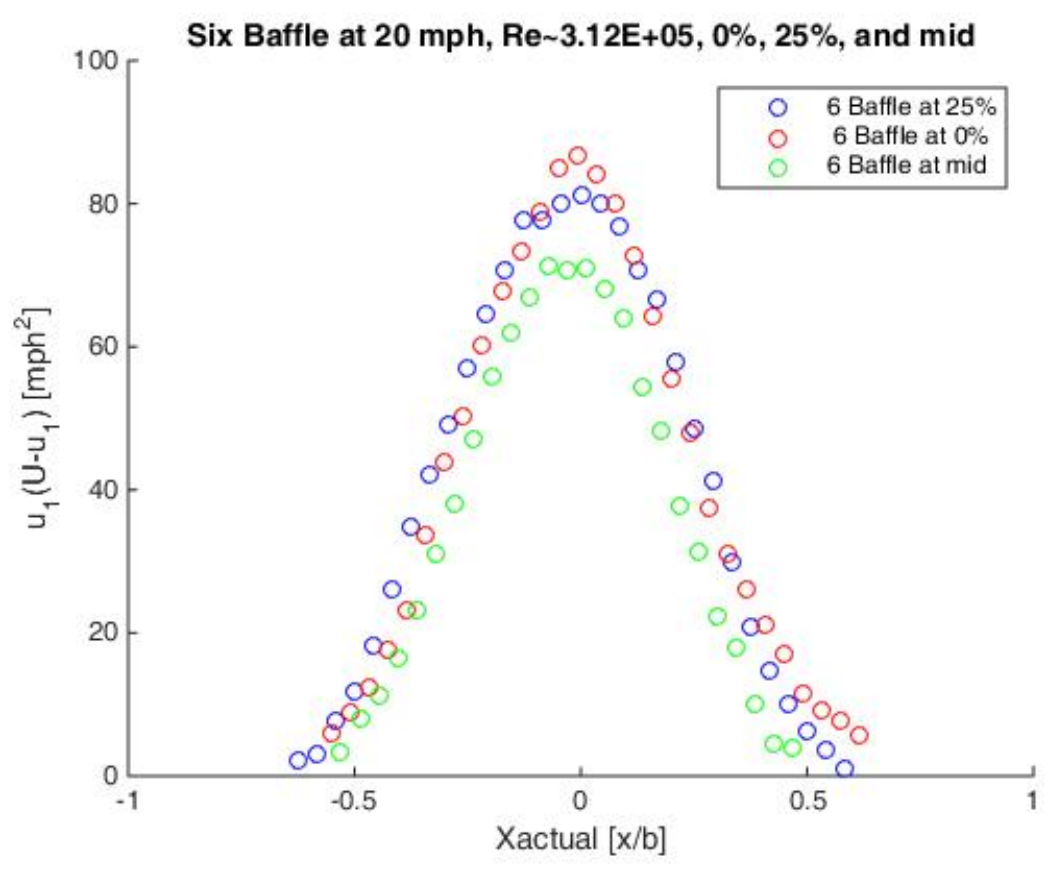

Figure 81: Six-baffle boat-tail at 0\%,25\% and mid 


\subsubsection{Variation of Attack Angles}

In addition to wake surveys on boat-tail systems at $0^{\circ}$ attack angles as shown previously, boat-tail systems were tested by wake survey at $5^{\circ}, 10^{\circ}$, and $15^{\circ}$ attack angles. Results are shown in Fig. 82 through 87 . Plots show offset velocity profiles due to the variation in attack angle. Results of $15^{\circ}$ tests show that this attack angle was too large for the wind tunnel, as most of the profile is out of the recording range of the pitot probe as upstream air is sent directly into the wall of the wind tunnel.

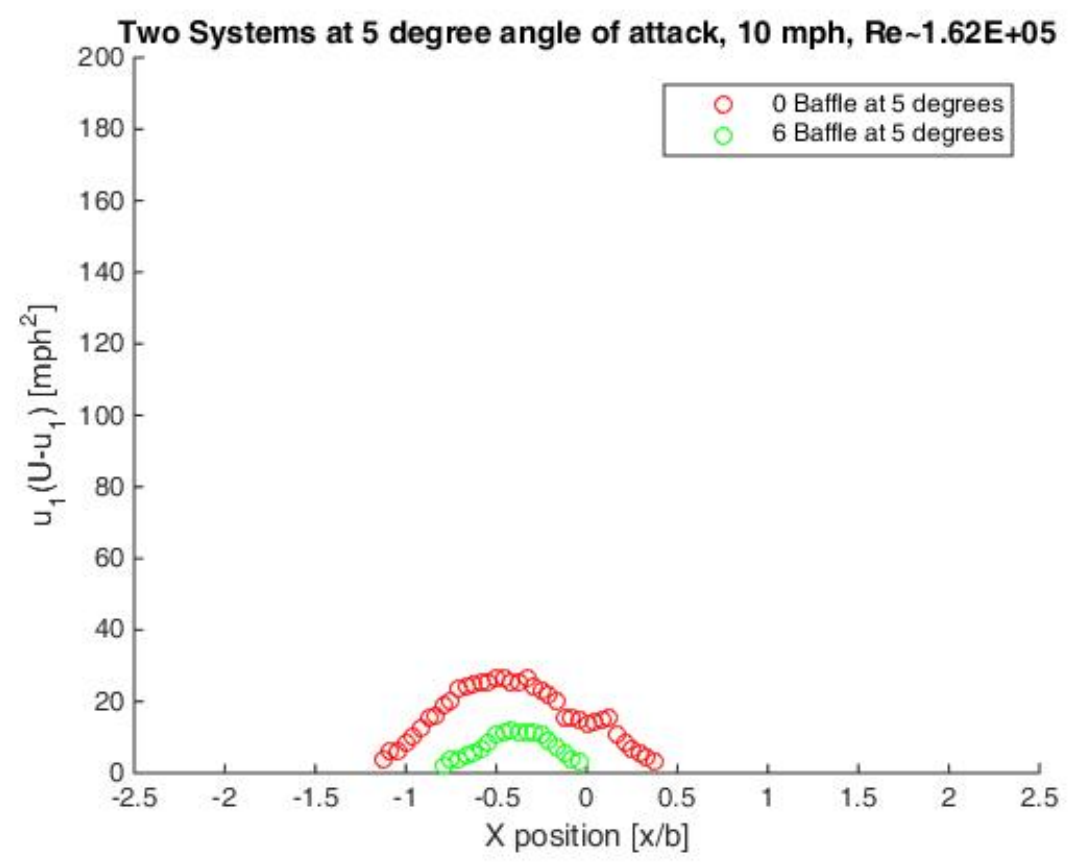

Figure 82: Six-baffle and zero-baffle systems at $5^{\circ}$ angle of attack, $\mathrm{Re}=1.62 \mathrm{E}+5$ 


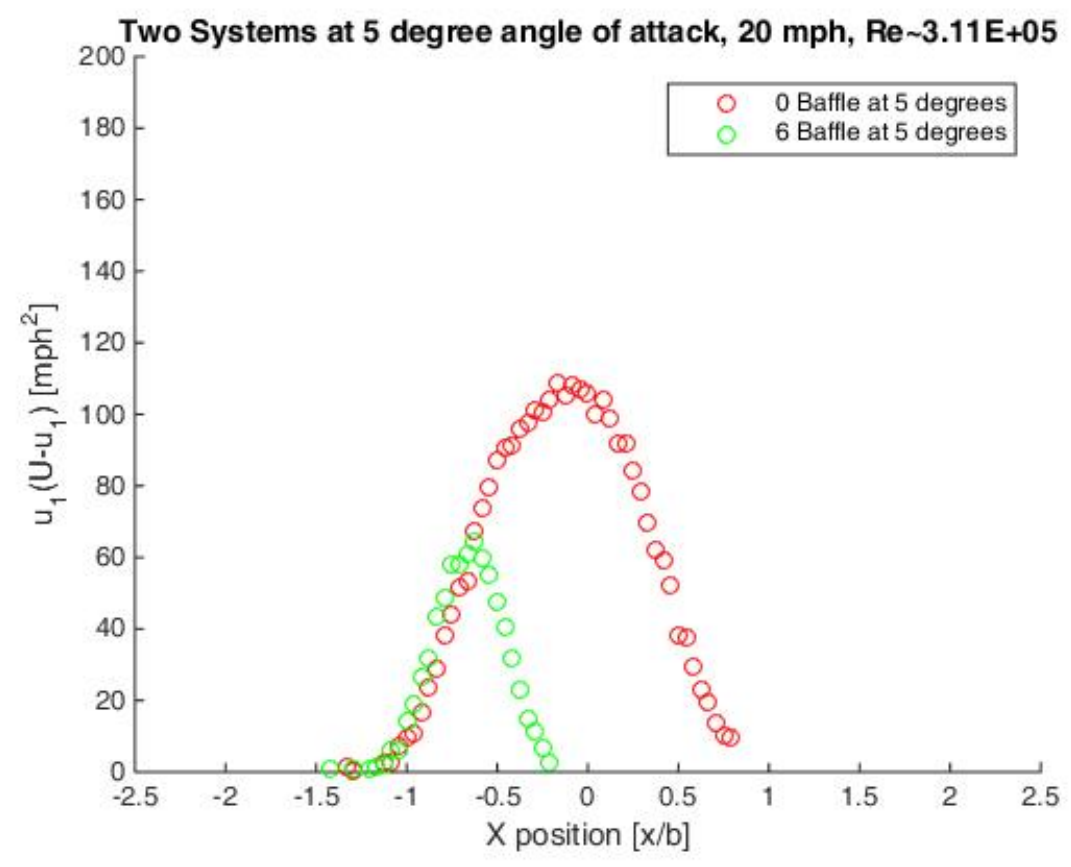

Figure 83: Six-baffle and zero-baffle systems at $5^{\circ}$ angle of attack, $\operatorname{Re}=3.11 \mathrm{E}+5$

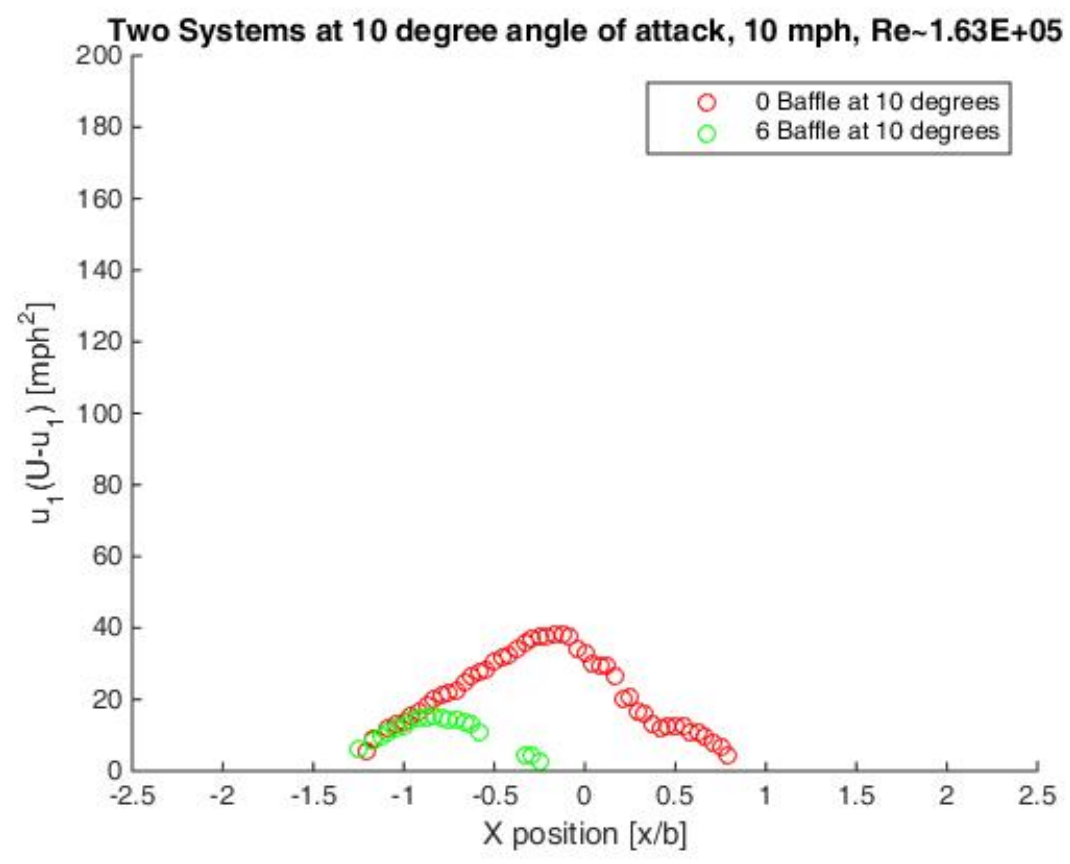

Figure 84: Six-baffle and zero-baffle systems at $10^{\circ}$ angle of attack, $R e=1.63 \mathrm{E}+5$ 


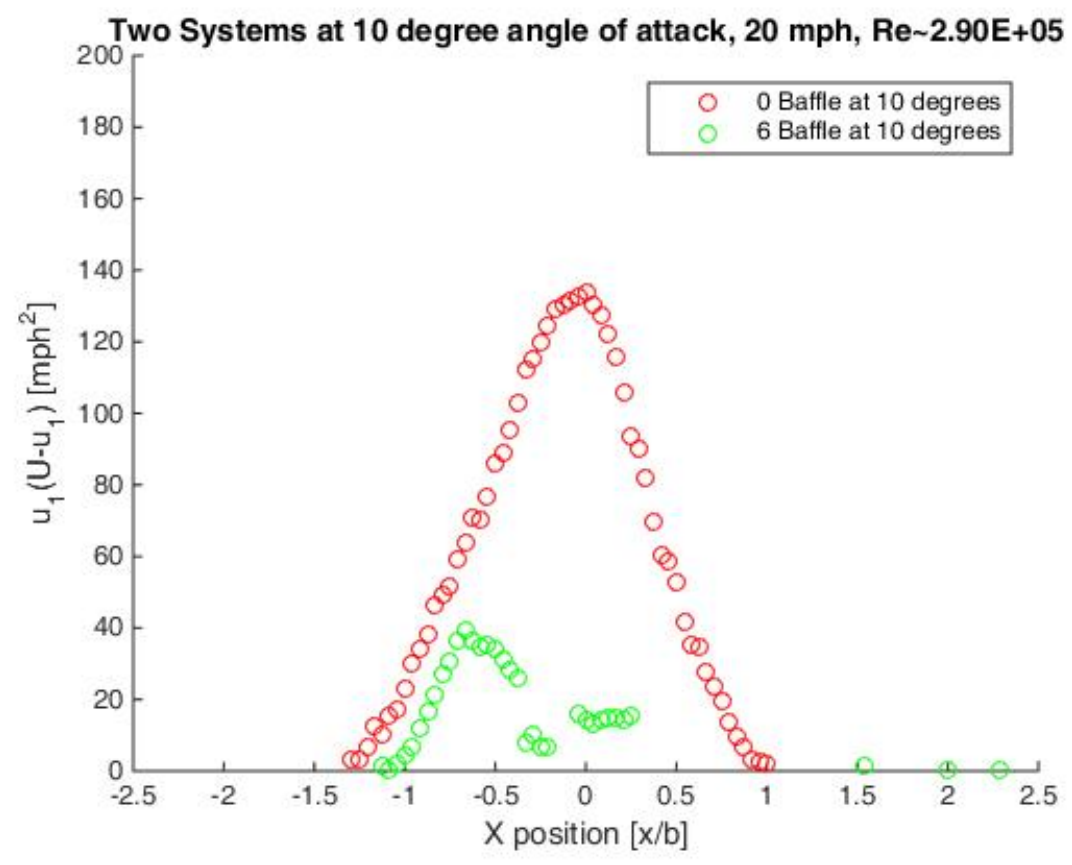

Figure 85: Six-baffle and zero-baffle systems at $10^{\circ}$ angle of attack, $R e=2.90 \mathrm{E}+5$

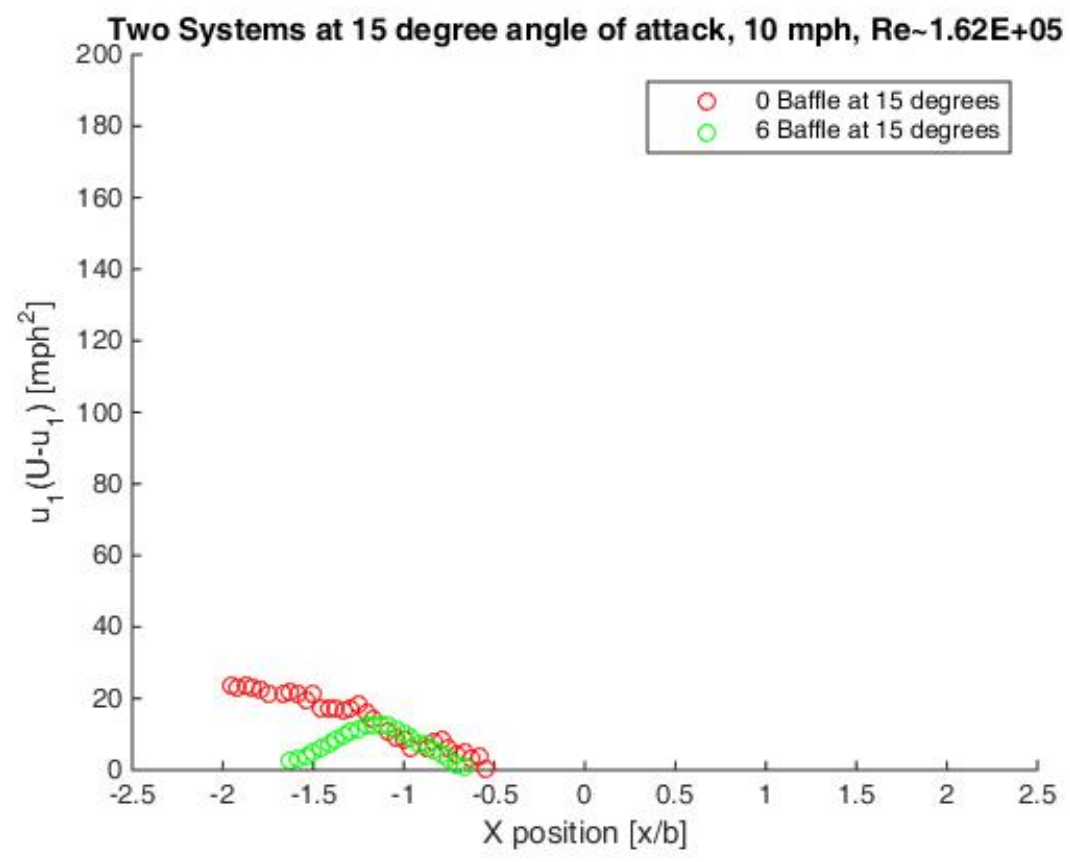

Figure 86: Six-baffle and zero-baffle systems at $15^{\circ}$ angle of attack, $R e=1.62 \mathrm{E}+5$ 


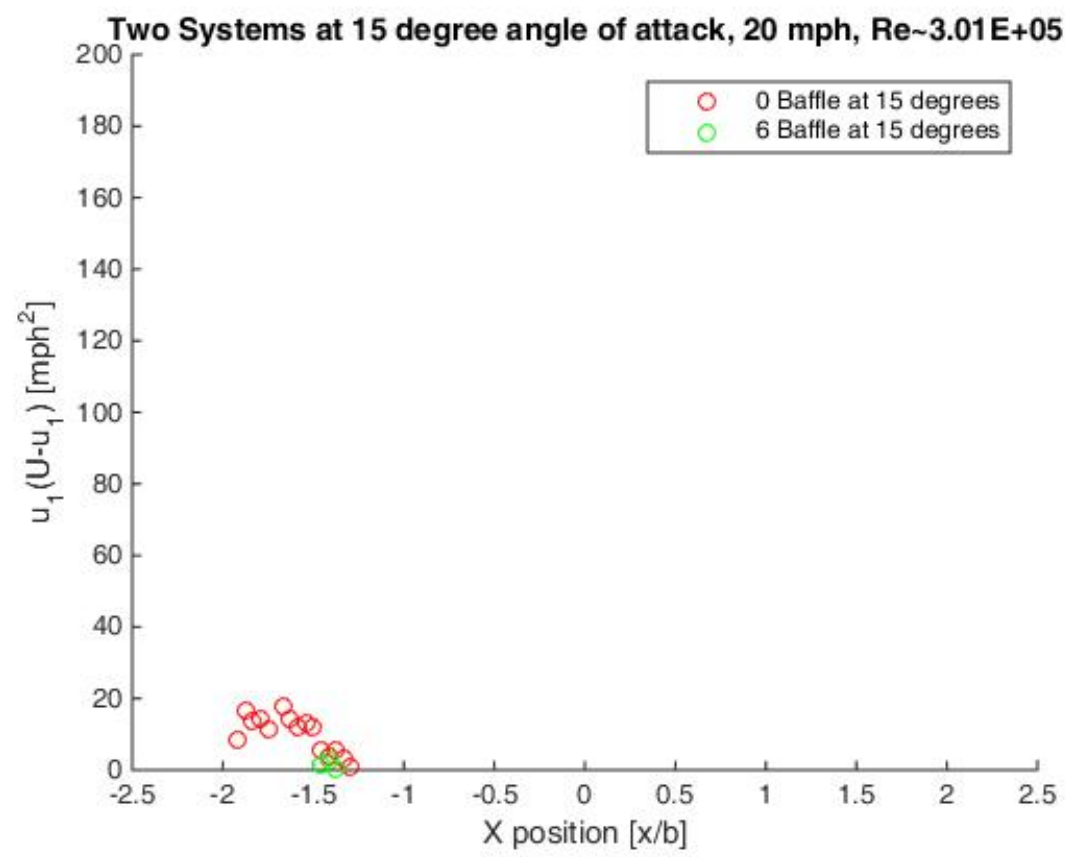

Figure 87: Six-baffle and zero-baffle systems at $15^{\circ}$ angle of attack, Re $=3.01 \mathrm{E}+5$ 


\subsubsection{Deflection Under Dynamic Pressure}

Deflection results are shown in Fig. 89 where the combined systems of the cover and internal inflatable boat-tail have a high enough stiffness to resist deflection during wind tunnel testing, in both deflated and inflated states. Since the boat-tail systems show high stiffness even under wind speeds up to $30 \mathrm{mph}$ at angles as large as $15^{\circ}$ this shows promising results that if pressure loss occurs while the boat-tail is deployed, it can still function as a drag reduction device and will not become unstable. More testing can be performed at higher wind speeds and more significant attack angles to better understand how the boat-tail systems will react in the case of pressure loss failure.

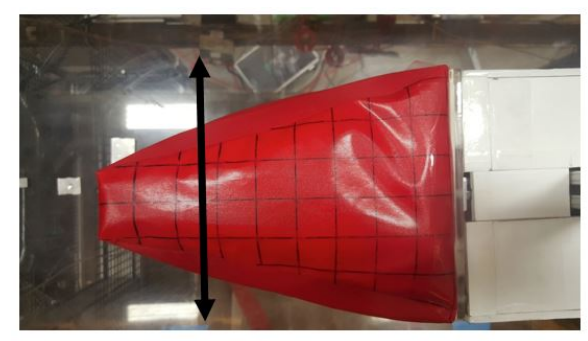

Figure 88: Study of deflection under dynamic pressure

\begin{tabular}{|c|c|c|c|}
\hline $\begin{array}{c}\text { Deflection } \\
\text { Results }\end{array}$ & $\begin{array}{c}\mathrm{P}=0 \mathrm{psi} \\
\mathrm{V}=0 \mathrm{mph}\end{array}$ & $\begin{array}{c}\mathrm{P}=0 \mathrm{psi} \\
\mathrm{V}=30 \mathrm{mph}\end{array}$ \\
\hline $\begin{array}{c}\text { Deflection } \\
\text { Angle } 0^{\circ}\end{array}$ & $\begin{array}{c}\mathrm{P}=0.5 \mathrm{psi} \\
\mathrm{V}=30 \mathrm{mph}\end{array}$ \\
\hline $\begin{array}{l}\text { Deflection } \\
\text { Angle 15 }\end{array}$ & & & \\
\hline
\end{tabular}

Figure 89: Results of deflection under dynamic pressure 


\subsubsection{Standard Deviation}

As velocity profiles are averaged, it is important to have some information about confidence of the data, and how close the data points are to the average. Standard deviation is one way of understanding how much uncertainty exists in experimental data. As bias error for instrumentation is discussed in the experimental set-up, it is insignificant when compared to the variation of measurements taken during wind tunnel experiments. Since velocity profiles are functions of $\mathrm{u}(\mathrm{U}-\mathrm{u})\left(m p h^{2}\right)$, experimental variation for $\mathrm{u}$ is taken to the squared power. Variation in this data is directly due to regions of high turbulence behind the boat-tail. These regions of high turbulence during $2 \mathrm{D}$ wake surveys cause more spread in the data due to the wind velocity fluctuations happening during testing. Figures 90 - 95 show a one standard deviation distribution for individual averaged velocity points along profiles for all three systems at $15 \mathrm{mph}$ and $30 \mathrm{mph}$ testing conditions. For all three systems, standard deviation reaches maximums just to the left and right of the boat-tail, (where boat-tail center is shown as $\mathrm{x}$-position $=0$, or normalized $\mathrm{x}$-position). This provides insight to where regions of higher turbulence exists with respect to each boat-tail system and is directly related to the shape of each system. This is especially noticeable when comparing maximum standard deviations of Fig. 93 to 95 , the baseline system to six-baffle system respectively. 


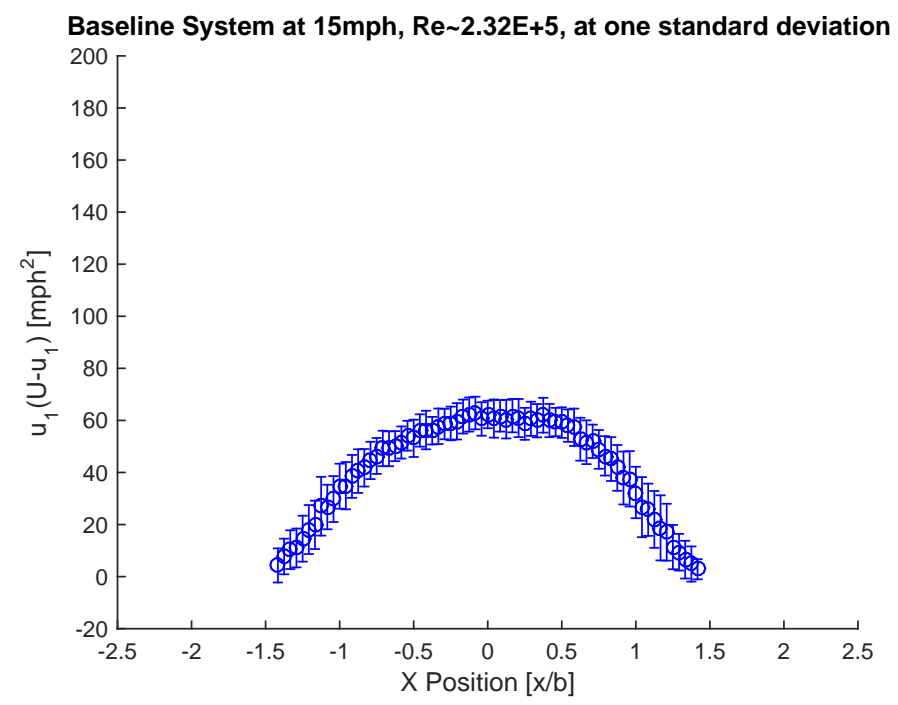

Figure 90: Standard deviation for baseline system at $15 \mathrm{mph}$

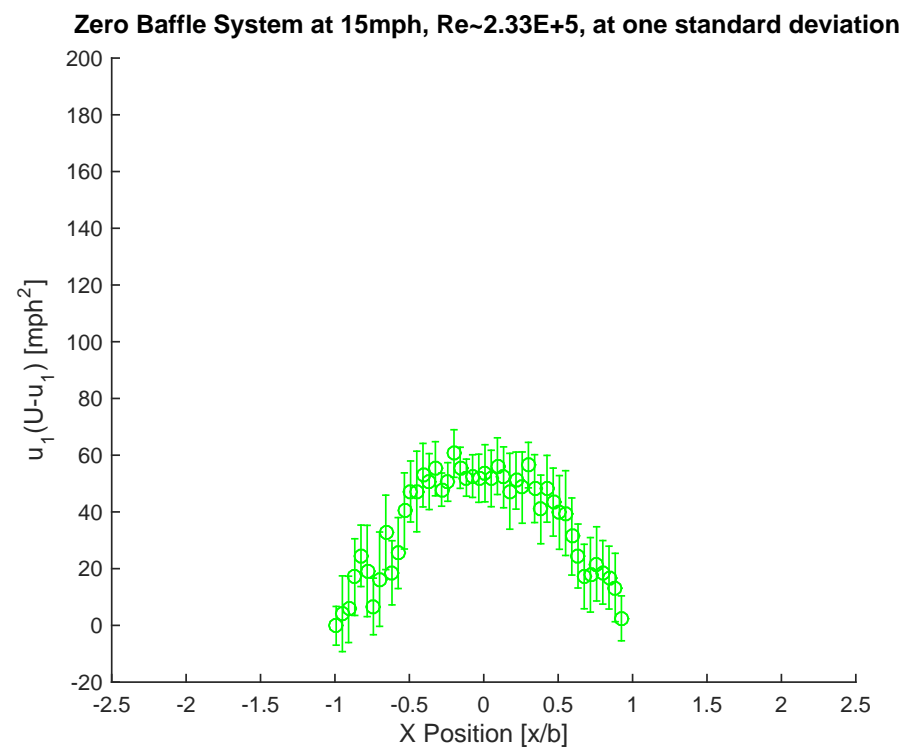

Figure 91: Standard deviation for zero-baffle system at $15 \mathrm{mph}$ 77 


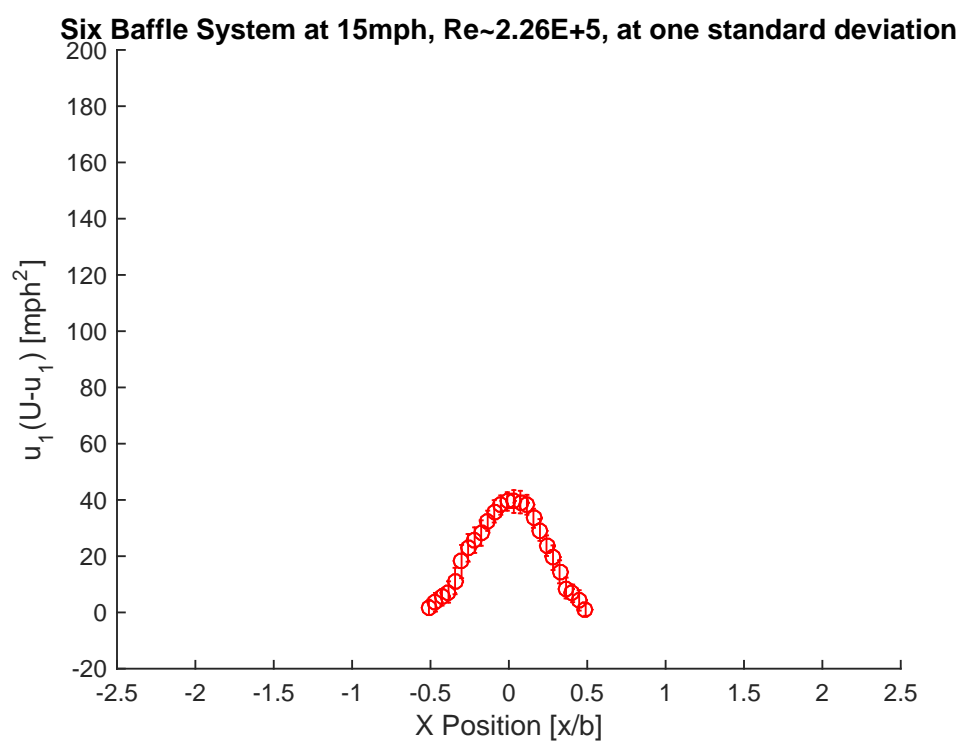

Figure 92: Standard deviation for six-baffle system at $15 \mathrm{mph}$ 


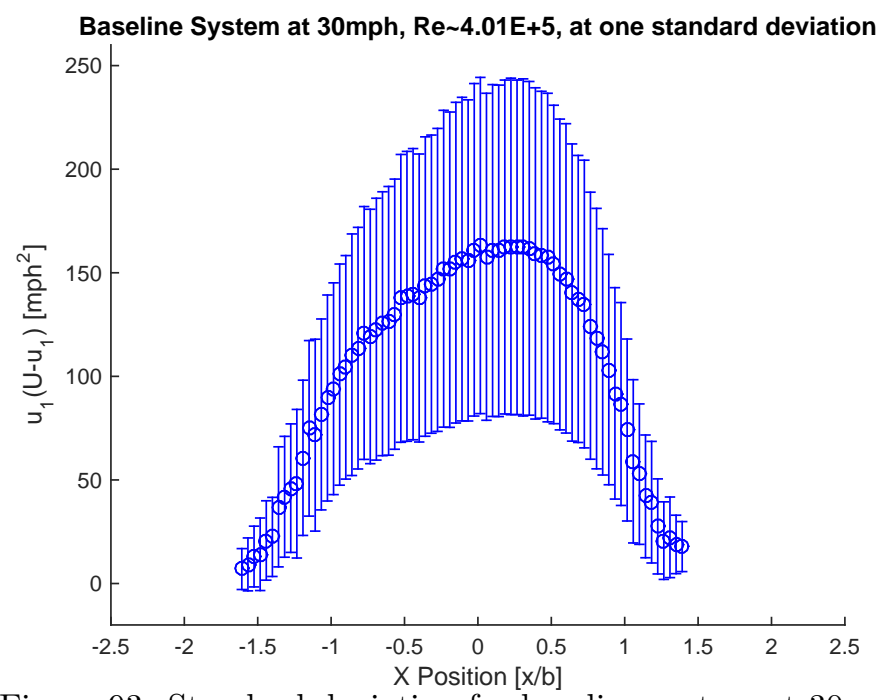

Figure 93: Standard deviation for baseline system at $30 \mathrm{mph}$

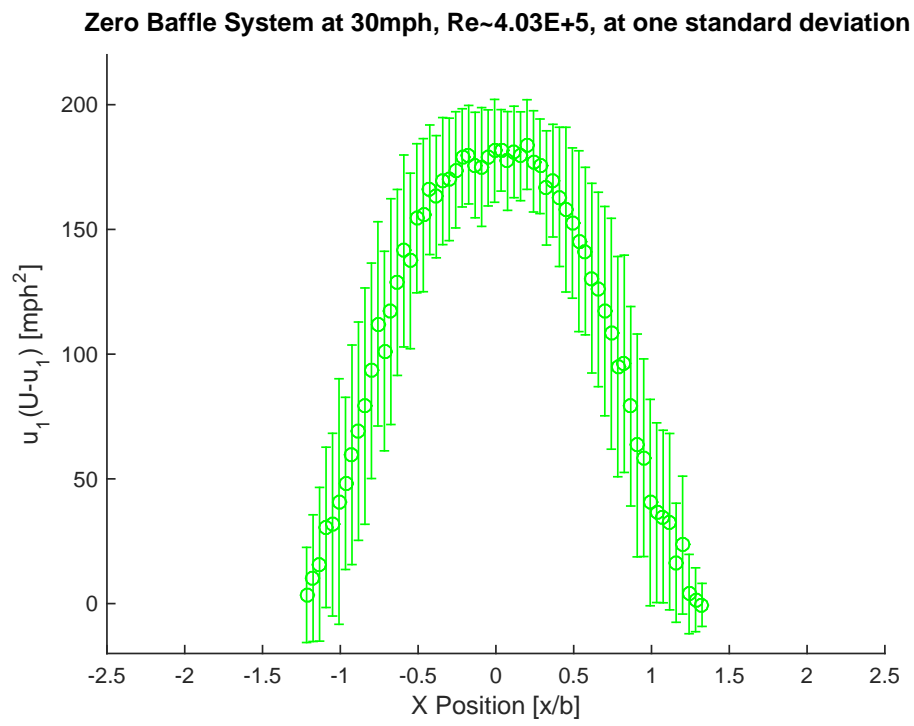

Figure 94: Standard deviation for zero-baffle system at $30 \mathrm{mph}$ 
Six Baffle System at 30mph, Re 3.85E +5 , at one standard deviation

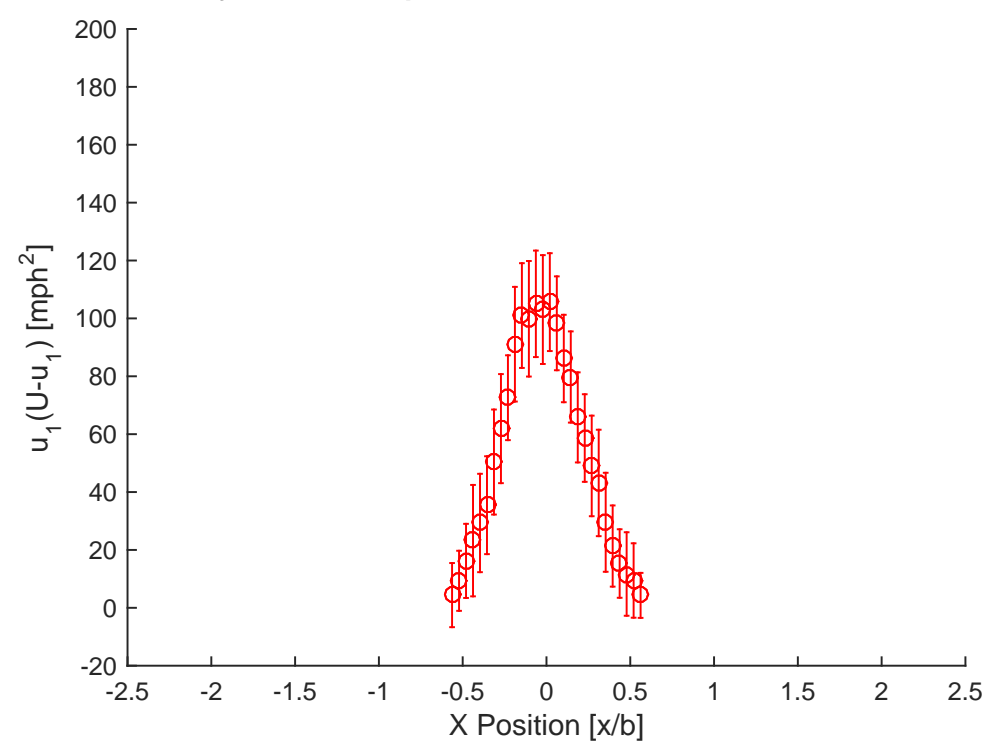

Figure 95: Standard deviation for six-baffle system at $30 \mathrm{mph}$ 


\subsubsection{Measurement Variation}

Another factor which should be observed for these sets of experimental data is that of measurement variation. Variation in measurements is observed to changed significantly depending on the $\mathrm{x}$ location behind the boat-tail systems. This is seen in the variation of standard deviations, but is more obvious when plotted directly as measurement variation. Figures 96 through 101 show variation of $100 \%$ of the data for all three systems at $15 \mathrm{mph}$ and $30 \mathrm{mph}$ testing conditions. Each point is that of the maximum range seen per x-position, specific to each test and test system. Plotting data in this format shows exactly how measurements vary according to boat-tail system. The highest points of measurement variation for the baseline system are towards the outer sides, see Fig. 96 and 99. This shows that those areas are of higher turbulence and see an increased range in velocity measurements. Similar results are seen for the zero-baffle system except that for the zero-baffle $30 \mathrm{mph}$ case, the difference in measurements is quite significant and a clear pattern is seen in Fig. 100. Results for the six-baffle system are less significant, see Fig. 98 and 101. Due to the more optimized shape of the six-baffle system, there are much less turbulent regions in the wake, and as a result much less variation in velocity measurements. 


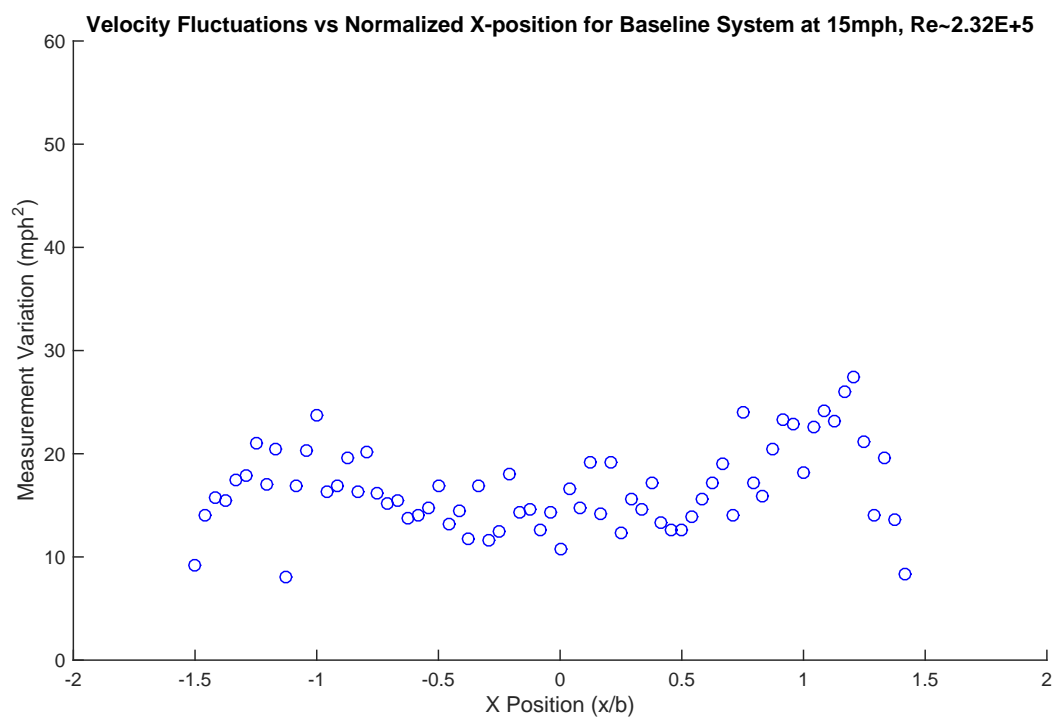

Figure 96: Velocity fluctuation for baseline system at $15 \mathrm{mph}$

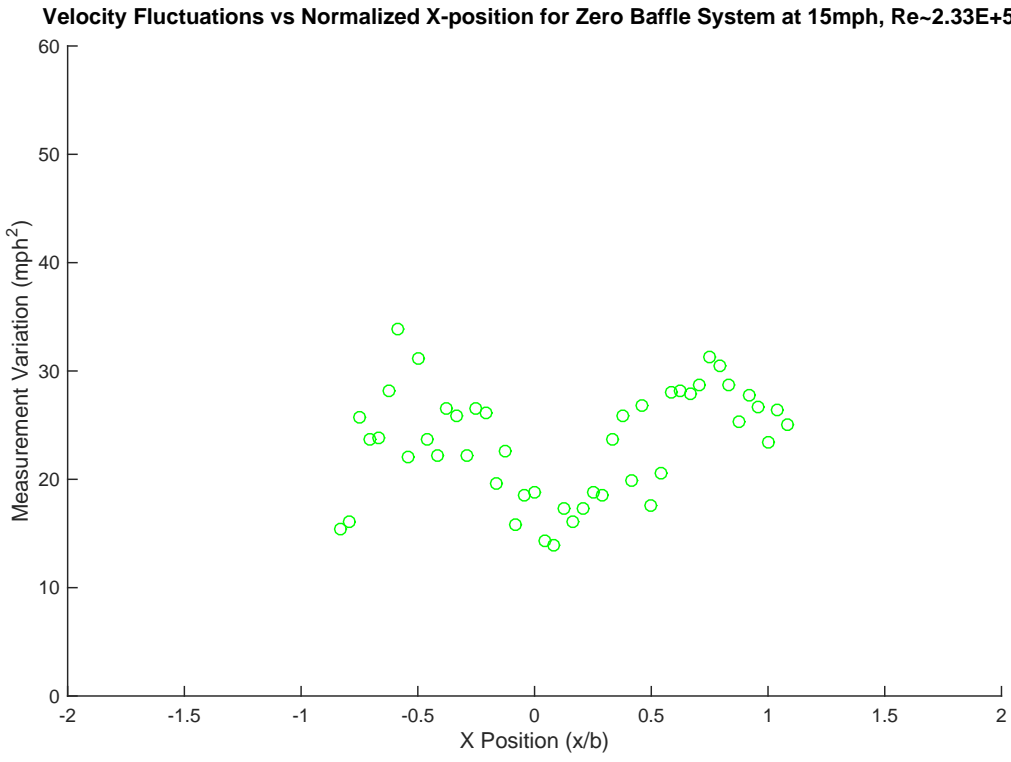

Figure 97: Velocity fluctuation for zero-baffle system at $15 \mathrm{mph}$ 


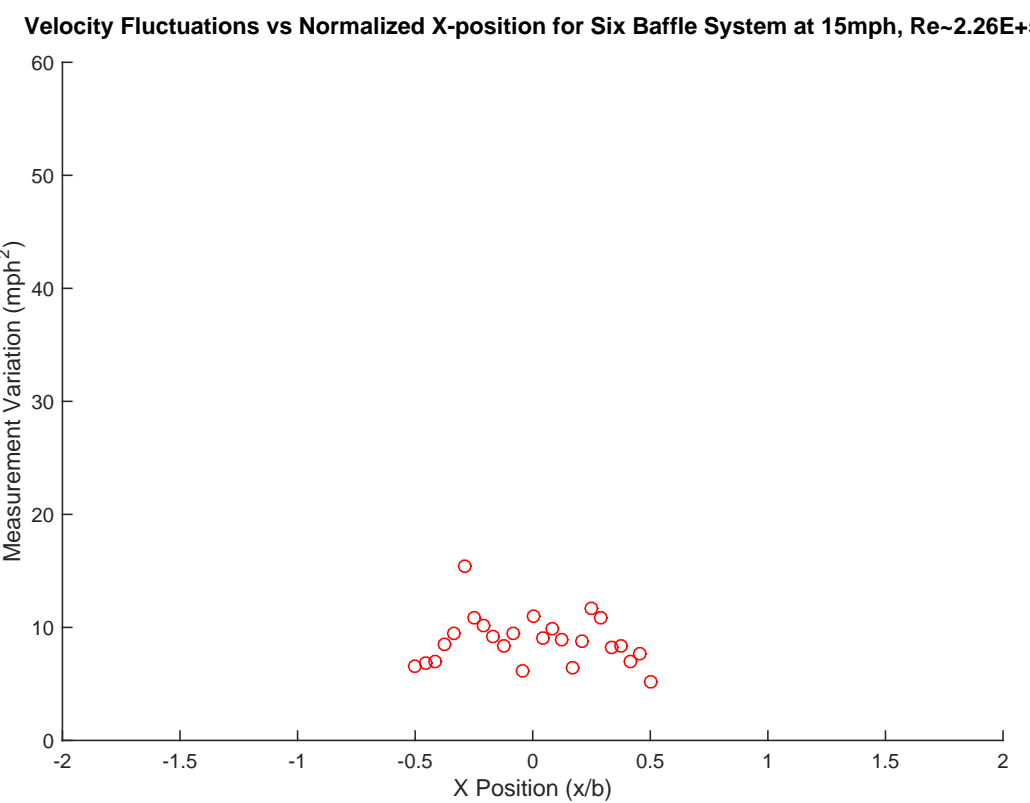

Figure 98: Velocity fluctuation for six-baffle system at $15 \mathrm{mph}$ 


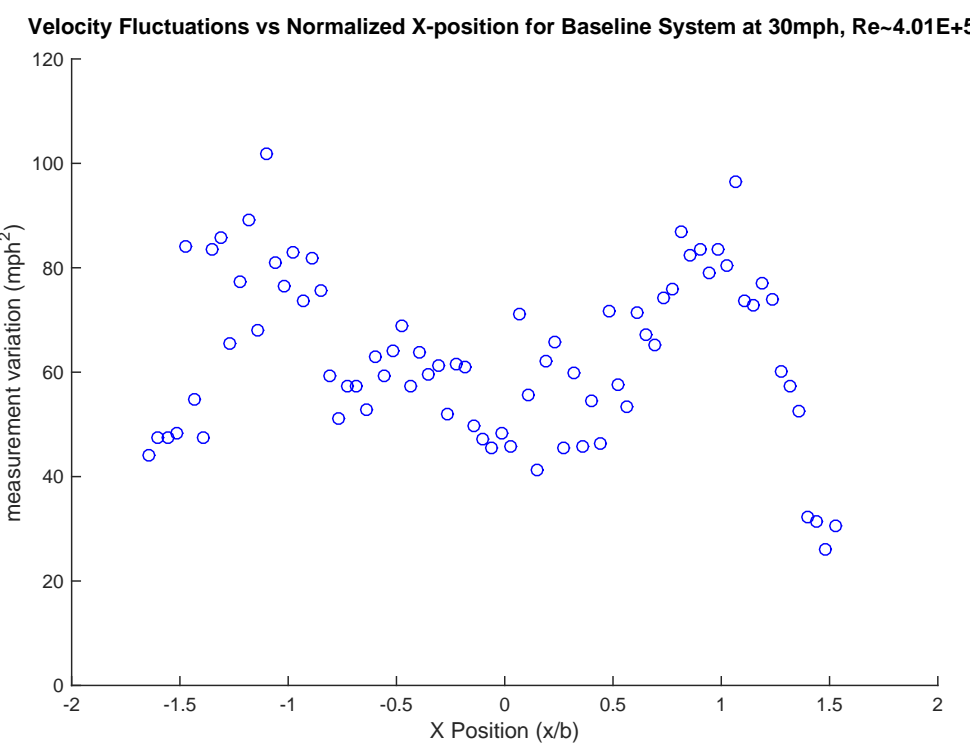

Figure 99: Velocity fluctuation for baseline system at $30 \mathrm{mph}$

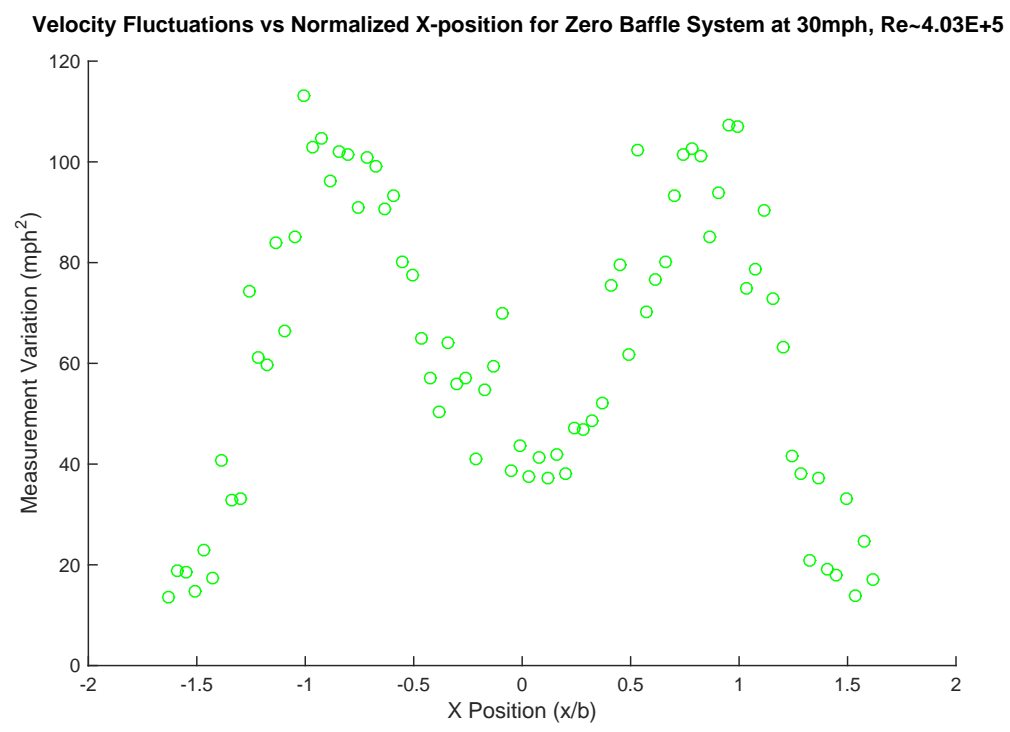

Figure 100: Velocity fluctuation for zero-baffle system at $30 \mathrm{mph}$ 


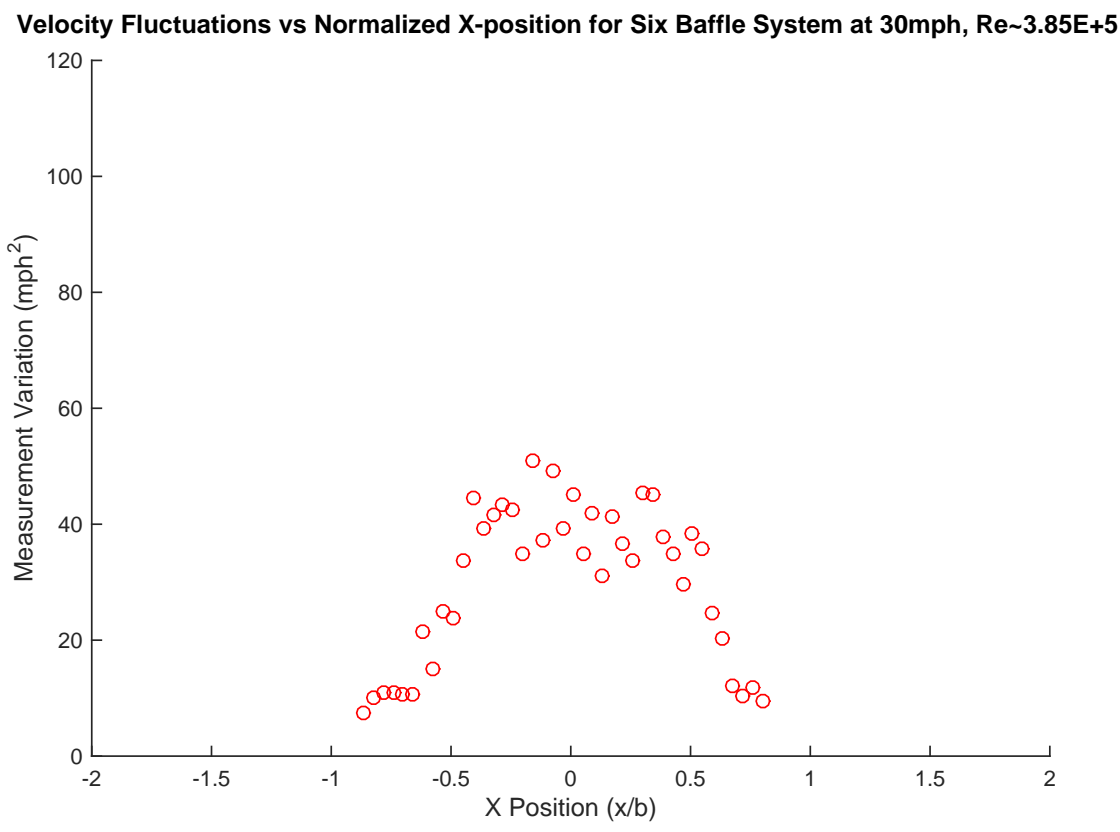

Figure 101: Velocity fluctuation for six-baffle system at $30 \mathrm{mph}$ 


\section{Conclusions}

\subsection{Summary}

Specific objectives are reiterated below from Chapter 1 to establish what has been accomplished and what the next steps will be. Success has been achieved through the accomplishment of these objectives as follows:

- An inflatable boat-tail as a drag reduction device has been investigated and achieved through multiple iterative steps and processes.

- Surveys were taken of existing inflatable technologies, and design specifications for the inflatable boat-tail were developed.

- Model sizes were determined as 1/5 ratio, and 3D models were developed along with 2D fabric design drawings.

- Inflatable fabrics were evaluated by heat sealability, UV resistance, and peel strength of adhesive bonds testing.

- Test articles were manufactured, and new and more optimized designs emerged as construction evolved.

- Burst testing was completed for experimental evaluation of peel strength as a function of internal pressure.

- A test system was developed for wind tunnel testing and 2D wake surveys were performed while varying Reynolds number and boat-tail geometries.

- A Matlab program was developed in order to back out drag coefficients from wind tunnel test data. Wake surveys continued, and more interesting tests were developed by varying boat-tail attack angles, and performing 2D wake surveys along multiple planes for a 3D effect.

- Boat-tail systems were monitored for deflection under dynamic pressure at deflated and inflated states and results showed high stiffness in all boat-tail systems. 
Overall, the inflatable boat-tail showed decreased drag coefficients of $10 \%$ to $80 \%$ as a function of boat-tail geometry when compared to a baseline system. PIV models were designed and built by 3D printing as exact replicas of inflatable test systems, for testing in the OSU small wind tunnel. These models replicated the system of the large wind tunnel by taking up the same $\%$ cross-sectional area as previous tests. The following Figures 102 and 103 summarize the work of this investigation of an inflatable boat-tail for drag reduction applications.

The difference of $\Delta C_{D}$ in Fig. 103 comes from the velocity profiles at one standard deviation. Since $C_{D}$ is a direct function of area under the velocity curve, minimum and maximum possible $C_{D}$ are found, and presented as variation in the $C_{D}$ vs Re plot. It is important to note that this standard deviation and variation in results are due to the fluctuating velocities of the wake behind each boat-tail system, especially when considering the large variation of $C_{D}$ for the baseline system. Due to its non-aerodynamic fundamental shape, there is a large wake and high velocity fluctuation. When observing $C_{D}$ results for the zero-baffle system, there is some variation, and due to this it is difficult to conclude that there is a significant difference between the zero-baffle and baseline systems. Comparing these to the six-baffle system, of which $\Delta C_{D}$ is relatively very small, it is clear that there is a significant decrease in drag coefficient and a higher level of confidence in the results. Overall, the six-baffle design shows significant drop in drag coefficients at varying Reynolds numbers and proves that the inflatable boat-tail is a realistic and lightweight source for drag reduction applications applied to motor vehicles.

Since this investigation included $1 / 5$ size scale model systems compared to a full scale system it is interesting to discuss how results may change when scaled to full size. While surface area is proportional to $\mathrm{size}^{2}$, volume is proportional to $\operatorname{size}^{3}$, as size increases so does loading. When considering bending moment, the moment increases to the fourth power of the size, which is the bending moment at the root, $M=F d \propto W l \propto l^{4}$. This is why results may vary for full scale systems. As inflatable boat-tails are built as baffled inflatables, or inflatables with internal fabric sections for shape consistency and stiffness, it is clear that these baffled sections have some impact on the aerodynamics of the boat-tail. Since the zero-baffle system contained no baffles, its shape was round and blunt. As the number of baffles increases, shape gets closer to optimum aerodynamic shape. Even though baffles created bowed out regions, by adding the external fabric cover, those 
regions are smoothed out. Overall, the higher number of internal baffles, the better the aerodynamic shape of the boat-tail. Another item discussed during the design stages of this investigation included the deployment and stowage methods of the inflatable boat-tail. Initial ideas consist of both rapid and slow deployment, of which pressure would be controlled by design of the inflation system included within the vehicle. Other ideas consist of possible RAM air designs, of which an inflation system would not be necessary if wind speeds were high enough for initial inflation. Other concerns brought up throughout design processes include longevity and end-of-life of the inflatable boat-tail. More studies will have to be included concerning the cyclic loading lifestyles of inflatable systems, as well as weather/UV resistance of inflatable fabrics. Another futuristic interest is that of failure modes for full scale systems. These boat-tail system investigations can also include modeling of aerodynamic aspects of which CFD or FEM can be investigated.

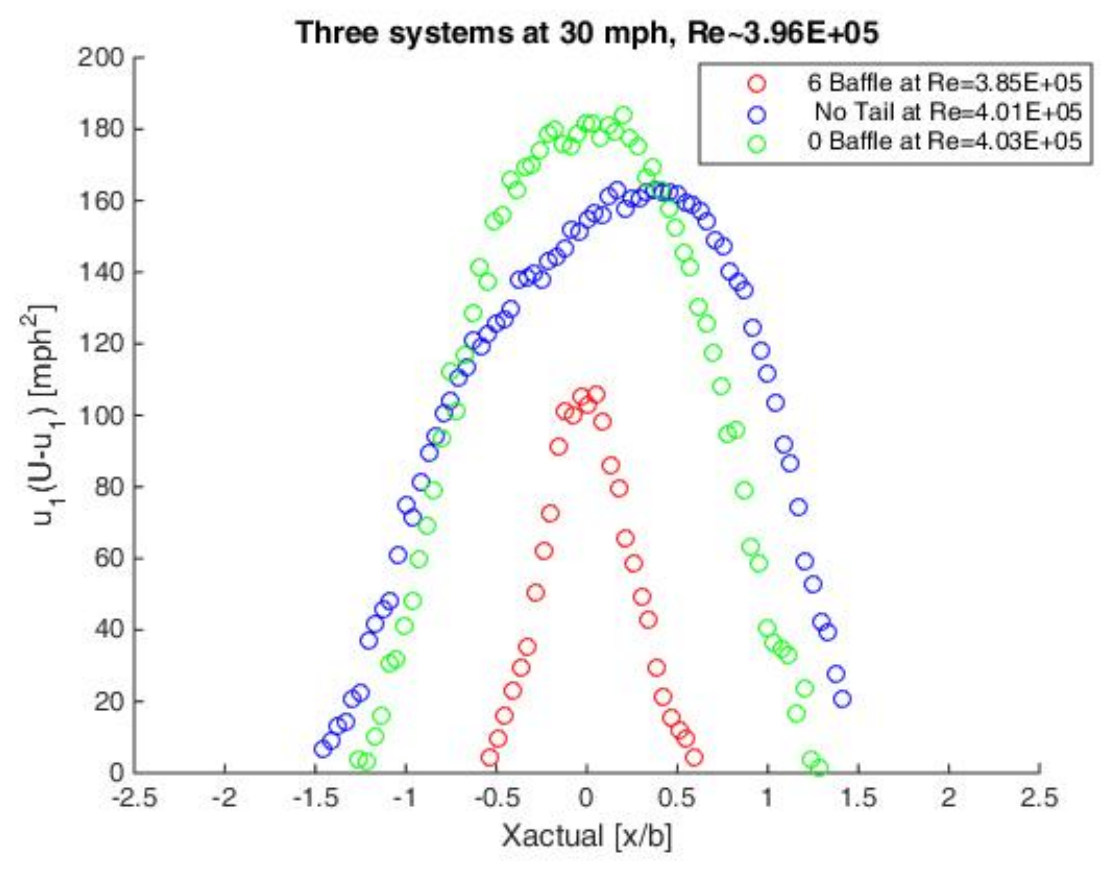

Figure 102: Three systems at $\mathrm{Re}=3.96 \mathrm{E}+5$ 


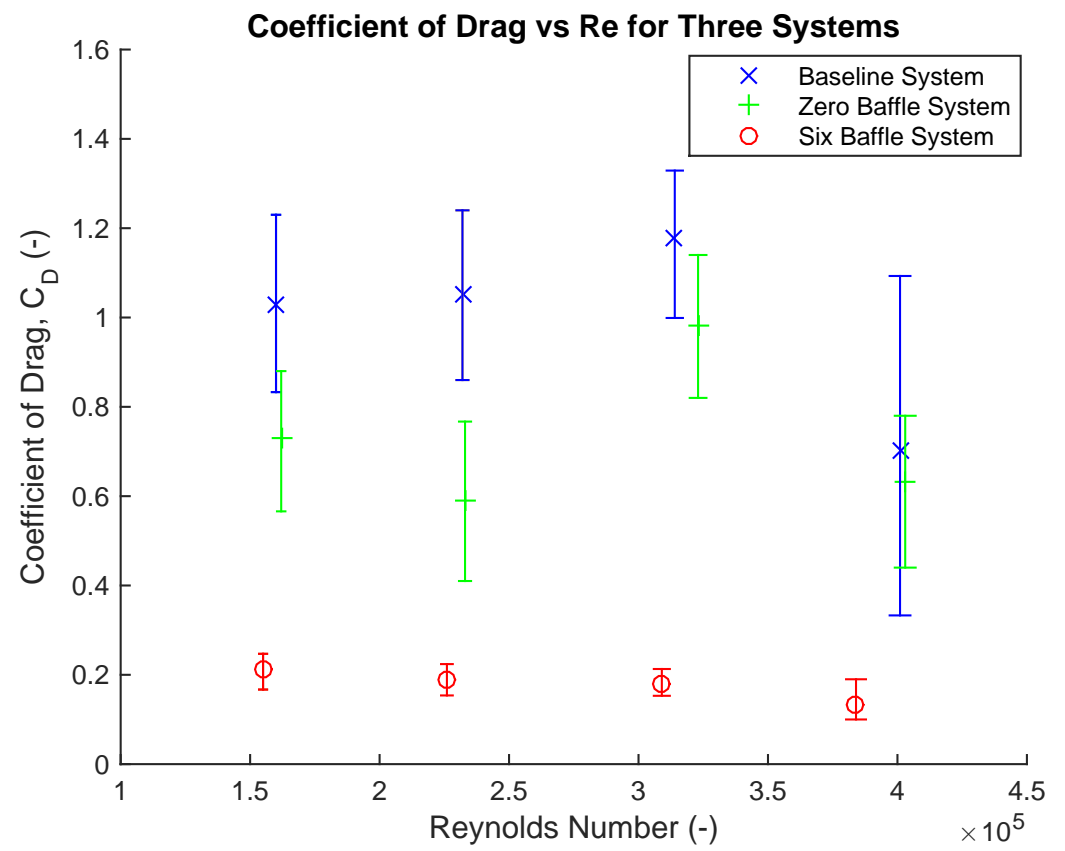

Figure 103: Coefficient of drag vs Reynolds number for three systems 


\subsection{Future Work}

The original objectives are reiterated below, but can be expanded for future interest in inflatable boat-tail systems.

- Survey existing inflatable structure elements and concepts including system envelope, internal structure, materials, and support systems, and recognize design specifications

- Investigate how to design ideal shapes and sizes of inflatable structures

- Develop 3D models of inflatable boat-tails and 2D fabric layouts and drawings for 3D construction

- Compare the different designs and their load carrying capability to determine the design variables and how they are connected including but not limited to pressure tensile strength, elasticity, geometry etc

- Evaluate inflatable fabric options through testing by ASTM International specifications, determine best fabrics and how to avoid failure

- Design, fabrication, and assembly of a demonstration article to illustrate the concept of using inflatable structures for future vehicles and show the effect of pressure on performance

- Establish construction techniques for inflatable boat-tails

- Develop test system for wind-tunnel wake surveys

- Conduct wake surveys following conservation of momentum theory and back out drag coefficients for various boat-tail models

Besides completing original objectives, many interesting tests such as wake survey variation of height and wake survey variation of attack angles were added. Overall, the inflatable boat-tail has been proven as a realistic and reliable drag reduction device for motor vehicles. More interesting results could be seen by manufacturing full scale models for vehicle applications, and testing in a full scale wind tunnel system (available at other locations). Design optimization and further fabric investigations for light weight inflatable applications are of great interest.

Some suggestions for future work include the following: 
- Qualitative and quantitative flow field testing (such as Particle Image Velocimetry) for better understanding of the entire flow-field behind the boat-tail

- Optimize design of inflatable boat-tails with higher baffle numbers and sharper geometries

- Manufacture full-scale models and test in large wind tunnel or on full-scale vehicles

- Fabric investigation for lighter weight, more durable fabrics for inflatable applications

- Include load cells into the test apparatus to measure the integrated drag force 


\section{Appendix A}

\section{PIV Models}

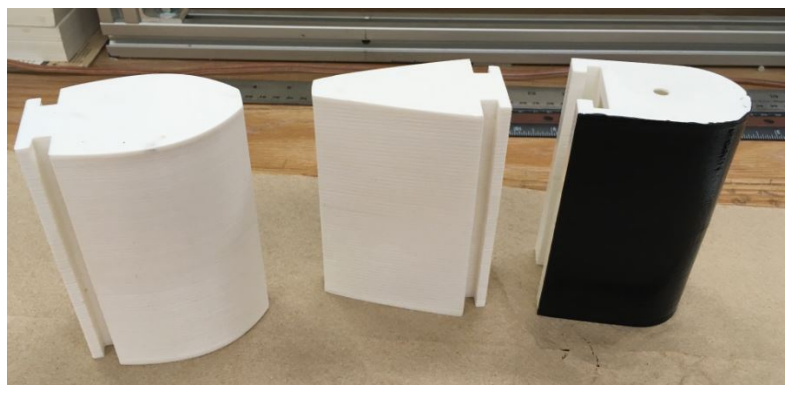

Figure 104: PIV boat-tail models

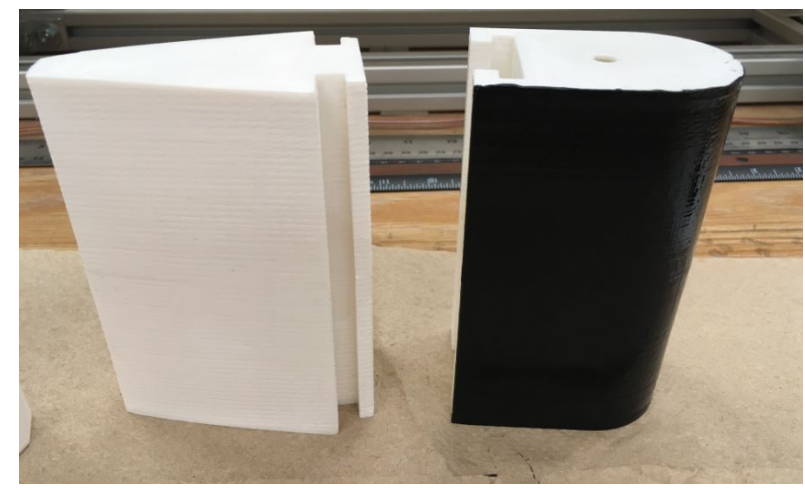

Figure 105: PIV boat-tail models 


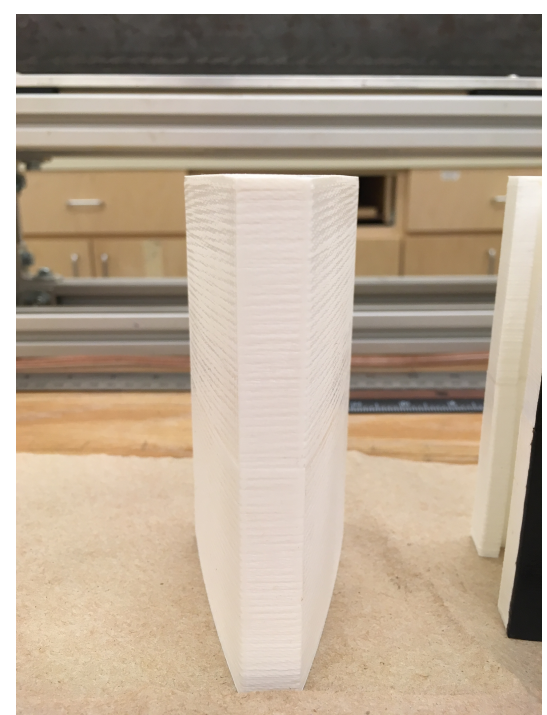

Figure 106: PIV six-baffle replica boat-tail model 


\section{LabView Control and VI}

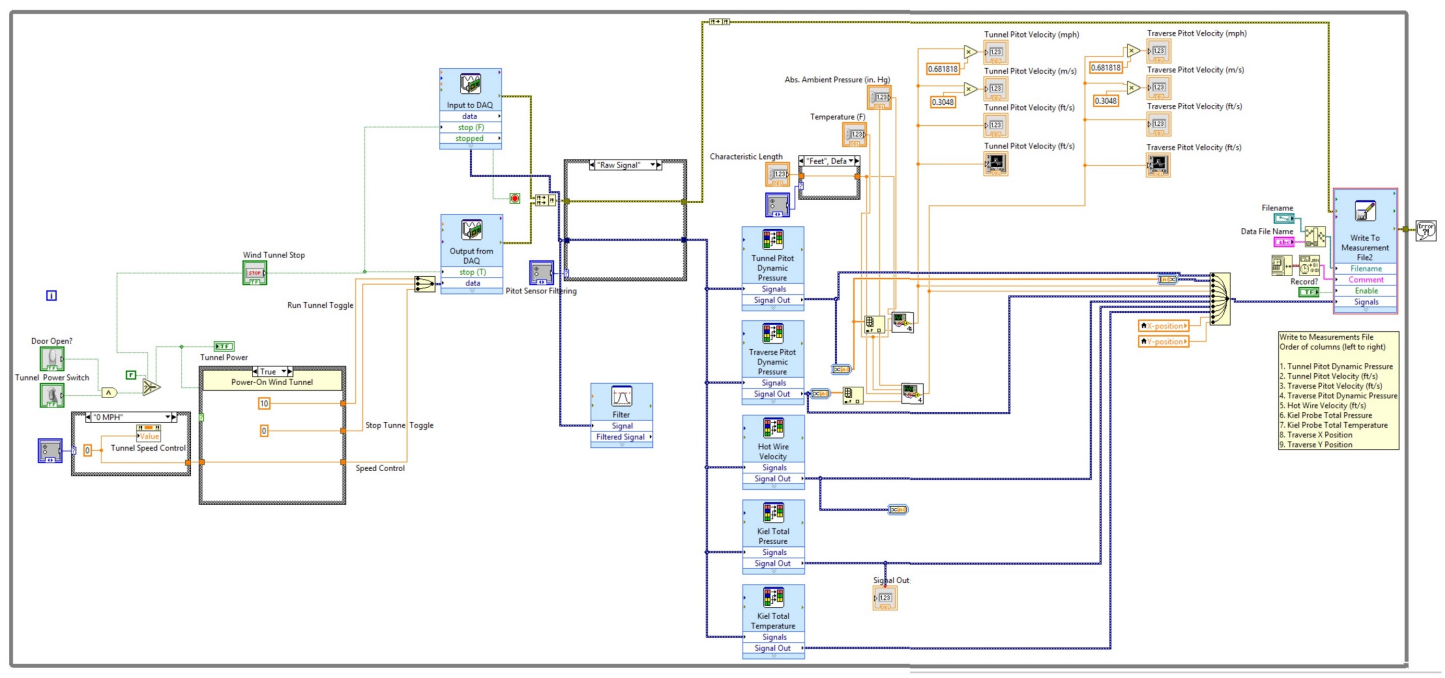

Figure 107: LabView VI 


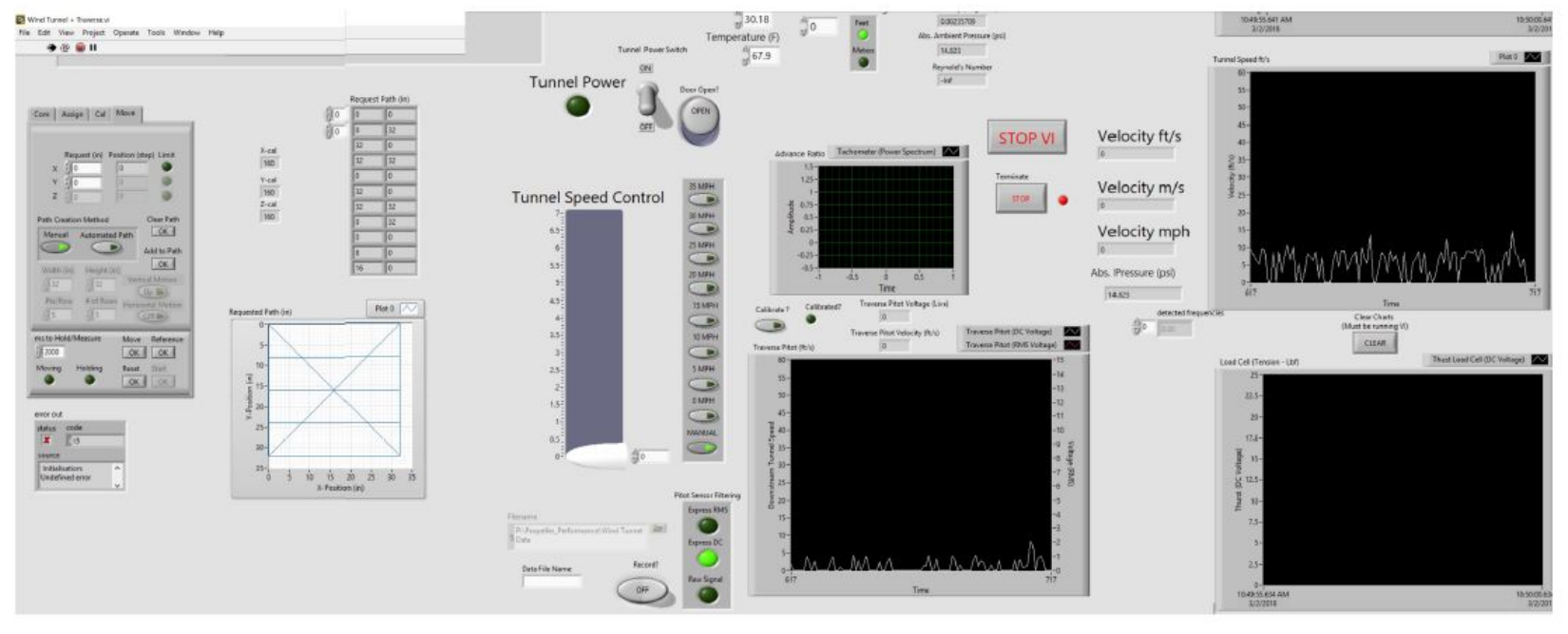

Figure 108: LabView Control 


\section{MATLAB Script}

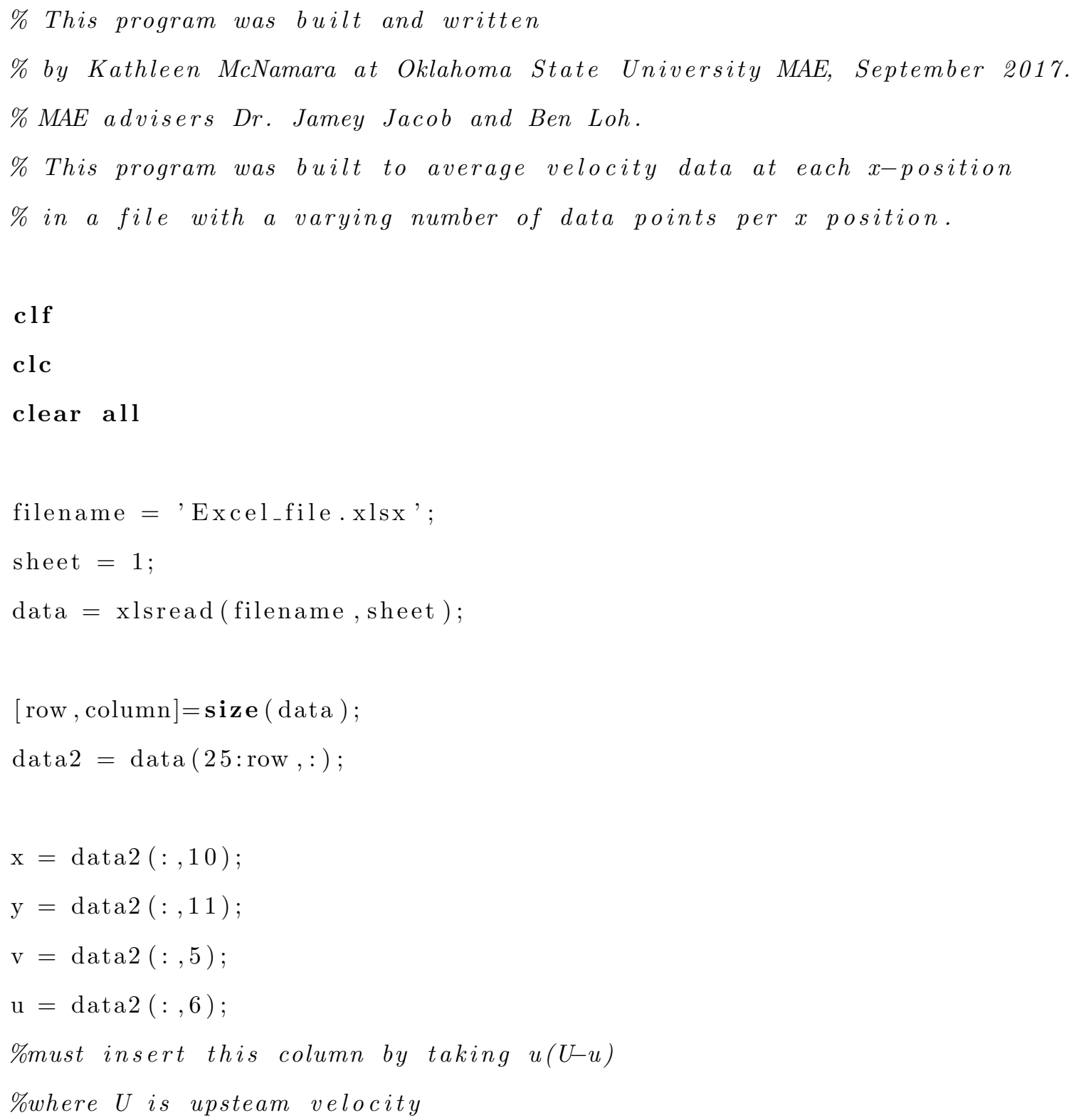

$\%$ Some data file processing may be necessary before running this script 


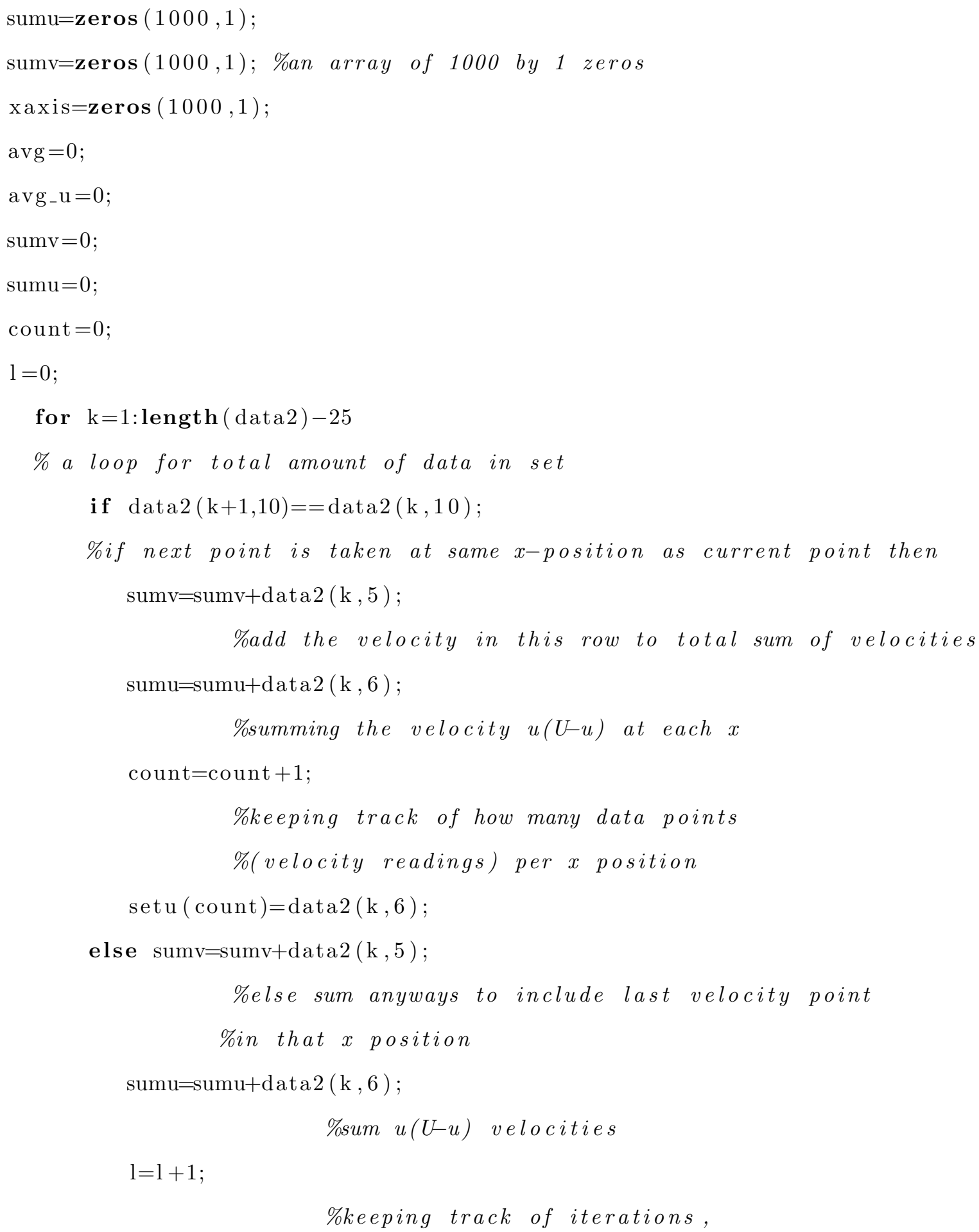




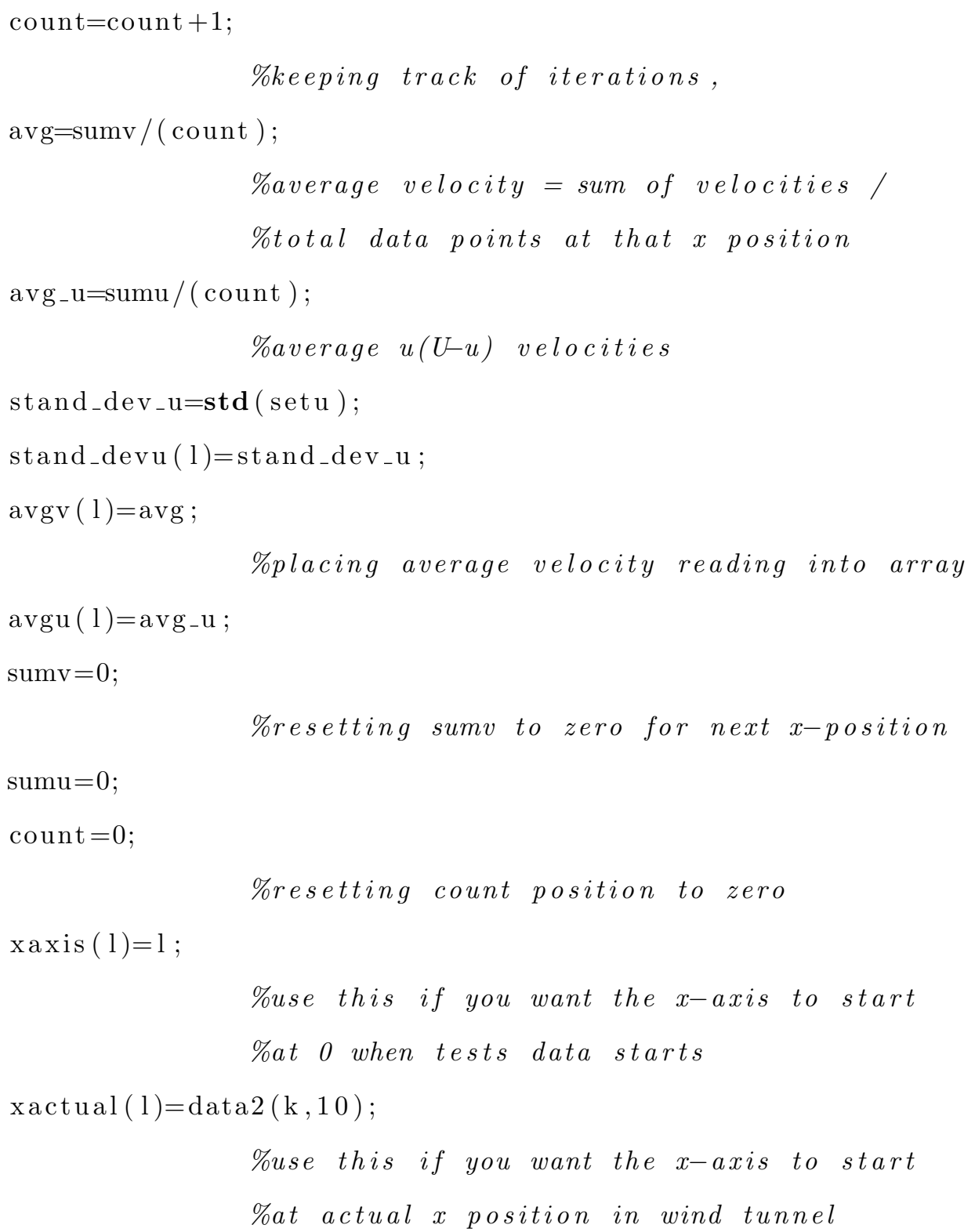




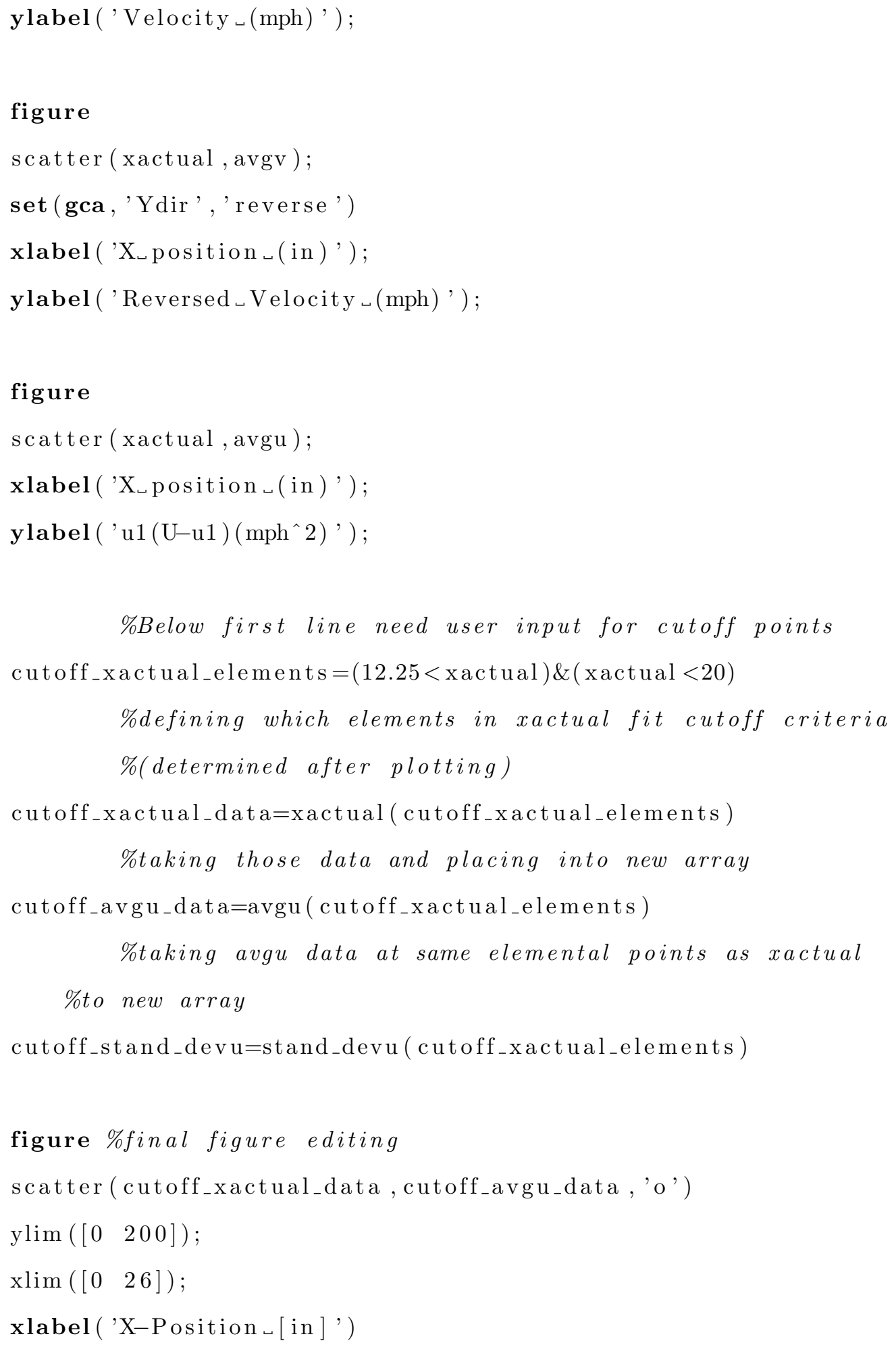




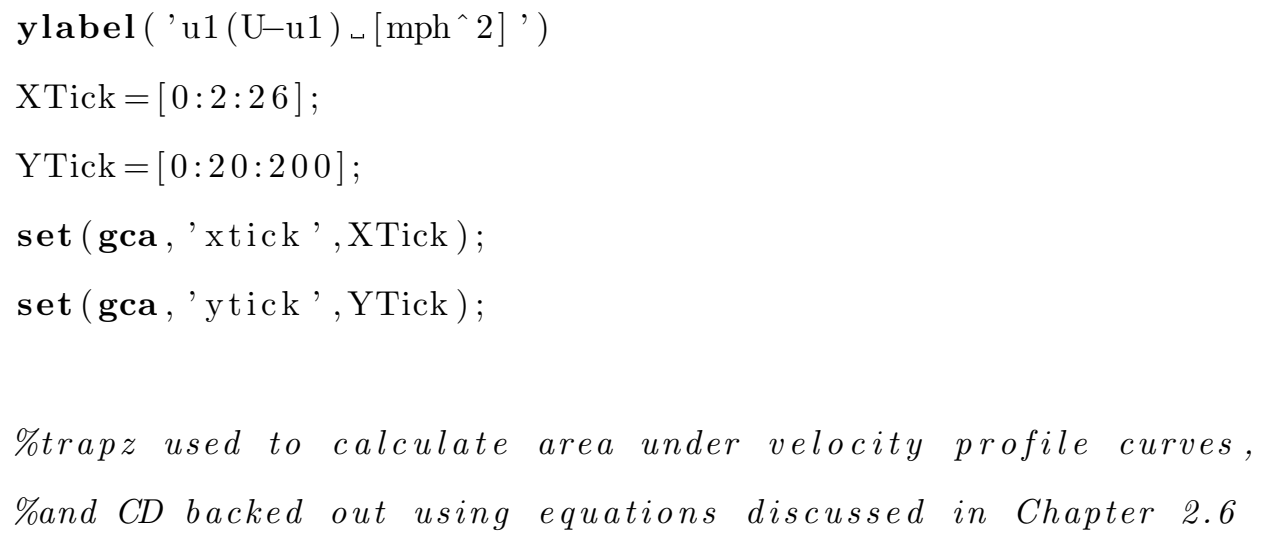




\section{References}

[1] Torbijorn Gustavsson, "Alternative Approaches to Rear End Drag Reduction" (2006). KTH, Department of Aeronautical and Vehicle Engineering, Royal Institure of Technology. Stockholm.

[2] Heisler, Heinz.(2002). Advanced Vehicle Technology. Woburn, MA: Butterworth-Heinemann.

[3] Saltzman Edwin J., Meyer Robert R., "A Reassessment of Heavy-Duty Truck Aerodynamic Design Features and Priorities" (1999). NASA. Technical Paper.

[4] Main J.A., Peterson S. W., Strauss A. M., "Load-Deflection Behavior of Space-Based Inflatable Fabric Beams" (1994).

[5] Le van Anh, Wielgosz Christian, 2007. "Finite Element Formulation for Inflatable Beams" Journal of Thin-Walled Structures.

[6] Loh, Ben. (2006). Deployment Dynamics of Inflatable Wings (Master's Thesis). Oklahoma State University, Stillwater, OK.

[7] Bernal, William, "Relating Burst Pressure to Seal Peel Strength In Pouches" (2012). All Theses. Paper 1490.

[8] Comer, R.L., and Levy, S. (1963). "Deflections of in inflated circular-cylindrical cantilever beam." AIAA J., 1(7), 1652- 1655.

[9] Main J.A., Peterson S.W., Strauss A.M., "Beam-Type Bending of Space-Based Inflated Membrane Structures" (1995). Journal of Aerospace Engineering.

[10] Brown, G., Haggard R., Norton, B. (2001). "Inflatable Structures for Deployable Wings." AIAA2001-2068.

[11] Breuer, J., Ockels, W. "An Inflatable Wing Using the Principle of Tensairity." AIAA-2007-2117.

[12] Luciano Amaury dos Santos "Drag Estimation by Wake Survey Performed Measuring Velocities and Measuring Total Static Pressures," Proceedings of the 11th Brazilian Congress of Thermal Sciences and Engineering - ENCIT 2006 Braz. Soc. of Mechanical Sciences and Engineering ABCM, Curitiba, Brazil, Dec. 05 - 08, 2006 
[13] Munson, Young, Okiishi. Fundamentals of Fluid Mechanics. Indianapolis, IN: Wiley, 2006. Print.

[14] ASTM D903-98(2017), Standard Test Method for Peel or Stripping Strength of Adhesive Bonds, ASTM International, West Conshohocken, PA, 2017, www.astm.org

[15] Franks, Stephen. Seal Strength and Package Integrity- The Basics of Medical Package Testing. 2006. TM Electronics Inc.

[16] Yam Kit L., Rossen J., Wu X.F., Relationship Between Seal Strength and Burst Pressure for Pouches. (1993). Packaging Technology and Science, Vol 6. pp 239-244.

[17] Munson, B.R., Okiishi, T.H., Huebsch, W.W., Rothmayer, A.P. (2013). Fundamentals of Fluid Mechanics. Hoboken, NJ: John Wiley \& Sons Inc.

[18] Herzog, Thomas. (1976). Pneumatic Structures. New York, NY: Oxford University Press.

[19] Barlow, J.B., Rae, W.H., Pope, A. (1999). Low-Speed Wind Tunnel Testing. New York, NY: John Wiley \& Sons Inc.

[20] Kline S.J., McClintock F.A., "Describing Uncertainties in Single-Sample Experiments," Mechanical Engineering, 75,1,January 1953,pp 3-9. 
VITA

Kathleen Michele McNamara

Candidate for the Degree of

Master of Science

Thesis: EXPERIMENTAL INVESTIGATION OF DRAG REDUCTION ON AUTOMOBILES WITH AN INFLATABLE BOAT-TAIL

Major Field: Mechanical and Aerospace Engineering

Biographical:

Education:

Completed the requirements for the Master of Science in Mechanical and Aerospace Engineering at Oklahoma State University, Stillwater, Oklahoma in May, 2018.

Completed the requirements for Bachelor of Science in Mechanical Engineering at Oklahoma State University, Stillwater, Oklahoma in December 2015.

Experience:

Undergraduate Research Assistant- University of Central Oklahoma- Mathematics and Statistics, Edmond, OK

Undergraduate Research Assistant- Chemical Engineering- Oklahoma State University, Stillwater, OK

Graduate Teaching Assistant - Mechanical and Aerospace Engineering- Oklahoma State University, Stillwater, OK

Graduate Research Assistant- Mechanical and Aerospace Engineering- Oklahoma State University, Stillwater, OK 